\title{
Transferring 2001 National Household Travel Survey
}

\author{
Patricia S. Hu \\ Oak Ridge National Laboratory \\ Oak Ridge, Tennessee 37831 \\ Timothy Reuscher \\ MacroSys Research and Technology \\ Washington, DC 20006 \\ Richard L. Schmoyer \\ Shih-Miao Chin \\ Oak Ridge National Laboratory \\ Oak Ridge Tennessee 37831
}

May 2, 2007

Prepared for the

Federal Highway Administration

U.S. Department of Transportation

Prepared by

Oak Ridge National Laboratory

Managed by UT-Battelle, LLC

for the

U.S. Department of Energy

Under Contract DE-AC-05-00OR22725 


\section{DOCUMENT AVAILABILITY}

Reports produced after January 1, 1996, are generally available free via the U.S. Department of Energy (DOE) Information Bridge.

Web site http://www.osti.gov/bridge

Reports produced before January 1, 1996, may be purchased by members of the public from the following source.

National Technical Information Service

5285 Port Royal Road

Springfield, VA 22161

Telephone 703-605-6000 (1-800-553-6847)

TDD 703-487-4639

Fax 703-605-6900

E-mail info@ntis.fedworld.gov

Web site http://www.ntis.gov/support/ordernowabout.htm

Reports are available to DOE employees, DOE contractors, Energy Technology Data Exchange (ETDE) representatives, and International Nuclear Information System (INIS) representatives from the following source.

Office of Scientific and Technical Information

P.O. Box 62

Oak Ridge, TN 37831

Telephone 865-576-8401

Fax 865-576-5728

E-mail reports@adonis.osti.gov

Web site http://www.osti.gov/contact.html

This report was prepared as an account of work sponsored by an agency of the United States Government. Neither the United States Government nor any agency thereof, nor any of their employees, makes any warranty, express or implied, or assumes any legal liability or responsibility for the accuracy, completeness, or usefulness of any information, apparatus, product, or process disclosed, or represents that its use would not infringe privately owned rights. Reference herein to any specific commercial product, process, or service by trade name, trademark, manufacturer, or otherwise, does not necessarily constitute or imply its endorsement, recommendation, or favoring by the United States Government or any agency thereof. The views and opinions of authors expressed herein do not necessarily state or reflect those of the United States Government or any agency thereof. 


\section{TABLE OF CONTENTS}

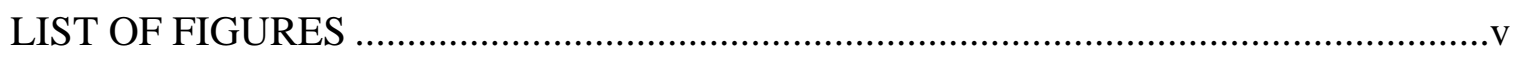

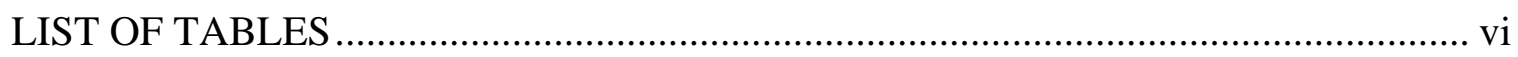

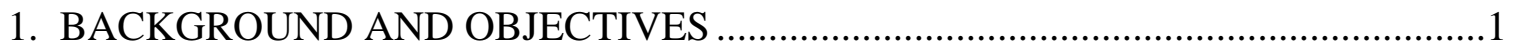

2. EXPECTED OUTCOMES/PARAMETERS OF INTEREST .........................................

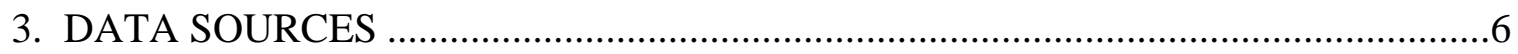

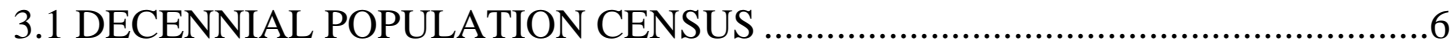

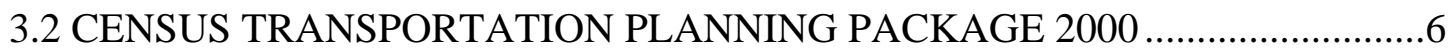

3.32001 NATIONAL HOUSEHOLD TRAVEL SURVEY (NHTS)............................

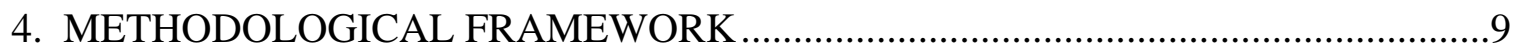

5. APPLICATION OF CLUSTER APPROACH TO 2001 NHTS DATA …...................24

5.1 IDENTIFICATION OF SIGNIFICANT TRAVEL DETERMINANTS .............25

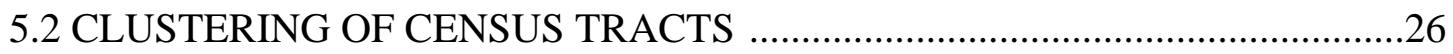

5.3 ASSESSMENTS OF CLUSTER-BASED APPROACH ……………………........30

6. REGRESSION WITHIN GEO-ECONOMIC CLUSTERS ..........................................33

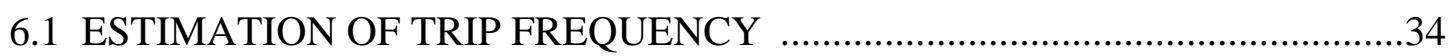

6.2 ASSESSMENT OF TRIP FREQUENCY ESTIMATES ......................................36

6.3 ESTIMATION OF HOUSEHOLD PMT AND VMT ………………………........36

6.4 ASSESSMENT OF PMT AND VMT ESTIMATES .............................................39

7. ESTIMATION OF TRIPS BY TRIP PURPOSE ……………………………........

7.1 LOGISTIC REGRESSION ……………………………………………….....41

7.2 ASSESSMENT OF TRIP ESTIMATES BY TRIP PURPOSE ............................44

8. CONVERTING TRAVEL ESTIMATES TO TAZ LEVEL ……………………........45

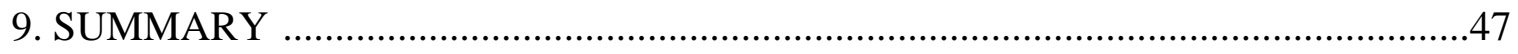

APPENDIX 1: TRAVEL CONCEPTS AND GLOSSARY .......................................... A1 - 1

APPENDIX 2: KEY CHANGES IN THE 2001 NHTS SURVEY

METHODOLOGY AND CONTENT A2 - 1 
APPENDIX 3: ADJUSTMENT OF INCOME BY THE ACCRA COST OF

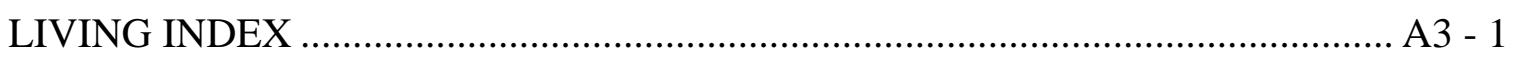

APPENDIX 4: DETERMINATION OF 19 “MEGA-URBAN” MSAs.......................A4 - 1

APPENDIX 5: TUTORIAL TO USE THE GIS-BASED WEB TOOL.......................... - 1 


\section{LIST OF FIGURES}

Figure

Page

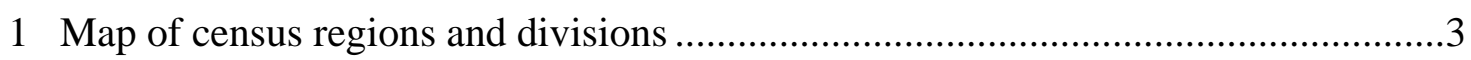

2 NHTS survey components and links among them...............................................8

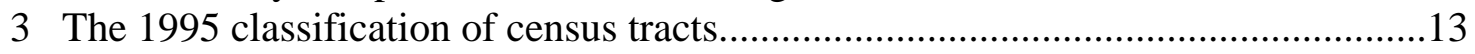

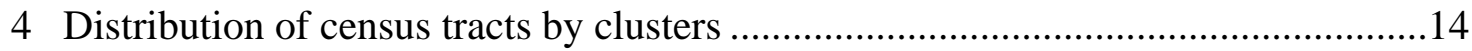

5 Classify census tracts in the city of Oak Ridge to appropriate clusters ...................14

6 Assignment of NPTS Households to eleven clusters.............................................16

7 Comparison of household income between NPTS sample household and all households in the same cluster.......................................................................17

8 Comparisons of alternative estimates of New York State, 1995 NPTS ..................23

9 Average daily VMT per household by household income, 2001 NHTS .................28

10 Classification of 2001 eligible census tracts ..................................................29 


\section{LIST OF TABLES}

\section{Table}

1 Travel Parameter Specification. .5

2 Household Distribution by Household Size and Vehicle Ownership Tract 51149850100, Prince George County, Virginia....

3 Number of 1995 NPTS Households Assigned to Each of the 11 Clusters ................15

4 Average Number of Daily Person Trips per Rural Low-Income Household, Estimated based on 1995 NPTS...

5 Estimated Total Number of Daily Person Trips Census Tract 201, City of Oak Ridge

6 Comparisons of Alternative Estimates to Baseline Standards ...................................22

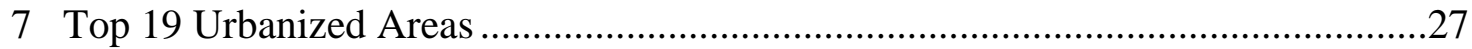

8 Classification of 64,791 Eligible Census Tracts, 2001 …........................................29

9 Comparison of Alternative Estimates to Baselines Data from Nine 2001 NHTS Add-on Areas .................................................................................................

10 Number of Eligible Census Tracts and NHTS Households in Five

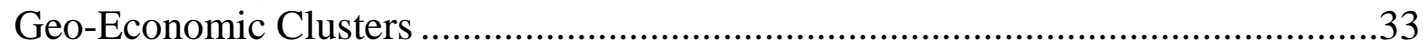

11 Significant Independent Variables to Estimate Household Travel Rates ...................35

12 Comparing Baseline Standards to Various Trip-Frequency Estimates Data from Nine 2001 NHTS Add-on Areas..........................................................................37

13 Significant Independent Variables for Estimating Household PMT and VMT.........38

14 Comparison of Alternative PMT and VMT Estimates to Baseline Standards Data from Nine 2001 NHTS Add-on Areas ..........................................................40

15 Parameter Specification of Trips by Trip Purpose.......................................................41

16 Significant Independent Variables for Estimating Person Trip Distribution by Trip Purpose.......................................................................................................4

17 Comparison of Methods to Estimate Trips by Trip Purpose ......................................45

18 An Example of Estimating Person Trips at TAZ Level, TAZ01001000299 .............46

19 Summary of Assessment Results Based on 2001 NHTS Add-on Area Data ............48 


\section{BACKGROUND AND OBJECTIVES}

Policy makers rely on transportation statistics, including data on personal travel behavior, to formulate strategic transportation policies, and to improve the safety and efficiency of the U.S. transportation system. Data on personal travel trends are needed to examine the reliability, efficiency, capacity, and flexibility of the Nation's transportation system to meet current demands and to accommodate future demand. These data are also needed to assess the feasibility and efficiency of alternative congestion-mitigating technologies (e.g., high-speed rail, magnetically levitated trains, and intelligent vehicle and highway systems); to evaluate the merits of alternative transportation investment programs; and to assess the energy-use and air-quality impacts of various policies.

To address these data needs, the U.S. Department of Transportation (USDOT) initiated an effort in 1969 to collect detailed data on personal travel. The 1969 survey was the first Nationwide Personal Transportation Survey (NPTS). The survey was conducted again in 1977, 1983, 1990, 1995, and 2001. Data on daily travel were collected in 1969, 1977, 1983, 1990 and 1995. In 2001, the survey was renamed the National Household Travel Survey (NHTS) and it collected both daily and long-distance trips.

The 2001 survey was sponsored by three USDOT agencies: Federal Highway Administration (FHWA), Bureau of Transportation Statistics (BTS), and National Highway Traffic Safety Administration (NHTSA). The primary objective of the survey was to collect trip-based data on the nature and characteristics of personal travel so that the relationships between the characteristics of personal travel and the demographics of the traveler can be established. Commercial and institutional travel were not part of the survey.

Due to the survey's design, data in the NHTS survey series were not recommended for estimating travel statistics for categories smaller than the combination of Census division (e.g., New England, Middle Atlantic, and Pacific), MSA size, and the 
availability of rail. Extrapolating NHTS data within small geographic areas could risk developing and subsequently using unreliable estimates. For example, if a planning agency in City X of State Y estimates travel rates and other travel characteristics based on survey data collected from NHTS sample households that were located in City X of State $\mathrm{Y}$, then the agency could risk developing and using unreliable estimates for their planning process. Typically, this limitation significantly increases as the size of an area decreases. That said, the NHTS contains a wealth of information that could allow statistical inferences about small geographic areas, with a pre-determined level of statistical certainty. The question then becomes whether a method can be developed that integrates the NHTS data and other data to estimate key travel characteristics for small geographic areas such as Census tract and transportation analysis zone, and whether this method can outperform other, competing methods.

While some metropolitan areas conduct their own household travel/activity survey to estimate the required inputs to "feed their planning model," many more lack the resources to do so. In absence of their own travel surveys, these communities typically use one of the following options to estimate the required inputs by calculating travel rates and other needed model parameters:

Option 1. based on the entire NHTS survey data (e.g., national-based estimates),

Option 2. based on data from NHTS sample households that are located in the same Census Region (i.e., Northeast, Midwest, South, West) (Figure 1),

Option 3. based on data from NHTS sample households that are located in the same Census Division (i.e., New England, Middle Atlantic, East North Central, West North Central, South Atlantic, East South Central, West South Central, Mountain, and Pacific) (Figure 1), or

Option 4. based on data from NHTS sample households that are located in Metropolitan Statistical Areas of similar size such as those with more 
than 3 million people, between one and three million people, between five hundred thousand and one million people,..., or fewer than two hundred and fifty thousand people.

These options are in ascending geographic resolution with the presumption that the precision of the estimated travel rates could increase by using data collected from households in a finer geographically resolution. That said, it was theorized: (1) whether an alternative can be developed to "transfer" estimated travel rates from sample households to geographic areas with similar socioeconomic and demographic characteristics, and (2) whether this alternative could provide estimates that can better reflect the characteristics of small geographic areas than the four typical options listed above.

Figure 1. Map of census regions and divisions.

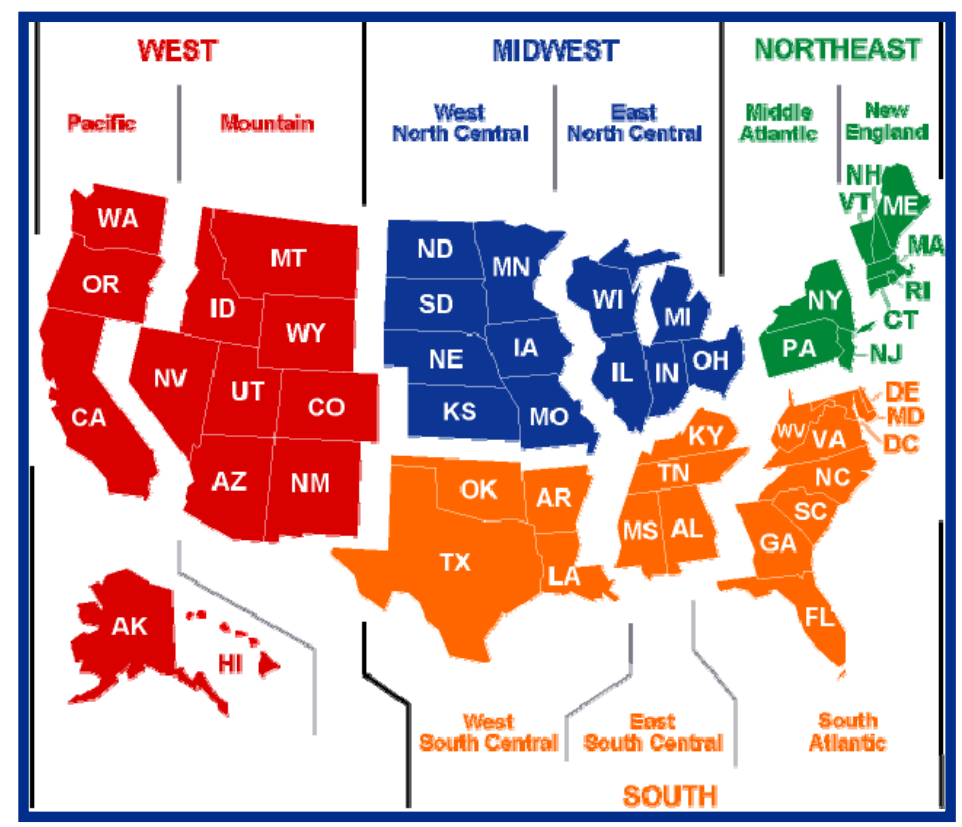

In the late 1900s, the Federal Highway Administration's (FHWA) Office of Highway Policy Information funded a proof-of-concept (POC) study, which used the 1995 NPTS data. The geographic units for the POC study were Census tracts. Results 
from the POC study suggested that travel estimates generated using this concept are second best only to travel parameters estimated with data from locale-specific household surveys ${ }^{1}$. A spreadsheet tool was developed to facilitate the use of the model ${ }^{2}$.

With the availability of the 2001 National Household Travel Survey (NHTS), the model developed using the 1995 NPTS data was updated and improved using the latest personal travel data. This report documents the approaches and steps taken to update, develop, and validate this model. Section 2 outlines the travel parameters of interest the outcomes. The data sources used are described in Section 3. Methods used for the 1995 data are outlined in Section 4 while various approaches used to better refine the 2001 estimates are documented in Sections 5 through 7. The report concludes with a summary and conclusions in Section 8. A tutorial of the GIS-based web tool is provided in the appendix.

\section{EXPECTED OUTCOMES/PARAMETERS OF INTEREST}

Key parameters commonly used in transportation planning are projections of the number, type, and purpose of trips; the origins and destinations (i.e., distribution) of these trips; the mode shares; and the routes. A specification of the travel parameters illustrates the expected outcomes and guides the development of the method (Table 1). The specification of the parameters suggests that for each of the Census tracts around the country, the model will calculate or estimate the parameters categorized by:

o area (urban vs. rural),

o household income (high, medium, and low), and

o household size (1-, 2-, 3-, 4-, and 5+- person).

\footnotetext{
${ }^{1}$ Reuscher, T.R., Schmoyer, R. L., Hu, P. S. "Transferability of Nationwide Personal Transportation Survey Data to Regional and Local Scales.” Transportation Research Record. No. 1817 (2002) pp. 25-32. ${ }^{2}$ http://npts.ornl.gov/npts/1995/Doc/transfer.xls
} 
While not explicitly stated in the table, per household estimates of person and vehicle miles of travel (PMT and VMT) were also investigated.

Table 1. Travel Parameter Specification ${ }^{3}$

\begin{tabular}{|c|c|c|c|c|c|c|}
\hline & \multicolumn{6}{|c|}{ Travel Parameters } \\
\hline & \multirow[t]{2}{*}{$\begin{array}{l}\text { Avg. Autos per } \\
\text { Household }\end{array}$} & \multirow{2}{*}{$\begin{array}{l}\text { Avg. Daily } \\
\text { Person Trips per } \\
\text { Household }\end{array}$} & \multirow{2}{*}{$\begin{array}{l}\text { Average Daily } \\
\text { Vehicle Trips per } \\
\text { Household }\end{array}$} & \multicolumn{3}{|c|}{$\begin{array}{l}\text { \% Average Daily Person } \\
\text { Trips by Purpose* }\end{array}$} \\
\hline & & & & HBW & HBO & NHB \\
\hline \multicolumn{7}{|c|}{ Urban Area $=500,000$ to 999,999} \\
\hline \multicolumn{7}{|l|}{ Household Income } \\
\hline \multicolumn{7}{|l|}{ Low } \\
\hline \multicolumn{7}{|l|}{ Medium } \\
\hline \multicolumn{7}{|l|}{ High } \\
\hline \multicolumn{7}{|l|}{ Weighted Average } \\
\hline \multicolumn{7}{|l|}{ Household Size } \\
\hline \multicolumn{7}{|l|}{ One } \\
\hline \multicolumn{7}{|l|}{ Two } \\
\hline \multicolumn{7}{|l|}{ Three } \\
\hline \multicolumn{7}{|l|}{ Four } \\
\hline \multicolumn{7}{|l|}{ Five \& over } \\
\hline \multicolumn{7}{|l|}{ Weighted Average } \\
\hline \multicolumn{7}{|c|}{ Urban Area $=1,000,000+$} \\
\hline. & & & & & & \\
\hline \multicolumn{7}{|c|}{ Urban Area $=250,000$ to 499,999} \\
\hline$\dot{.}$. & & & & & & \\
\hline
\end{tabular}

\footnotetext{
${ }^{3}$ W. A. Martin and N. A. McGuckin. NCHRP Report 365. Travel Estimation Techniques for Urban Planning. Transportation Research Board. National Research Council. Washington, DC. 1998.
} 


\section{DATA SOURCES}

The optimal data source for transportation planning would be to have data for an adequate number of households' socioeconomic, demographic, and trip making characteristics, as well as for land use and transportation infrastructure-related characteristics. Unfortunately, limited resources preclude this ideal situation. In reality, there are the decennial Census of Population and Housing, "Census 2000," the Census Transportation Planning Package 2000 which uses the Census 2000 microdata, the 2001 NHTS, the American Community Survey, and many others. None of these by themselves can fulfill all of the data needs. However, if integrated, they help fill each other's void.

\subsection{Decennial Population Census}

Since 1790, the Bureau of the Census has been enumerating the population every ten years ${ }^{4}$. While the decennial Census of Population and Housing provides household socioeconomic and demographic characteristics relevant to travel patterns, it does not collect data on household trip-making patterns. The specific data items used for this project are the total number of households by household size, median household income, and employment rate at the Census tract level.

\subsection{Census Transportation Planning Package 2000}

Census Transportation Planning Package (CTPP) 2000 is a set of special tabulations from the decennial census designed for transportation planners. The data are tabulated from answers to the Census 2000 long form questionnaire which was mailed to one in six U.S. households ${ }^{5}$. The Census 2000 long form questionnaire asks about "usual mode to work" and travel time, and work location, but does not ask about information related to other trip purposes.

\footnotetext{
${ }^{4}$ Bureau of the Census, http://factfinder.census.gov/jsp/saff/SAFFInfo.jsp?_pageId=sp4_decennial\&_submenuId

5 http://www.fhwa.dot.gov/ctpp/about.htm
} 
The specific data used for this project is the household distribution by household size and the number of vehicles available to the households. For example, Census 2000 enumerated 27 households in Census Tract No. 850100 in Virginia’s Prince George County that are of a household size of 3 persons and that have one vehicle available to each of these 27 households (Table 2). This household-distribution information will be used later to total the number of trips taken by all of the households in this tract.

Table 2. Household Distribution by Household Size and Vehicle Ownership Tract 51149850100, Prince George County, Virginia

\begin{tabular}{|l|c|c|c|c|c|}
\hline \multirow{2}{*}{$\begin{array}{l}\text { Number of Available } \\
\text { Vehicles }\end{array}$} & \multicolumn{5}{|c|}{ Number of Persons in Household } \\
\cline { 2 - 6 } & 1 & 2 & 3 & 4 & 5 or more \\
\hline 0 & 17 & 4 & 0 & 0 & 0 \\
\hline 1 & 69 & 23 & 27 & 4 & 1 \\
\hline 2 & 9 & 28 & 14 & 4 & 1 \\
\hline 3 & 9 & 19 & 9 & 19 & 6 \\
\hline $4+$ & 0 & 0 & 0 & 4 & 1 \\
\hline
\end{tabular}

\subsection{National Household Travel Survey (NHTS)}

The National Household Travel Survey ${ }^{6}$ (NHTS) is the only source of information on personal travel in the U.S. The survey included demographic characteristics of households, people, vehicles, and detailed information on daily and longer-distance travel for all purposes by all modes. The NHTS consists of a sample of almost 70,000 U.S. households, and provides national estimates of trips and miles by travel mode, trip purpose, and a host of household attributes. The 2001 NHTS was conducted over a period from March 2001 through July 2002.

Specifically, the NHTS survey series is the only information source at the national level that link characteristics about a household, its members and vehicles, drivers in that household, and individual trips taken by the members of the household (Figure 2). The

\footnotetext{
${ }^{6}$ http://nhts.ornl.gov/2001/index.shtml
} 
Figure 2. NHTS survey components and links among them.

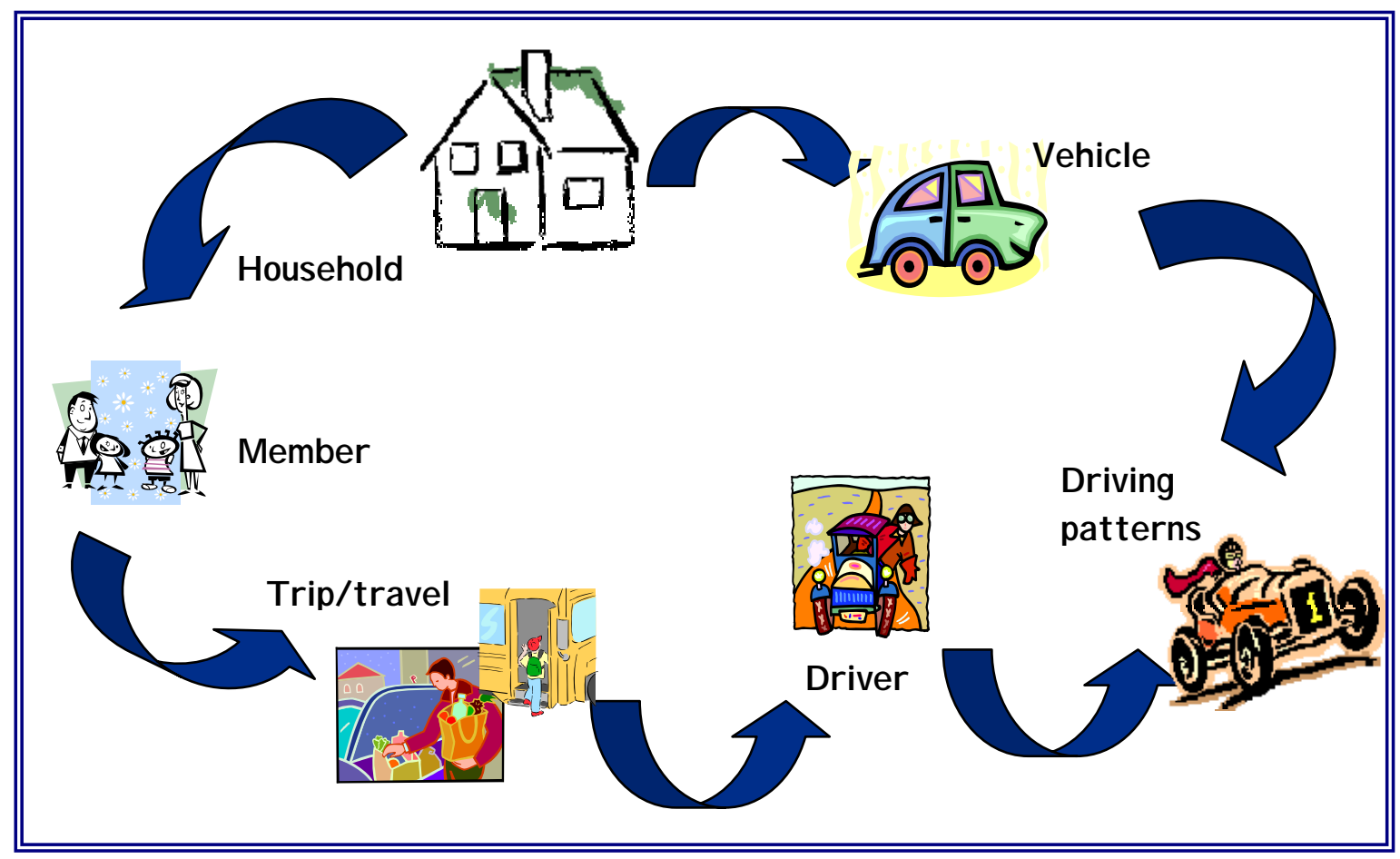

ability to link data on households, drivers, vehicles, vehicle usage, driving and tripmaking enables a better understanding of "Who owns what type of vehicle, going to where, when, for what purpose and by what mode?” A limitation of the NHTS survey series is that, excluding add-ons purchased by cities and states, its data reliability does not extend beyond geographic categories smaller than a Census division (e.g., New England, Middle Atlantic, and Pacific), MSA size, and the availability of rail. This aggregate level of geographic detail is the motivation of this project. Can the trip and travel characteristics estimated from the NHTS data be "transferred" to Census tracts with similar socioeconomic and demographic profiles?

Improvements have been made continuously to the NHTS survey series. Among the changes in the 2001 NHTS, two are especially significant. First, the 2001 survey was the first survey in the NHTS series that collected travel by household members younger than 5 years old. All previous surveys had collected travel information only from 
household members age 5 and older. The second improvement in the 2001 NHTS was the improved, multiple prompting for walk and bike trips. This latter change significantly increased the number of walk and bike trips recorded. It is important to recognize these improvements and their implications for the analysis of trends. A complete comparison between the 1995 and 2001 survey methods is summarized in Appendix 2.

\section{METHODOLOGICAL FRAMEWORK}

Our approach hinges on three premises:

Premise 1. The majority of the households within a Census tract are sufficiently homogeneous with respect to the travel determinants (e.g., household income, employment status, life cycle, vehicle ownership) reported for each tract,

Premise 2. Census tracts can be grouped into homogeneous clusters with respect to travel determinants reported for each tract, and

Premise 3. There are enough NHTS households assigned to each cluster, and NHTS households in a cluster are representative of all households within that cluster, with respect to travel determinants.

If all of these premises are met, then the transferring of the NHTS data statistics is relatively straightforward. The specific steps to carry out the approach are:

Step 1. Identify significant travel determinants (e.g., household income, number of workers, number of vehicles and drivers, life cycle, etc.) based on NHTS data and literature review. 
Step 2. Categorize all of the census tracts in the country into "homogeneous" clusters, with respect to travel determinants reported for each tract. This is accomplished by using cluster analysis.

Step 3. Assign NHTS households to these clusters based on the census tract where the sample household is located.

Step 4. Calculate cluster-specific travel statistics based on data collected from NHTS households.

Step 5. Assess cluster-based estimates by using the add-on samples. If assessment results are undesirable, then Steps 2 through 5 are repeated -- developing an alternative clustering of Census tracts.

Step 6. Calculate travel demand or other travel statistics for any geographic area based on final results from Step 4 and on the household distribution and profiles reported in the Census 2000.

The framework and the steps are elaborated below by using examples from the 1995 POC study.

\section{Step 1. Identify significant travel determinants}

Results from the analysis of the 1995 NPTS data and literature review establish relationship(s) between explanatory variables and travel (e.g., person trips (PT), person miles of travel (PMT), vehicle trips (VT), and vehicle miles of travel (VMT)). While many socioeconomic and demographic characteristics are predictors of travel, only household income, household size, and employment rate emerged from our analysis as the three most important variables in predicting, say, VMT and VT. Although other variables were significant, they added no significant additional explanatory power beyond that provided by those three variables. Also, although many other variables are found in the literature as significant travel determinants, if these variables are not available at the individual Census tract level, then they were not be used in this effort. 
Step 2. Categorize all of the Census tracts around the country into "homogeneous" clusters

In 1995, there were 61,258 tracts nationwide. Excluding Manhattan tracts and tracts without any population (1,430 tracts), 59,828 tracts remained. The decision to exclude Manhattan tracts was based on the fact that household profiles and travel patterns of households in these tracts are so different from those in the rest of the country that including them in the analysis could bias the national results ${ }^{7}$.

Using the three most important variables identified in Step 1, cluster analysis was used to categorize these 59,000+ tracts into homogeneous groups based on data available for these tracts. It is important to emphasize that since the goal is to classify Census tracts into homogenous groups with respect to travel determinants, the classification scheme must be based on data available for all Census tracts, not just the tracts containing households surveyed in the NHTS. That way, the classification is used to group all tracts, not just those tracts for which NHTS data are available.

The main purpose of classifying Census tracts was to reduce estimation error to a reasonable, minimum degree by determining a classification scheme that identifies tracts with similar travel determinants, and thus, travel patterns. Although choosing homogeneous classes tends to reduce bias, it also increases the variability of the estimates by reducing sample sizes in the individual classes. Thus, the key to arriving at a satisfactory classification is to determine how to split groups and when to stop splitting.

\footnotetext{
${ }^{7}$ Hu, P.S. Young, J. R. “1995 New York NPTS: A Comparison Study.” Oak Ridge National Laboratory, Oak Ridge, TN. November 1999. http://www.dot.state.ny.us/ttss/1995npts/nynpts95_comparison_study.pdf
} 
Furthermore, it is well known that classification algorithms such as cluster analysis sometimes lead to difficult-to-interpret classification schemes. Therefore, another goal of the 1995 effort was a classification that makes sense in terms of the known relationships. Specifically, the 1995 classification scheme of Census tracts was based on a combination of cluster analysis, regression analysis, judgment about data quality and outliers, and wellestablished relationships between travel behavior and various predictor variables.

The final clustering scheme using the 1995 data resulted in 11 clusters of Census tracts $^{8}$ (Figure 3). For example, 4,565 Census tracts are grouped into a homogeneous class that is characterized as "the middle class in urban areas." According to this classification scheme, every eligible tract (59,236 tracts out of the 61,258 tracts nationwide) is assigned to one of the 11 clusters. The final distribution of all eligible tracts by cluster is in Figure 4. Note that the definition of low-, middle-, and high-income are not absolute but are relative with respect to each type of area (i.e., urban, rural, and suburban).

${ }^{8}$ For detail discussion of the 1995 cluster analysis, see Reuscher, T.R., Schmoyer, R. L., Hu, P. S. "Transferability of Nationwide Personal Transportation Survey Data to Regional and Local Scales." Transportation Research Record. No. 1817 (2002) pp. 25-32. 
Figure 3. The 1995 classification of census tracts.

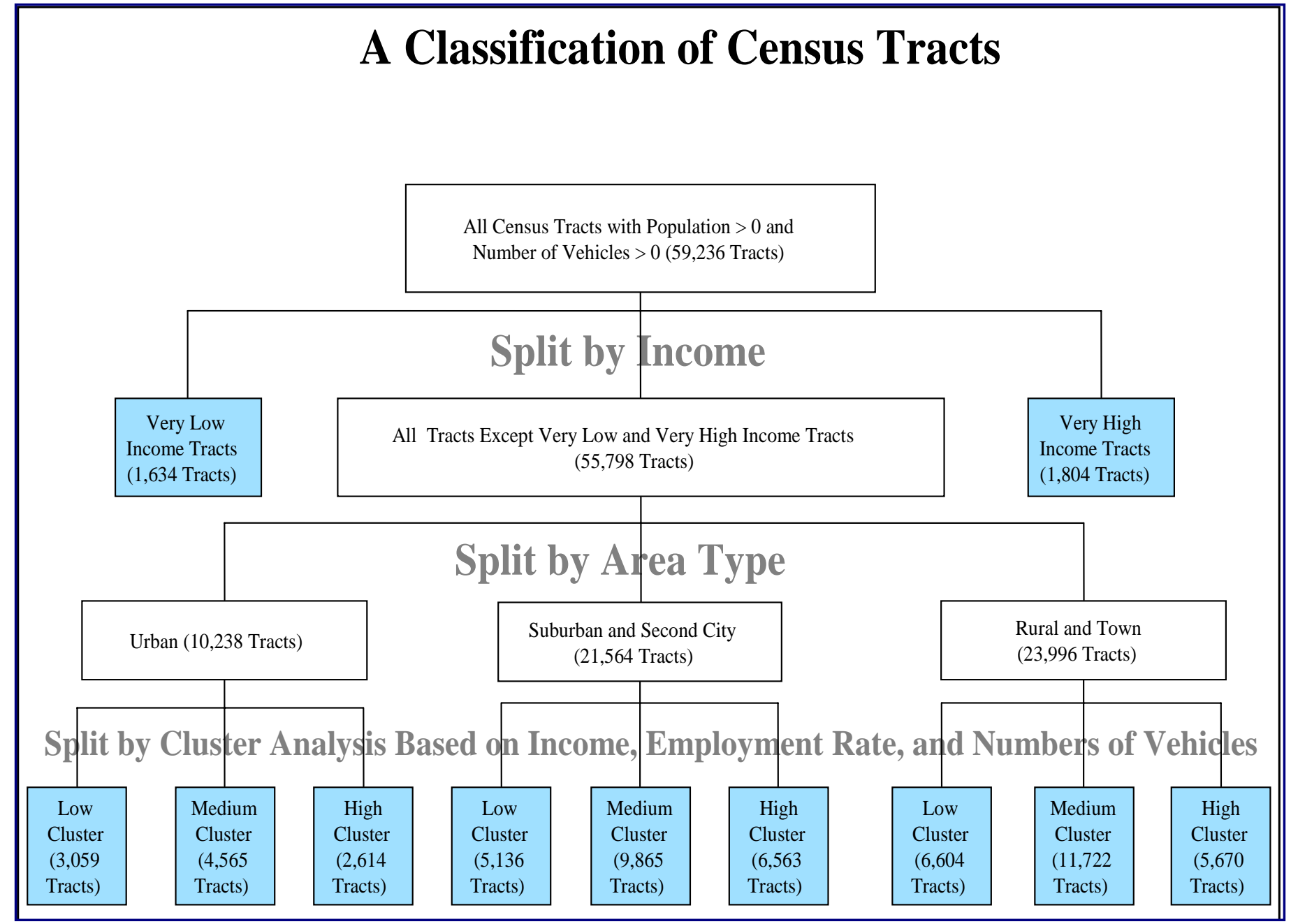


Figure 4. Distribution of census tracts by clusters.

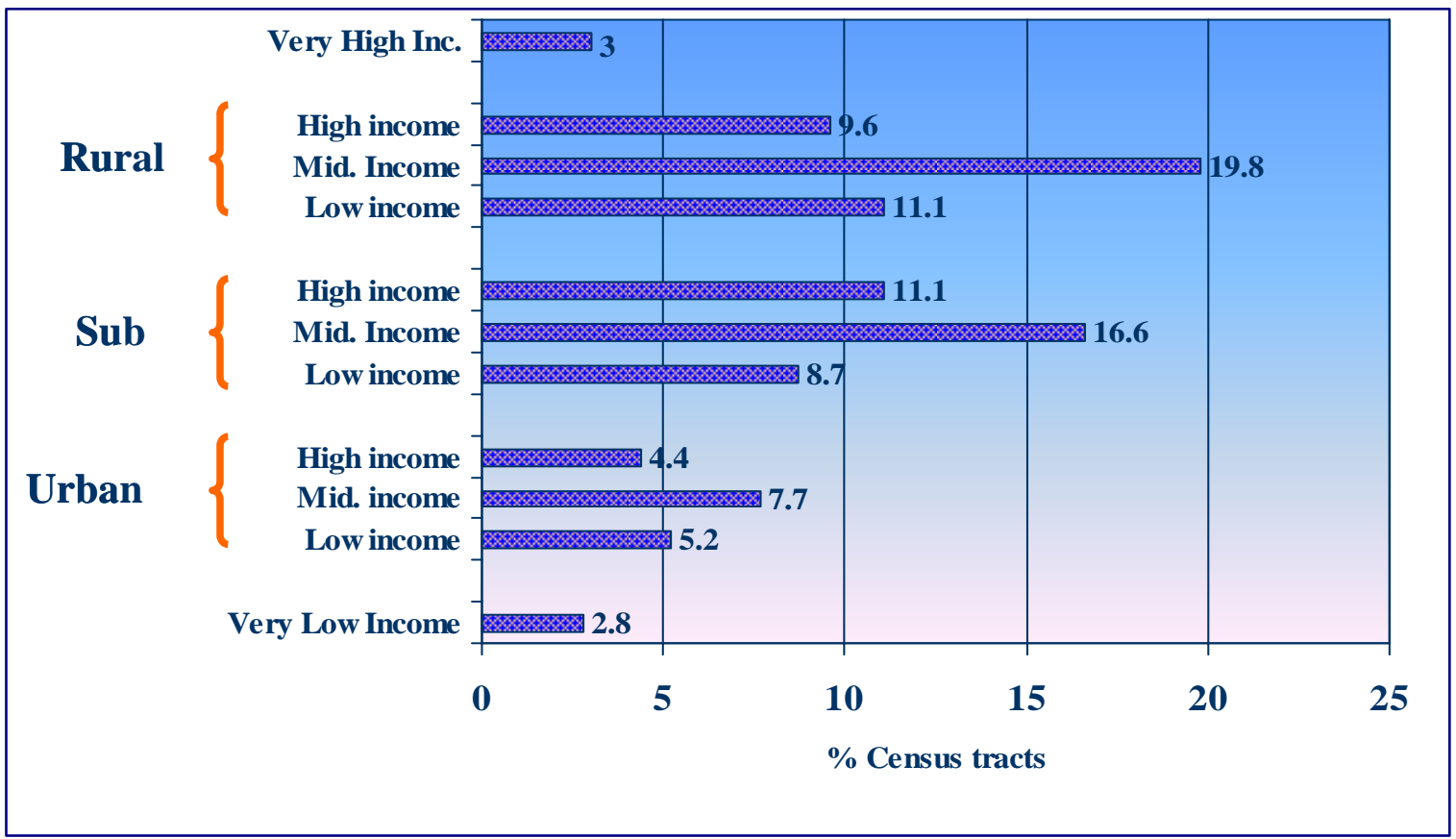

The City of Oak Ridge is used here as an example to illustrate how the NPTS data can be "transferred." Using the final classification scheme, the 7 Census tracts in the City of Oak Ridge, Tennessee were classified as illustrated in Figure 5. For example, Census tract 201 in the city is assigned to the "low-income rural households" cluster.

Figure 5. Classify census tracts in the City of Oak Ridge to appropriate clusters.

\begin{tabular}{|c|c|}
\hline T. 201 & Rural "low" \\
\hline T. 202 & Rural "high" \\
\hline T. 203 & Rural "mid" \\
\hline T. 204 & Rural "mid" \\
\hline T. 205 & Rural "low" \\
\hline T. 206 & Rural "high" \\
\hline T. 301 & Very "high" \\
\hline
\end{tabular}


Step 3. Assign NHTS households to these clusters based on the Census tract where the sample household is located.

For each of the households surveyed in the NPTS, information was available on the Census tract in which a surveyed household resided ${ }^{9}$. Using this information, all NPTS sample households were assigned to the appropriate clusters. Then the questions become: are there enough NHTS households assigned to each cluster? And, are the NHTS households in a cluster representative of all households (i.e., those surveyed, and those NOT surveyed, in the NHTS) within that cluster, with respect to travel determinants?

Table 3 depicts the assignment of the 1995 NPTS households to the 11 clusters. The assignment appears reasonably close to that of all of the tracts (Figure 6). This similarity gives the assurance that there are enough, and also appropriate shares of, 1995 NPTS households assigned to each cluster.

Table 3. Number of 1995 NPTS Households Assigned to Each of the 11 Clusters

\begin{tabular}{|l|c|}
\hline Cluster & $\begin{array}{c}\text { No. of NPTS Sample } \\
\text { Households Assigned }\end{array}$ \\
\hline Very low income & 413 \\
\hline Rural, high income & 5,934 \\
\hline Rural, medium income & 7,890 \\
\hline Rural, low income & 2,886 \\
\hline Suburban, high income & 6,015 \\
\hline Suburban, medium income & 8,740 \\
\hline Suburban, low income & 2,859 \\
\hline Urban, high income & 1,509 \\
\hline Urban, medium income & 2,425 \\
\hline Urban, low income & 1,320 \\
\hline Very high income & 1,182 \\
\hline
\end{tabular}

\footnotetext{
${ }^{9}$ Due to privacy concerns, this information is not available in the public use file.
} 
Figure 6. Assignment of 1995 NPTS households to eleven clusters.

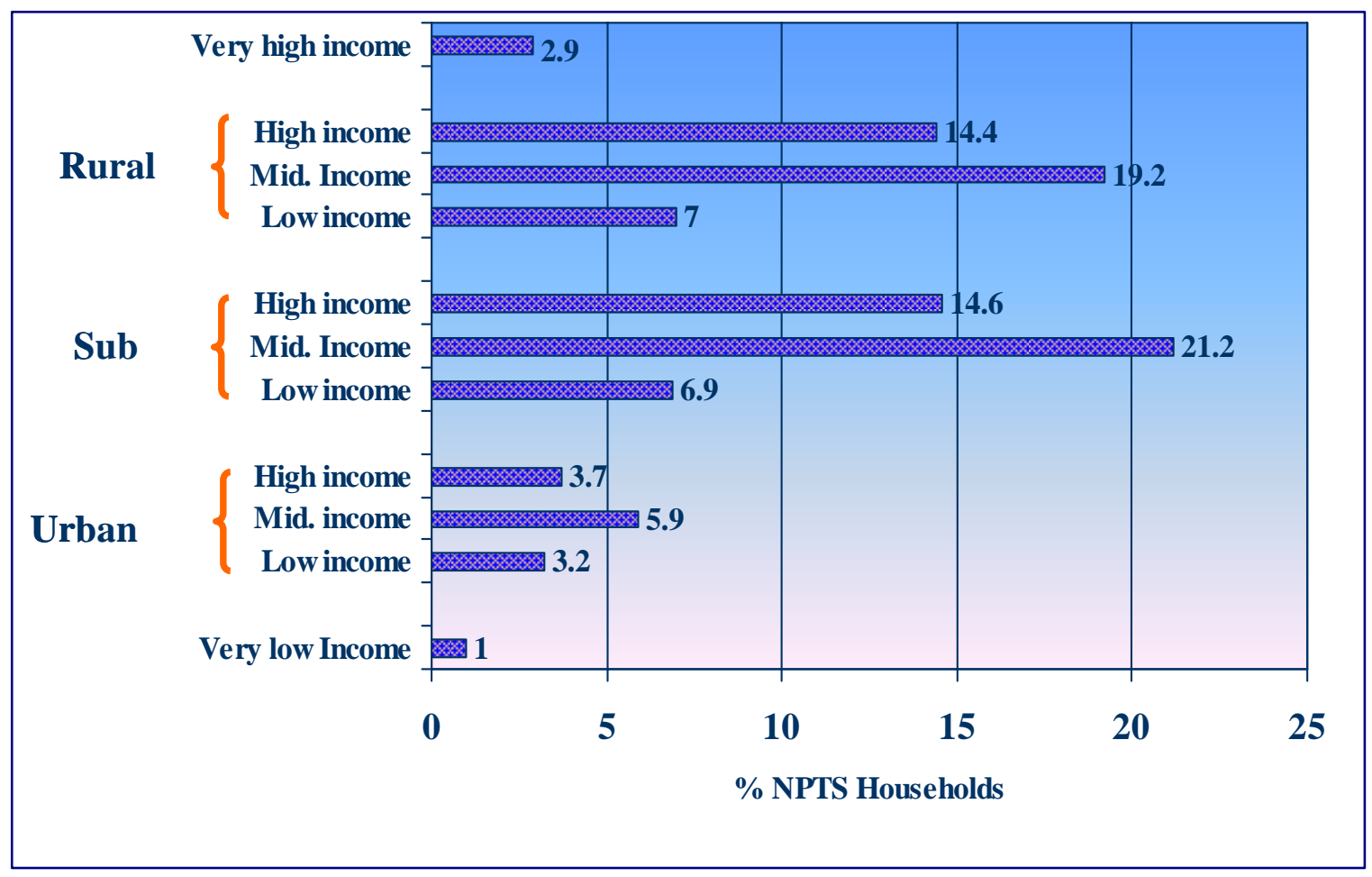

Although there are an adequate number of 1995 NPTS households in each of the 11 clusters and the distribution of NPTS households into the 11 clusters is compatible with that of all of the tracts around the country, are the NPTS households in a cluster representative of all households (i.e., those surveyed, and those NOT surveyed, in the NPTS) within that cluster, with respect to travel determinants?

Comparisons of major travel determinants suggest that NPTS households, in general, are representative of the households in their corresponding clusters, with a few exceptions. For example, an income comparison of NPTS households in a given cluster to the average of all Census tracts in that cluster shows that except for the very-low and very-high income clusters, the NPTS households in a given cluster are similar to other households in the Census tracts that are grouped into 
that cluster (Figure 7). The computer-aided telephone interview (CATI) technique used in the 1995 NPTS tends to under-sample low-income households. As a result, it is not surprise to find that the NPTS sample households in the "very low income" cluster have an average income higher than that of the remaining households in that cluster.

Figure 7. Comparison of household income between NPTS sample household and all households in the same cluster

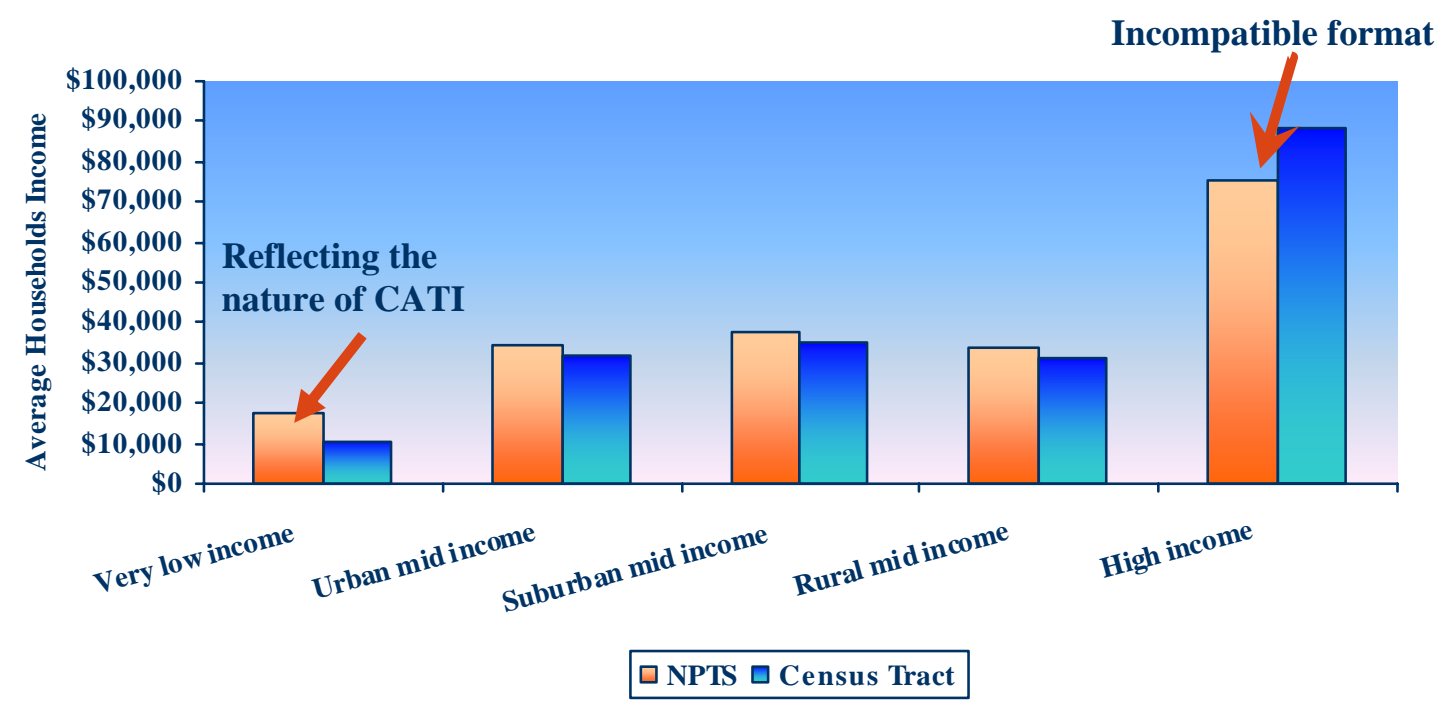

To encourage the number of households reporting income information, the NPTS sample households were asked to report their income in pre-determined categories with the highest category of ">\$100,000." However, the Census asked the reporting of actual household income and made available information only at different aggregate levels (e.g., average and median income). Much of the inconsistency between the NPTS and the Census data was addressed to ensure meaningful comparisons. However, the inconsistency in the highest income category $(>\$ 100,000)$ can not be fully reconciled, thereby contributing to the difference observed in the "very high income" cluster (Figure 7). The difference presumably is an artifact of how income data were categorized. 
Given that Premises 1 through 3 were satisfactorily met, this implies that the survey data collected from the NPTS households in a given cluster can be used to calculate key travel statistics for all of the tracts within that cluster, thus "transferring" the NPTS data. For example, 7,890 households surveyed in the NPTS (Table 3) were located in one of the 11,722 tracts that are characterized as "middle class in rural area" (Figure 3). Data collected from these 7,890 NPTS households are representative, with respect to key travel parameters, to all of the households in these 11,722 tracts.

Step 4. Calculate cluster-specific travel statistics based on data collected from 1995 NPTS households

With an adequate number of representative NPTS households in each of the 11 clusters, survey data collected from these sample households can now be used to calculated cluster-specific travel statistics. Combining results from Steps 2 and 3, travel statistics can now be calculated for every one of the 59,236 eligible Census tracts around the country.

Now return to the example of the City of Oak Ridge. The key travel characteristics for each of the 7 tracts in the city can be calculated. For example, Census tract 201 was classified in the "rural low-income household" cluster. Close to three thousand NPTS households $(n=2,886)$ were located in the 6,604 Census tracts that were classified in the "low income rural household" cluster (Table 3).

\begin{tabular}{|c|c|c|}
\hline \multicolumn{3}{|c|}{ Census Tracts in City of Oak Ridge } \\
\hline T. 201 & Rural “low” & 2,886 NPTS HHs \\
\hline T. 202 & Rural "high" & 5,934 NPTS HHs \\
\hline T. 203 & Rural "mid" & 7,890 NPTS HHs \\
\hline T. 204 & Rural "mid" & 7,890 NPTS HHs \\
\hline T. 205 & Rural “low” & 2,886 NPTS HHs \\
\hline T. 206 & Rural “high” & 5,934 NPTS HHs \\
\hline T. 301 & Very “high” & 1,182 NPTS HHs \\
\hline
\end{tabular}


The number of person trips per household, by household size, is estimated by using survey data collected from these 2,886 NPTS households (Table 4).

Table 4. Average Number of Daily Person Trips Per Rural Low-Income Household, Estimation based on 1995 NPTS

\begin{tabular}{|l|c|}
\hline Household Size & $\begin{array}{c}\text { No. of Daily Person Trips } \\
\text { per Household }\end{array}$ \\
\hline One-Person & 3.6 \\
\hline Two-Person & 8.0 \\
\hline Three-Person & 12.0 \\
\hline Four-Person & 15.6 \\
\hline More than four persons & 19.3 \\
\hline
\end{tabular}

The Census 2000 provides the number of households by household size in each Census tract. Using that information and person-trip rates in Table 4, the travel demand for Census tract 201 in the City of Oak Ridge can be calculated as in Table 5. Applying this approach to the remaining six Census tracts in the city provides a city-wide profile of total personal travel demand. With this approach, key household travel characteristics can be estimated and annualized for every Census tract in the country.

Table 5. Estimated Total Number of Daily Person Trips Census Tract 201, City of Oak Ridge

\begin{tabular}{|l|c|c|c|}
\hline Household Size & $\begin{array}{c}\text { No. of Daily } \\
\text { Person Trips } \\
\text { per Household }\end{array}$ & $\begin{array}{c}\text { No. of } \\
\text { Households } \\
\text { in Tract 201 }\end{array}$ & $\begin{array}{c}\text { Total No. of Daily } \\
\text { Trips in Tract 201 }\end{array}$ \\
\hline One-Person & 3.6 & 632 & $2,275=3.6 \times 632$ \\
\hline Two-Person & 8.0 & 365 & $2,920=8.0 \times 365$ \\
\hline Three-Person & 12.0 & 174 & $2,088=12 \times 174$ \\
\hline Four-Person & 15.6 & 124 & $1,934=15.6$ x 124 \\
\hline More than four persons & 19.3 & 72 & $1,390=19.3 \times 72$ \\
\hline Total for Census tract 201 & & $\mathbf{1 , 3 6 7}$ & $\mathbf{1 0 , 6 0 7}$ \\
\hline
\end{tabular}


Transferring 2001 National Household Travel Survey

Step 5. Assess cluster-based estimates by using the add-on samples.

Once trip and travel characteristics are "transferred" from the NPTS survey, the next question is how useful these cluster-based estimates are. It is important to point out that the purpose of the assessment is to judge whether cluster-based estimates are superior to estimates derived from one of the typical approaches outlined in the Introduction Section. It is equally important to keep in mind that the purpose of the assessment is NOT to determine whether the cluster-based estimates can replace the estimates derived from locale-specific household travel surveys.

That said, the performance of the cluster-based estimates was assessed against the estimates using Options 2 through 4 discussed in the Introduction Section. The add-on survey data were used for the assessment. An "add-on area" is an area that purchased larger samples than the national NPTS stipulated in order to meet the statistical variability requirements at a geographic level smaller than the NPTS national sample was able to support. In 1995, there were five add-on areas that purchased larger samples: New York State; Commonwealth of Massachusetts; Oklahoma City, Oklahoma; Tulsa, Oklahoma; and Seattle, Washington.

Three separate assessments were conducted using data from three add-on areas: New York, Massachusetts, and Oklahoma areas. These areas were selected for their relatively large samples: 11,004 surveyed households in New York, 7,801 in Massachusetts, and 3,932 in Oklahoma. Surveyed households from each of these areas were separated into two halves - one was used to calculate travel estimates (using clustering and alternative approaches as discussed in the Introduction Section), and one was "reserved" for the assessment. The reason for separating the add-on sample into two halves is to assure that the assessment was conducted objectively using two statistically independent samples. 
The "reserved" set was used to calculate the "baseline standards"10 which were then compared to travel estimates derived from the cluster approach as well as from Options 2 through 4 (referred to as "the estimates" thereafter). Although the estimates and baseline standards were statistically independent, they were all based on sample survey data. Therefore, standard errors for the baseline standards were computed to help interpret their differences from the estimates.

The assessments focused on four key travel parameters: person trips (PT), person miles of travel (PMT), vehicle trips (VT), and vehicle miles of travel (VMT). Assessment results are summarized in Table 6 . Figure 8 compares the standardized New York alternative estimates to the baseline standards (set to equal 1).

Clearly, the cluster-based estimates are the closest to the baseline standards in the cases of New York and Massachusetts. However, results from the Oklahoma data are mixed. While the cluster approach is the best in estimating PMT and VMT, it is not the best in estimating trip parameters (i.e., PT and VT). Nonetheless, all methods yield trip estimates that are within one standard error of the Oklahoma baseline total.

${ }^{10} \mathrm{~A}$ baseline standard is a travel statistic computed using half of the households in an NHTS sample addon. The other half of the add-on data is re-weighted and included in estimates using other computational methods (National, MSA Size, Clustering, Regression-based, etc.). 
Transferring 2001 National Household Travel Survey

Table 6. Comparisons of Alternative Estimates to Baseline Standards

\begin{tabular}{|c|c|c|c|c|c|c|c|c|c|c|}
\hline & $\begin{array}{l}\text { Baseline } \\
\text { Standards }\end{array}$ & $\mathrm{SE}$ as $\%$ & Cluster-based & $\%$ diff & $\begin{array}{l}\text { Option 4: } \\
\text { MSA Size- } \\
\text { based }\end{array}$ & $\%$ diff & \begin{tabular}{|c|} 
Option 3: \\
Census Division \\
- based
\end{tabular} & $\%$ diff & $\begin{array}{c}\text { Option 2: } \\
\text { Census Region- } \\
\text { based }\end{array}$ & $\%$ diff \\
\hline \multicolumn{11}{|c|}{ New York } \\
\hline PT & $53,657,551$ & $2.16 \%$ & $52,389,300$ & $-2.36 \%$ & $51,344,771$ & $-4.31 \%$ & $38,462,883$ & $-28.32 \%$ & $41,745,500$ & $-22.20 \%$ \\
\hline PMT & $459,178,922$ & $4.37 \%$ & $439,123,402$ & $-4.37 \%$ & $433,631,520$ & $-5.56 \%$ & $291,870,089$ & $-36.44 \%$ & $330,857,392$ & $-27.95 \%$ \\
\hline VT & $28,653,474$ & $2.04 \%$ & $28,835,004$ & $0.63 \%$ & $27,977,015$ & $-2.36 \%$ & $20,960,605$ & $-26.85 \%$ & $23,202,606$ & $-19.02 \%$ \\
\hline VMT & $255,795,187$ & $3.71 \%$ & $249,083,376$ & $-2.62 \%$ & $248,447,090$ & $-2.87 \%$ & $175,011,971$ & $-31.58 \%$ & $198,455,142$ & $-22.42 \%$ \\
\hline \multicolumn{11}{|c|}{ Massac } \\
\hline PT & $22,905,841$ & $2.20 \%$ & $22,650,765$ & $-1.11 \%$ & $22,434,511$ & $-2.06 \%$ & $16,892,483$ & $-26.25 \%$ & $20,102,290$ & $-12.24 \%$ \\
\hline PMT & $202,132,709$ & $4.14 \%$ & $202,387,508$ & $0.13 \%$ & $194,204,818$ & $-3.92 \%$ & $153,415,946$ & $-24.10 \%$ & $167,192,631$ & $-17.29 \%$ \\
\hline VT & $14,684,173$ & $2.20 \%$ & $13,912,160$ & $-5.26 \%$ & $13,176,923$ & $-10.26 \%$ & $10,475,399$ & $-28.66 \%$ & $11,974,009$ & $-18.46 \%$ \\
\hline VMT & $130,907,651$ & $3.23 \%$ & $122,510,744$ & $-6.41 \%$ & $117,071,084$ & $-10.57 \%$ & $94,120,125$ & $-28.10 \%$ & $102,768,840$ & $-21.50 \%$ \\
\hline \multicolumn{11}{|c|}{ Oklahoma } \\
\hline PT & $6,463,309$ & $2.88 \%$ & $6,449,930$ & $-0.21 \%$ & $6,505,491$ & $0.65 \%$ & $6,456,894$ & $-0.10 \%$ & $6,335,251$ & $-1.98 \%$ \\
\hline PMT & $59,150,730$ & $4.24 \%$ & $60,285,795$ & $1.92 \%$ & $60,457,496$ & $2.21 \%$ & $69,268,367$ & $17.10 \%$ & $63,860,543$ & $7.96 \%$ \\
\hline VT & $4,337,423$ & $2.51 \%$ & $4,211,490$ & $-2.90 \%$ & $4,148,946$ & $-4.35 \%$ & $4,296,229$ & $-0.95 \%$ & $4,200,352$ & $-3.16 \%$ \\
\hline VMT & $37,623,890$ & $4.05 \%$ & $37,720,723$ & $0.26 \%$ & $37,017,886$ & $-1.61 \%$ & $41,608,888$ & $10.59 \%$ & $40,065,992$ & $6.49 \%$ \\
\hline
\end{tabular}

$\mathrm{PT}=$ Person Trips

PMT $=$ Person Miles of Travel

VT $=$ Vehicle Trips

VMT $=$ Vehicle Miles of Travel

$\mathrm{SE}=$ Standard Errors

$\%$ Diff $=$ Percent difference from the baseline standards

Percent differences in bold indicate the method that gives estimates closest to the baseline for a given statistic. 
Figure 8. Comparisons of alternative estimates of New York State 1995 NPTS

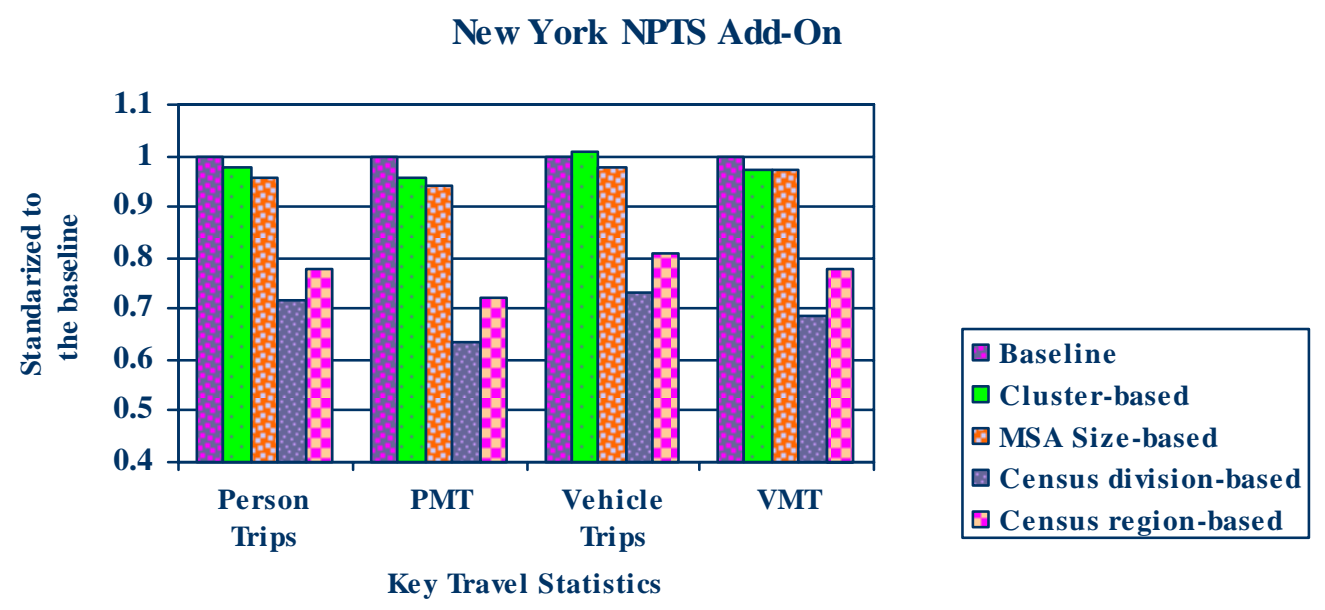

If resources are available, a locale-specific household survey is likely to yield estimates that are more accurate than those based on other surveys. If there is no locale-specific survey, then there are five alternative ways using the NPTS data to estimate local travel statistics:

o Cluster based,

o MSA-size based,

o Census-Division based,

o Census-Region based, and

o Nationwide.

The assessment results suggest that cluster-based estimates are more accurate than those derived from the other 4 approaches. 


\section{APPLICATION OF CLUSTER APPROACH TO 2001 NHTS DATA}

Suggestions by the planner community and the availability of additional data led to a number of improvements and changes to the 2001 approach. They were:

a. In addition to household income, the household buying-power index was included.

b. Data on household size and the number of vehicles were available, through the CTPP, for individual tracts.

c. Census tracts with available public transit were identified.

d. A separate clustering approach was used for tracts with public transit and tracts without public transit.

e. The greater number of add-on samples increased the ability of these data to assess/validate the cluster-based estimates.

f. Based on recommendations from planners, only week-day travel was included in the model.

g. The estimation methods were assessed on the basis of two criteria: (i) similar to the 1995 study, methods were compared by the number of addons in which they are closer to the baseline standards. This criterion is referred to as the number of "wins" a method has over other, competing methods. This criterion has the effect of favoring the method that performs the best for larger add-on areas that have the resources to conduct their own survey. (ii) To compensate for this effect, a second criterion was added to compare competing methods on the basis of the mean absolute deviation from the baseline standard across all nine add-on areas. This second criterion had the effect of making the results of a method in, say, the New York state add-on, equal to those in a smaller add-on, such as the Kentucky 4-county add-on. 


\subsection{Identification of Significant Travel Determinants}

Based on the 2001 NHTS data, demographic and socioeconomic factors were identified that significantly influence travel patterns (e.g., PT, PMT, VT, and VMT). These factors will then be used as potential "classifiers" to help categorize Census tracts into homogeneous clusters. A least squares regression model was developed to establish a statistically significant relationship between travel patterns and demographic and socioeconomic factors. More than two dozen potential factors were considered:

o household size,

o household vehicle count,

0 the percent and number of workers in the Census tract who take public transit to work,

o the ACCRA cost of living and cost of transportation indices,

o population density,

o household income and buying power,

o Census division and region,

o MSA size,

o life cycle, and

o the number of bus and train routes in a Census tract.

Instead of using median household income to reflect a household's buying power, the ACCRA Cost of Living index were used to adjust income data reported in the NHTS and in the Census. While proprietary, the ACCRA index has become the de facto standard for cost of living data for city-to-city comparisons ${ }^{11}$. Their data contains cost of living indices broken down into different components. For this study, the overall cost of living was used to adjust household income data and was used as a "classifier" by itself in the cluster analysis. Furthermore, the ACCRA cost of transportation index was also

\footnotetext{
${ }^{11}$ Bureau of the Census, https://ask.census.gov/cgi-bin/askcensus.cfg/php/enduser/std_adp.php?p_faqid=695
} 
included. For more information on how the ACCRA data was used to adjust income data, see Appendix 3.

Household size, buying power, number of household vehicles, employment rate, and life cycle status are among the significant classifiers. Note that potential travelinfluencing factors that are available in the NHTS survey, but not available for all Census tracts, such as the number of drivers per household, were omitted from the model because the goal of the clustering is to identify factors that can categorize all Census tracts into homogeneous clusters.

\subsection{Clustering of Census Tracts}

In 2000, there were 65,443 tracts. After eliminating Manhattan tracts and tracts without any inhabitants, 64,791 eligible tracts remained. Similar to the 1995 approach, tracts with a median household income less than $\$ 14,000$ in 2001 (equivalent to $\$ 12,000$ in 1995) were grouped into the "Low Income" cluster, while tracts with a median household income greater than $\$ 87,000$ (equivalent to $\$ 75,000$ in 1995) were grouped into the "High Income" cluster. The remaining tracts were subject to the cluster analysis and categorized into 9 clusters, resulting in a total of 11 clusters.

Nine separate assessments were conducted using data from the nine add-on areas $^{12}$. The assessments indicated that the 11-cluster classification scheme was unsatisfactory. To improve the "transferability" results, the clustering scheme was revised.

To capture the travel patterns of households residing in densely populated urbanized areas with highly used transit services, "mega-urban” areas were identified. These areas were identified based on the number of transit-service hours, the extent to

\footnotetext{
12 There were nine add-on areas in the 2001 NHTS. They were: the states of Wisconsin, New York, Texas and Hawaii; Oahu, Hi; four counties in Kentucky; Baltimore, MD; Des Moines, IA; and Lancaster, PA.
} 
which transit was used for commute trips, and the population size. These criteria identified nineteen highly urbanized areas (Table 7). Appendix 4 describes in detail the method used to determine these areas.

A second revision to the clustering scheme is the modification of the "Very Low Income" cluster and the removal of the "Very High Income" cluster. The reason for this change is that NHTS data shows that travel propensity increases sharply with household income up to a certain point (around \$50,000), and then begins to plateau (Figure 9). Thus, the "Very High Income" cluster was removed from consideration.

Table 7. Top 19 Urbanized Areas

\begin{tabular}{|c|l|c|c|c|}
\hline $\begin{array}{c}\text { Overall } \\
\text { Rank }\end{array}$ & MSA/Urbanized area & $\begin{array}{c}\text { Transit } \\
\text { Service } \\
\text { Hours* } \\
(000 s)\end{array}$ & $\begin{array}{c}\text { Transit } \\
\text { Use }\end{array}$ & $\begin{array}{c}\text { Total } \\
\text { Pop. } \\
\text { (000s) }\end{array}$ \\
\hline 1 & New York-Newark, NY-NJ-CT & 35,206 & $24.0 \%$ & 21,200 \\
\hline 2 & Chicago, IL-IN & 11,055 & $11.6 \%$ & 9,158 \\
\hline 3 & San Francisco--Oakland--San Jose, CA & 11,177 & $8.9 \%$ & 7,039 \\
\hline 4 & Washington--Baltimore, DC--MD--VA--WV & 9,134 & $10.9 \%$ & 7,608 \\
\hline 5 & Philadelphia, PA-NJ-DE-MD & 6,599 & $8.4 \%$ & 6,188 \\
\hline 6 & Boston, MA-NH-RI & 4,715 & $8.2 \%$ & 5,819 \\
\hline 7 & Seattle, WA & 6,187 & $6.0 \%$ & 3,555 \\
\hline 8 & Los Angeles-Long Beach-Santa Ana, CA & 14,980 & $5.2 \%$ & 16,374 \\
\hline 9 & Pittsburgh, PA & 3,855 & $7.9 \%$ & 2,359 \\
\hline 10 & Miami, FL & 5,524 & $4.6 \%$ & 3,876 \\
\hline$($ tie) & Portland, OR-WA & 2,914 & $6.0 \%$ & 2,265 \\
\hline 12 & Honolulu, HI & 1,895 & $8.8 \%$ & 876 \\
\hline 13 & Minneapolis-St. Paul, MN & 3,593 & $5.3 \%$ & 2,969 \\
\hline$($ tie) & Atlanta, GA & 2,976 & $5.8 \%$ & 4,112 \\
\hline 15 & Milwaukee, WI & 2,317 & $7.2 \%$ & 1,690 \\
\hline 16 & Cleveland, OH & 2,546 & $5.8 \%$ & 2,946 \\
\hline 17 & New Orleans, LA & 1,485 & $8.7 \%$ & 1,338 \\
\hline 18 & Denver-Aurora, CO & 3,369 & $4.4 \%$ & 2,582 \\
\hline 19 & Houston, TX & 4,063 & $3.6 \%$ & 4,670 \\
\hline
\end{tabular}

* The annual totals of rail and non-rail hours, 2001 National Transit Database 
Figure 9. Average daily VMT per household by household income. 2001 NHTS

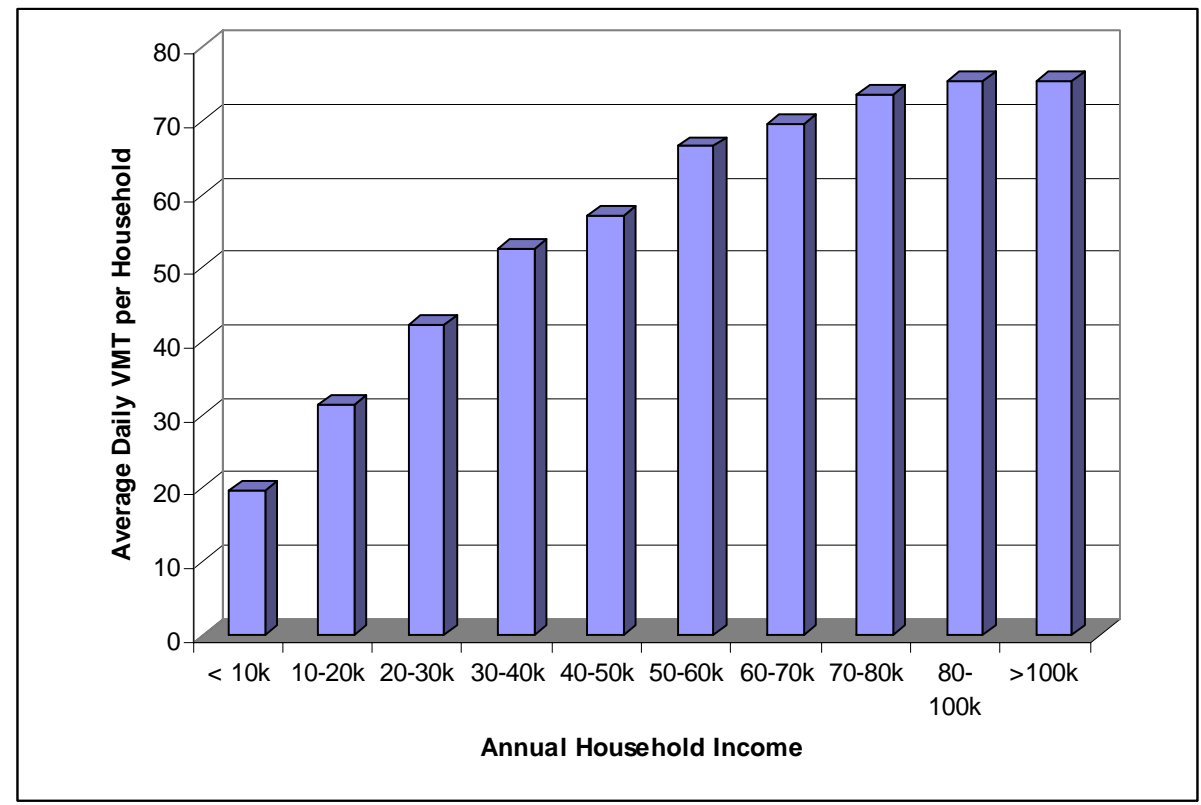

The very low income cluster was modified to account for the differences in household income between households with different household sizes. The Census Bureau defines the poverty line based on the size and the number of children in the household ${ }^{13}$. A Census tract with at least 20 percent of the residents below the poverty line is described by the Census Bureau as a "Poverty Area," while a tract with at least 40 percent of residents below the poverty line is called an "Extreme Poverty Area."14 Tracts with an "Extreme Poverty" designation were grouped into their own cluster, rather than a "Very Low Income" cluster ${ }^{15}$. The revised clustering scheme results in 10 clusters of Census tracts (Table 8 and Figure 10).

\footnotetext{
${ }^{13}$ Bureau of the Census, http://www.census.gov/hhes/www/poverty/threshld/thresh01.html

${ }^{14}$ Bureau of the Census, http://www.census.gov/population/socdemo/statbriefs/povarea.html

${ }^{15}$ Six "Extreme Poverty" tracts with median incomes that exceeded the highest threshold for the poverty line in $2000(\$ 38,322)$ were not, for our purposes, given the "Extreme Poverty" designation. These tracts were clustered as they would have been without the Extreme Poverty designation. A seventh tract had data that heavily influenced the urban clustering process, and thus it was manually assigned to the Urban High cluster. Since no NHTS households come from this tract, this re-designation did not impact the trip rate calculation.
} 
Table 8. Classification of 64,791 Eligible Census Tracts, 2001

\begin{tabular}{|l|c|c|}
\hline Geo-Economic Cluster & $\begin{array}{c}\text { No. of Census } \\
\text { Tracts }\end{array}$ & $\begin{array}{c}\text { No. of NHTS } \\
\text { Households }\end{array}$ \\
\hline Extreme Poverty & 1,965 & 887 \\
\hline Mega-Urban & \multicolumn{2}{|l|}{} \\
\hline Low Income & 4,840 & 3,481 \\
\hline Medium Income & 7,944 & 6,159 \\
\hline High Income & 8,771 & 8,341 \\
\hline Urban \\
\hline Low Income & 7,766 & 6,513 \\
\hline Medium Income & 13,753 & 19,677 \\
\hline High Income & 5,917 & 8,805 \\
\hline Rural & 4,492 & 3,768 \\
\hline Low Income & 6,479 & 6,580 \\
\hline Medium Income & 2,864 & 5,036 \\
\hline High Income & $\mathbf{6 4 , 7 9 1}$ & $\mathbf{6 9 , 2 4 7}$ \\
\hline TOTAL
\end{tabular}

Figure 10. Classification of 2001 eligible census tracts.

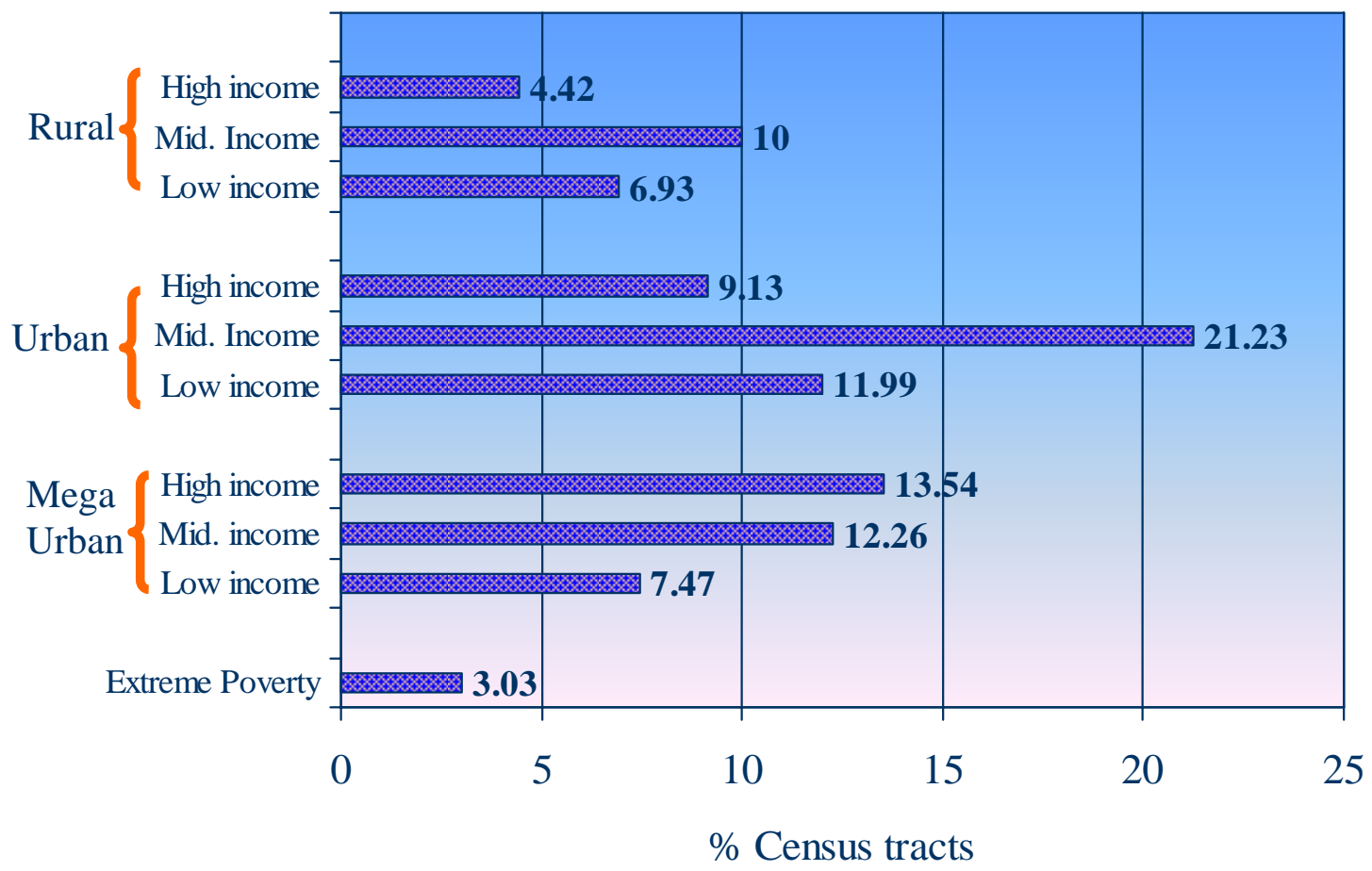




\subsection{Assessments of Cluster-based Approach}

Similar to the 1995 assessment, the superiority of alternative estimation methods ${ }^{16}$ is determined by the number of times a given method produces estimates that are closest to the baseline standards for all travel parameters (i.e., PT and VT). This is informally referred to as the number of "wins" a method has over other alternatives. Unlike the 1995 assessment, alternative estimation methods were assessed in 2001 on the basis of the mean absolute deviation from the baseline standards of all 9 add-on areas. In 1995, estimation methods were compared based on a sum of the travel statistics for all add-on areas. This previous approach had the effect of favoring the method that performed the best for larger add-on areas, which would have had the resources to conduct their own survey or purchase additional sample households from the national survey (i.e., add-on). Using the mean absolute deviation from the baseline as an assessment criterion had the effect of making the results of an approach in, say, the New York state add-on, equal to those in a smaller add-on, such as the Kentucky 4-county add-on.

There was a separate assessment for each of the nine add-on areas. Assessment results were mixed (Table 9). The percentage differences in bold indicate the method that produces estimates closest to the baseline standards while those in yellow highlight indicate the cluster-based approach that produces estimates closest to the baseline. For example, the "reserved" half of the New York add-on data estimate that a typical New York household takes 9.9 trips a day, with a standard error of 0.11 . The cluster-based approach yields an estimate that is 3.7\% greater than the baseline of 9.9 trips while the method based on MSA size yields an estimate that is 9.6\% greater. By comparing estimates generated by alternative approaches to the baseline, one observes that the method that categorizes NHTS national sample by Census Division, MSA size and rail availability (thereafter referred to as "Division-MSA-Rail method") is superior to other methods because it yields a PT estimate that is closest to the baseline. Repeating this

\footnotetext{
${ }^{16}$ The alternative estimation methods are based on different categorizations of NHTS households -categorized by (1) Census Division \& MSA Size, (2) MSA Size, (3) Census Division, (4) Census Region, and (5) Cluster-based.
} 
assessment to the remaining eight add-on areas, the cluster-based approach is superior to others only in two of the add-on areas (i.e., the State of Wisconsin and Oahu, Hawaii). The assessment concludes that the Division-MSA-rail method is superior more often than the other four approaches - in 5 out of 9 add-on areas for PT estimates, and in 4 out of 9 add-on areas for VT estimates (Table 9). That said, the percentage differences between the estimates based on the Division-MSA-Rail method and the baseline range widely, from less than $1 \%$ in Hawaii to close to $11 \%$ in Baltimore. Efforts are continuing to explore a hybrid approach that combines clustering and regression methods.

Why is the cluster method performing so poorly when it did so well in 1995 ? Potential explanations include increased statistical noise in the 2001 NHTS data, increased diversity of the add-ons used to assess the clustering approach, a potential "survey-firm" effect, and/or the aforementioned improvements made in 2001 to the assessment method.

The standard errors show that the 2001 data did not have greater variation than the 1995 data. In fact, standard errors were typically smaller in 2001 than in 1995 for simple trip statistics. This was probably due to the larger sample sizes in 2001 than in 1995.

The "survey-firm" effect also did not seem to explain much of the poor performance of the cluster method. The speculation of a "firm" effect stems from the fact that the 2001 add-ons were conducted by two different firms: New York and Wisconsin add-ons were conducted by one firm while the remaining seven add-ons were conducted by a different firm. Initial investigation of trip rates showed no statistically significant differences between data collected by the two different firms. This seems to suggest that the poorer performance of the clustering-based approach in 2001 could be attributable to the robustness of the assessment approach in 2001 and other reasons that can not be articulated. 
Table 9. Comparison of Alternative Estimates to Baselines Data from Nine 2001 NHTS Add-on Areas

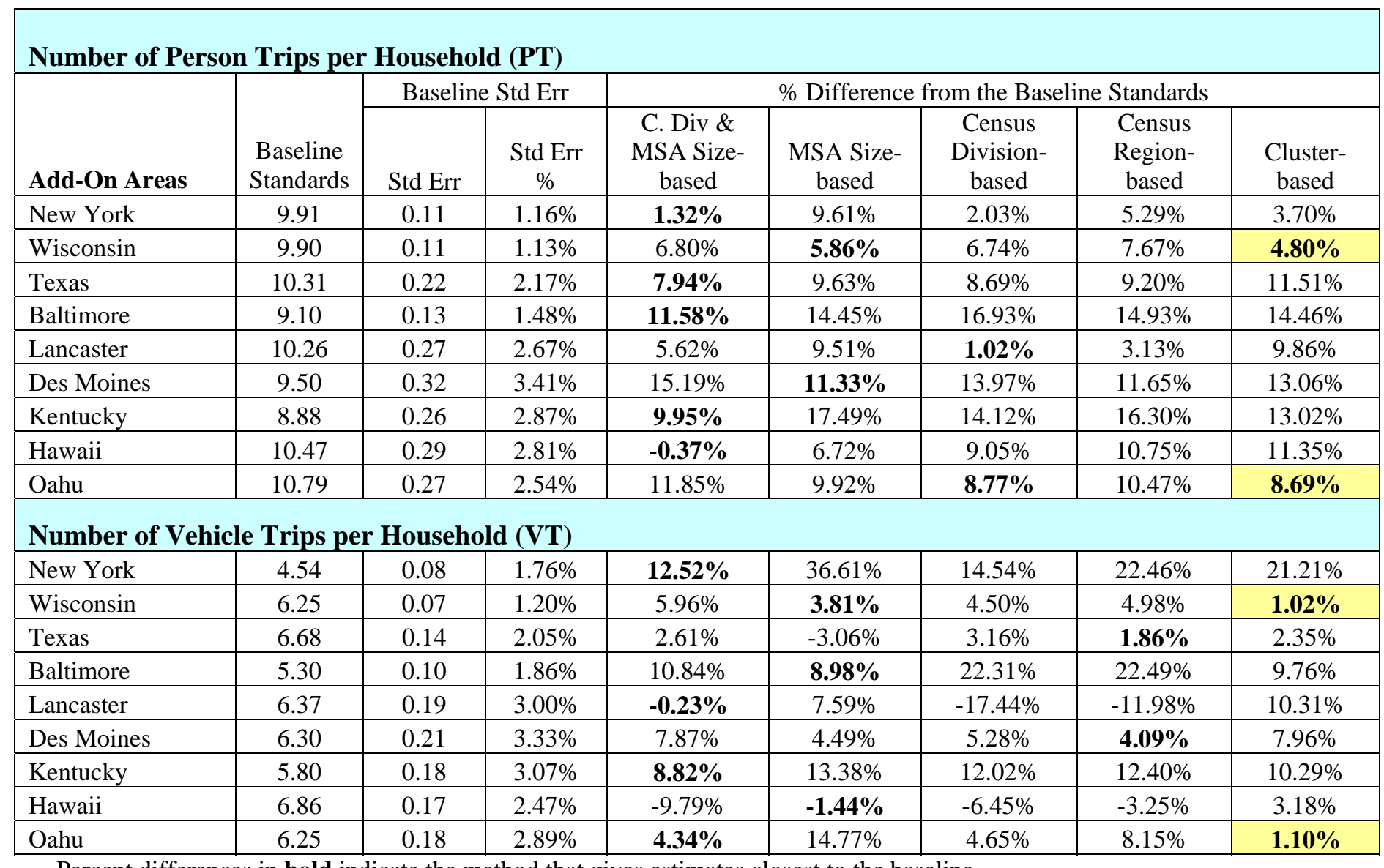

Percent differences in bold indicate the method that gives estimates closest to the baseline.

Percent differences in yellow highlight indicate the cluster-based approach that gives estimates closest to the baseline. 


\section{REGRESSION WITHIN GEO-ECONOMIC CLUSTERS}

Despite the fact that the clustering approach yields less desirable outcomes, it helps define a broad category of geo-economic clusters within which travel estimation methods could be refined. The geo-economic clusters are: mega-urban, urban, suburban, rural and extreme-poverty (Table 10). This section discusses the methods used to estimate travel parameters for each Census tract that are more precise than those estimated by the clustering approach.

Table 10. Number of Eligible Census Tracts and NHTS households in Five Geo-Economic Clusters

\begin{tabular}{|l|c|c|}
\hline Geo-Economic Cluster & $\begin{array}{c}\text { Number of } \\
\text { Census Tracts }\end{array}$ & $\begin{array}{c}\text { Number of NHTS } \\
\text { Households }\end{array}$ \\
\hline Extreme Poverty & 1,965 & 887 \\
\hline Mega-Urban & 11,910 & 9,719 \\
\hline Suburban & 24,344 & 27,165 \\
\hline Urban & 12,944 & 16,199 \\
\hline Rural & 13,628 & 15,277 \\
\hline TOTAL & $\mathbf{6 4 , 7 9 1}$ & $\mathbf{6 9 , 2 4 7}$ \\
\hline
\end{tabular}

Regression models were explored and developed - one for each of the travel parameters (i.e., PT, PMT, VT, and VMT) and geo-economic cluster combinations. A total of twenty ( $=4$ parameters $\mathrm{x} 5$ clusters) regression models were developed. Regressions used were linear models estimated via the least squares method. These models take the form below,

$$
y=\mathrm{B}_{0}+\mathrm{B}_{1} x_{1}+\mathrm{B}_{2} x_{2}+\ldots+\mathrm{B}_{k} x_{k}+\varepsilon
$$

where $\mathrm{y}$ is the dependent variable, $\mathrm{B}_{0}$ is the intercept, $\mathrm{B}_{1}-\mathrm{B}_{\mathrm{k}}$ are coefficients, $x_{1}-x_{k}$ are travel-influencing variables, and $\varepsilon$ is the model error. The total number of PT, PMT, VT, or VMT per household is the dependent variable, y. General assumptions of the 
regression model are that model error is uncorrelated from observation to observation and that the errors are normally distributed ${ }^{17}$. If these assumptions are not met, the estimates of the parameters $B_{1}-B_{k}$ might be biased. Since the ultimate goal for this modeling exercise was to produce estimates of travel and was not to establish relationships through parameter estimation, any violation of the aforementioned assumptions has no impact on meeting the ultimate goal. However, no inference should be drawn on the relationship(s) between the significant variables and the travel parameters.

\subsection{Estimation of Trip Frequency}

Table 11 summarizes the significant travel-influencing factors (marked by “+” for positive impact and "-" for negative impact) in estimating the total numbers of person trips and vehicle trips per household. For example, the household size, vehicle count, and household buying power have significant influence over the propensity to travel (as measured by the number of person trips) for households in urban, suburban, and rural clusters. Interestingly, income and buying power have no significant impact on the extreme poverty households' propensity to travel, probably reflecting a household's need to meet minimal non-discretionary travel needs in spite of household income. The frequency of travel, or of driving, by households in urban, suburban, and rural clusters seems to be influenced by the same factors (Table 11).

\footnotetext{
${ }^{17}$ Myers, Raymond H. “Classical and Modern Regression with Applications.” Second Edition. PWSKENT Publishing Company, Boston, MA. 1990. pp 82-83.
} 
Table 11. Significant Independent Variables

To Estimate Household Travel Rates

\begin{tabular}{|l|c|c|c|c|c|}
\hline & \multicolumn{5}{|c|}{ Geo-Economic Cluster } \\
\cline { 2 - 6 } & $\begin{array}{l}\text { Extreme } \\
\text { Poverty }\end{array}$ & $\begin{array}{c}\text { Mega- } \\
\text { Urban }\end{array}$ & Suburban & Urban & Rural \\
\hline Total Daily Person Trips per Household \\
\hline Household Size & + & + & + & + & + \\
\hline No. of Vehicles in Household & + & + & + & + & + \\
\hline Percent Who Use Transit to Work & - & & & & \\
\hline Number of Workers per Household & + & & & & \\
\hline Household Life Cycle (2 ${ }^{+}$A, 1 ${ }^{+}$C) & + & & & & \\
\hline MSA size (250-499,000) & - & & & & \\
\hline Household Income & & + & & & \\
\hline Household Buying Power & & & + & + & + \\
\hline R-SQUARED & 0.4366 & 0.3913 & 0.3821 & 0.3923 & 0.3834 \\
\hline Total Daily Vehicle Trips per Household & - & + & + & + & + \\
\hline Household Size & - & + & + & + & + \\
\hline No. of Vehicles in Household & + & - & & & \\
\hline Percent Who Use Transit to Work & & + & + & + & + \\
\hline Number of Workers per Household & + & & & & \\
\hline Household Life Cycle (2 ${ }^{+}$A, $1^{+}$C) & + & & & & \\
\hline Household Income & & + & + & + & + \\
\hline Household Buying Power & + & & + & & \\
\hline Census Divisions & + & & & & + \\
\hline R-SQUARED & 0.4645 & 0.3845 & 0.2811 & 0.3016 & 0.2836 \\
\hline
\end{tabular}

${ }^{*}$ Households with two or more adults and one or more children. 


\subsection{Assessment of Trip Frequency Estimates}

Using the same assessment approach described in Section 5.3, trip frequency estimates based on the "regression within geo-economic cluster" approach (hereafter referred to as the "regression-based approach") were compared to the baseline standards and to estimates generated by alternative estimation methods. Assessment results show that the performance of the regression-based approach is substantially improved over that of the clustering-based approach (Table 12). The regression-based approach produces estimates that are closest to the baseline standards in 6 of 9 add-ons for person-trip estimates; and in 4 of 9 for vehicle-trip estimates.

\subsection{Estimation of Household PMT and VMT}

Using an approach similar to that described in Section 6.1, least-square regression models were developed for household PMT and VMT. PMT was estimated by excluding air travel data. The significant travel-influencing factors for PMT and VMT are summarized in Table 13. In terms of R-squared, it is clear that PMT and VMT models are inferior to those of PT and VT. However, the R-squared values for VMT estimates are not uncommonly low. For example, the significant variables in the household VMT regression model developed by Pickrell and Shimek ${ }^{18}$ explained about $15 \%$ of the total variation in daily household motor vehicle travel.

\footnotetext{
${ }^{18}$ Pickrell, D. and Shimek, P. “Trends in Personal Motor Vehicle Ownership and Use: Evidence from the Nationwide Personal Travel Survey.” U.S. DOT Volpe Center. Cambridge, MA. 1998.
} 
Table 12. Comparing Baseline Standards to Various Trip-Frequency Estimates Data from Nine 2001 NHTS Add-on Areas

\begin{tabular}{|c|c|c|c|c|c|c|c|}
\hline \multicolumn{8}{|c|}{ Number of Person Trips per Household (PT) } \\
\hline \multirow[b]{2}{*}{ Add-On Areas } & \multirow[b]{2}{*}{$\begin{array}{c}\text { Baseline } \\
\text { Standards }\end{array}$} & \multirow[b]{2}{*}{$\begin{array}{c}\text { Std Err } \\
\% \\
\end{array}$} & \multicolumn{5}{|c|}{ \% Difference from the Baseline } \\
\hline & & & $\begin{array}{l}\text { C.Div \& MSA } \\
\text { Size-based }\end{array}$ & $\begin{array}{c}\text { MSA Size- } \\
\text { based }\end{array}$ & $\begin{array}{c}\text { CENSUS } \\
\text { Division- } \\
\text { based }\end{array}$ & $\begin{array}{c}\text { CENSUS } \\
\text { Region- } \\
\text { based } \\
\end{array}$ & $\begin{array}{c}\text { Regression- } \\
\text { based }\end{array}$ \\
\hline New York & 9.91 & $1.16 \%$ & $1.32 \%$ & $9.61 \%$ & $2.03 \%$ & $5.29 \%$ & $-6.52 \%$ \\
\hline Wisconsin & 9.90 & $1.13 \%$ & $6.80 \%$ & $5.86 \%$ & $6.74 \%$ & $7.67 \%$ & $-4.98 \%$ \\
\hline Texas & 10.31 & $2.17 \%$ & $7.94 \%$ & $9.63 \%$ & $8.69 \%$ & $9.20 \%$ & $-1.33 \%$ \\
\hline Baltimore & 9.10 & $1.48 \%$ & $11.58 \%$ & $14.45 \%$ & $16.93 \%$ & $14.93 \%$ & $5.35 \%$ \\
\hline Lancaster & 10.26 & $2.67 \%$ & $5.62 \%$ & $9.51 \%$ & $1.02 \%$ & $3.13 \%$ & $-2.18 \%$ \\
\hline Des Moines & 9.50 & $3.41 \%$ & $15.19 \%$ & $11.33 \%$ & $13.97 \%$ & $11.65 \%$ & $2.75 \%$ \\
\hline Kentucky & 8.88 & $2.87 \%$ & $9.95 \%$ & $17.49 \%$ & $14.12 \%$ & $16.30 \%$ & $2.44 \%$ \\
\hline Hawaii & 10.47 & $2.81 \%$ & $-0.37 \%$ & $6.72 \%$ & $9.05 \%$ & $10.75 \%$ & $-3.68 \%$ \\
\hline Oahu & 10.79 & $2.54 \%$ & $11.85 \%$ & $9.92 \%$ & $8.77 \%$ & $10.47 \%$ & $-5.90 \%$ \\
\hline Mean Absolute Deviation & & & $7.85 \%$ & $10.5 \%$ & $9.04 \%$ & $9.93 \%$ & $3.90 \%$ \\
\hline Number of "Wins" & & & 2 & 0 & 1 & 0 & 6 \\
\hline \multicolumn{8}{|c|}{ Number of Vehicle Trips per Household (VT) } \\
\hline New York & 4.54 & $1.76 \%$ & $12.52 \%$ & $36.61 \%$ & $14.54 \%$ & $22.46 \%$ & $-1.57 \%$ \\
\hline Wisconsin & 6.25 & $1.20 \%$ & $5.96 \%$ & $3.81 \%$ & $4.50 \%$ & $4.98 \%$ & $-4.83 \%$ \\
\hline Texas & 6.68 & $2.05 \%$ & $2.61 \%$ & $-3.06 \%$ & $3.16 \%$ & $1.86 \%$ & $-10.13 \%$ \\
\hline Baltimore & 5.30 & $1.86 \%$ & $10.84 \%$ & $8.98 \%$ & $22.31 \%$ & $22.49 \%$ & $6.28 \%$ \\
\hline Lancaster & 6.37 & $3.00 \%$ & $-0.23 \%$ & $7.59 \%$ & $-17.44 \%$ & $-11.98 \%$ & $-2.23 \%$ \\
\hline Des Moines & 6.30 & $3.33 \%$ & $7.87 \%$ & $4.49 \%$ & $5.28 \%$ & $4.09 \%$ & $0.99 \%$ \\
\hline Kentucky & 5.80 & $3.07 \%$ & $8.82 \%$ & $13.38 \%$ & $12.02 \%$ & $12.40 \%$ & $-2.59 \%$ \\
\hline Hawaii & 6.86 & $2.47 \%$ & $-9.79 \%$ & $-1.44 \%$ & $-6.45 \%$ & $-3.25 \%$ & $-12.30 \%$ \\
\hline Oahu & 6.25 & $2.89 \%$ & $4.34 \%$ & $14.77 \%$ & $4.65 \%$ & $8.15 \%$ & $-11.46 \%$ \\
\hline Mean Absolute Deviation & & & $7.0 \%$ & $10.46 \%$ & $10.04 \%$ & $10.18 \%$ & $5.82 \%$ \\
\hline Number of "Wins" & & & 2 & 2 & 0 & 1 & 4 \\
\hline
\end{tabular}

Percentage differences in bold indicate the method that gives estimates closest to the baseline.

Percentage differences in yellow highlight indicate the cluster-based approach that gives estimates closest to the baseline. 
Table 13. Significant Independent Variables for

Estimating Household PMT and VMT

\begin{tabular}{|c|c|c|c|c|c|}
\hline & \multicolumn{5}{|c|}{ Geo-Economic Cluster } \\
\hline & $\begin{array}{l}\text { Extreme } \\
\text { Poverty }\end{array}$ & $\begin{array}{l}\text { Mega- } \\
\text { Urban }\end{array}$ & Suburban & Urban & Rural \\
\hline \multicolumn{6}{|c|}{ Total Daily Person Miles of Travel per Household } \\
\hline Household Size & + & + & + & + & + \\
\hline No. of Vehicles in Household & + & + & + & + & + \\
\hline Life Cycle $\left(2^{+} \mathrm{A}, 1^{+} \mathrm{C}\right)^{*}$ & + & & & + & \\
\hline Life Cycle (1A,O C) & & & & & + \\
\hline Household Buying power & & & + & & \\
\hline $\begin{array}{l}\text { Census division (East North } \\
\text { Central) }\end{array}$ & + & & & & \\
\hline Home Ownership & & + & & & \\
\hline R-SQUARED & 0.2125 & 0.1593 & 0.0934 & 0.1201 & 0.1204 \\
\hline \multicolumn{6}{|c|}{ Total Daily Vehicle Miles of Travel per Household } \\
\hline Household Size & - & + & + & + & + \\
\hline No. of Vehicles in Household & + & + & + & + & + \\
\hline $\begin{array}{l}\text { ACCRA Cost of Transportation } \\
\text { Index }\end{array}$ & - & & & & \\
\hline No. of Workers & + & & & & \\
\hline Life Cycle $\left(2^{+} \mathrm{A} / 1^{+} \mathrm{C} ; 1 \mathrm{~A} / 1^{+} \mathrm{C}\right)^{*}$ & + & & & & \\
\hline Life Cycle ( $2^{+} \mathrm{A}$, Retired) & & - & & & \\
\hline Census Region (Midwest) & + & & & & \\
\hline Census Region (South) & & & & & + \\
\hline MSA size $(250-499,000)$ & + & & & & \\
\hline Household Buying Power & & & + & + & \\
\hline Home Ownership & & + & & & \\
\hline R-SQUARED & 0.2622 & 0.2051 & 0.1028 & 0.1185 & 0.0994 \\
\hline
\end{tabular}

* " $2^{+} \mathrm{A}, 1^{+} \mathrm{C}$ " denotes households with two or more adults and one or more children.

" $1 \mathrm{~A}, 1^{+} \mathrm{C}$ " denotes households with one adult and more than one child.

" $1 \mathrm{~A}, \mathrm{O} \mathrm{C}$ denotes households with one adult and no children. 


\subsection{Assessment of PMT and VMT Estimates}

Assessment results were excellent for PMT. The regression method produces PMT estimates that are closest to the baseline standards in 5 out of 9 add-ons, with a mean absolute deviation of $9.72 \%$. This deviation is only half the deviation of the next best competitor - the Census Region-based approach which had a mean absolute deviation of $19.9 \%$ (Table 14 ). The mean absolute deviation is calculated by averaging the absolute values of the nine differences from the baseline standards, thereby measuring the overall deviation from the baseline of a specific approach across all nine-on areas. As mentioned in Section 3.5, using the mean absolute deviation from the baseline as an assessment criterion had the effect of making the results of a method in, say, the New York state add-on, equal to those in a smaller add-on, such as the Kentucky 4-county add-on. In the case of assessing the alternative methods for estimating PMT, the regression-based approach is superior to the competing methods not only in terms of the number of "wins" but also in terms of the mean absolute deviation.

Assessment results for the VMT estimates were reasonably good, though not to the degree of those for PMT. Regression-based estimates were closest to the baseline in 4 of 9 add-on areas, closely followed by the estimates generated by the Census Regionbased approach. However, with the mean absolute deviation as the criterion, the regression-based method clearly outperformed the Census Region-based method, with a mean absolute deviation of $9.75 \%$ versus $21.16 \%$, respectively. 
Table 14. Comparison of Alternative PMT and VMT Estimates to Baseline Standards Data from Nine 2001 NHTS Add-on Areas

\begin{tabular}{|c|c|c|c|c|c|c|c|}
\hline \multicolumn{8}{|c|}{ Person Miles of Travel per Household (PMT) } \\
\hline \multirow[b]{2}{*}{ Add-on Areas } & \multirow[b]{2}{*}{ Baseline } & \multirow[b]{2}{*}{ Std Err \% } & \multicolumn{5}{|c|}{ \% Difference from the Baseline } \\
\hline & & & $\begin{array}{l}\text { C. Div \& MSA } \\
\text { Size-based }\end{array}$ & $\begin{array}{l}\text { MSA Size- } \\
\text { based }\end{array}$ & $\begin{array}{c}\text { Census Division- } \\
\text { based }\end{array}$ & $\begin{array}{c}\text { Census } \\
\text { Region-based } \\
\end{array}$ & $\begin{array}{c}\text { Regression- } \\
\text { based }\end{array}$ \\
\hline New York & 67.96 & $2.41 \%$ & $6.36 \%$ & $31.40 \%$ & $8.14 \%$ & $12.71 \%$ & $-3.38 \%$ \\
\hline Wisconsin & 87.99 & $2.52 \%$ & $6.82 \%$ & $9.95 \%$ & $3.23 \%$ & $5.80 \%$ & $-6.99 \%$ \\
\hline Texas & 100.12 & $3.89 \%$ & $4.99 \%$ & $-5.05 \%$ & $6.63 \%$ & $6.55 \%$ & $-17.30 \%$ \\
\hline Baltimore & 75.71 & $2.70 \%$ & $14.82 \%$ & $8.02 \%$ & $30.01 \%$ & $32.59 \%$ & $-3.61 \%$ \\
\hline Lancaster & 79.93 & $5.35 \%$ & $8.93 \%$ & $20.86 \%$ & $-4.48 \%$ & $-1.77 \%$ & $5.71 \%$ \\
\hline Des Moines & 71.69 & $9.94 \%$ & $25.82 \%$ & $29.98 \%$ & $38.05 \%$ & $29.25 \%$ & $11.86 \%$ \\
\hline Kentucky & 99.46 & $5.79 \%$ & $7.93 \%$ & $4.13 \%$ & $7.68 \%$ & $0.16 \%$ & $-4.50 \%$ \\
\hline Hawaii & 68.04 & $7.36 \%$ & $66.85 \%$ & $79.17 \%$ & $39.68 \%$ & $43.77 \%$ & $33.31 \%$ \\
\hline Oahu & 68.44 & $7.20 \%$ & $68.03 \%$ & $46.00 \%$ & $42.29 \%$ & $46.52 \%$ & $-0.78 \%$ \\
\hline Mean Absolute Deviation & & & $23.39 \%$ & $26.06 \%$ & $20.02 \%$ & $19.90 \%$ & $9.72 \%$ \\
\hline Number of "Wins" & & & 1 & 0 & 1 & 2 & 5 \\
\hline \multicolumn{8}{|c|}{ Vehicle Miles of Travel per Household (VMT) } \\
\hline New York & 38.78 & $2.54 \%$ & $15.00 \%$ & $51.48 \%$ & $17.17 \%$ & $26.03 \%$ & $0.42 \%$ \\
\hline Wisconsin & 60.85 & $2.76 \%$ & $4.74 \%$ & $5.02 \%$ & $1.10 \%$ & $1.64 \%$ & $-12.76 \%$ \\
\hline Texas & 68.12 & $4.44 \%$ & $4.78 \%$ & $-9.43 \%$ & $6.62 \%$ & $4.34 \%$ & $-20.90 \%$ \\
\hline Baltimore & 52.88 & $2.93 \%$ & $3.54 \%$ & $1.08 \%$ & $23.61 \%$ & $27.30 \%$ & $-9.41 \%$ \\
\hline Lancaster & 52.05 & $4.43 \%$ & $8.44 \%$ & $19.09 \%$ & $-10.84 \%$ & $-4.61 \%$ & $5.31 \%$ \\
\hline Des Moines & 48.28 & $8.98 \%$ & $19.12 \%$ & $24.93 \%$ & $30.64 \%$ & $27.62 \%$ & $12.21 \%$ \\
\hline Kentucky & 66.93 & $6.22 \%$ & $9.25 \%$ & $1.06 \%$ & $7.56 \%$ & $\mathbf{0 . 8 0 \%}$ & $-4.85 \%$ \\
\hline Hawaii & 44.49 & $4.14 \%$ & $32.67 \%$ & $74.43 \%$ & $36.27 \%$ & $41.76 \%$ & $20.79 \%$ \\
\hline Oahu & 41.10 & $3.40 \%$ & $57.62 \%$ & $66.55 \%$ & $50.26 \%$ & $56.33 \%$ & $-1.09 \%$ \\
\hline Mean Absolute Deviation & & & $17.24 \%$ & $28.12 \%$ & $20.45 \%$ & $21.16 \%$ & $9.75 \%$ \\
\hline Number of "Wins" & & & 0 & 1 & 1 & 3 & 4 \\
\hline
\end{tabular}

Percentage differences in bold indicate the method that gives estimates closest to the baseline.

Percentage differences in yellow highlight indicate the cluster-based approach that gives estimates closest to the baseline. 


\section{ESTIMATION OF TRIPS BY TRIP PURPOSE}

\subsection{Logistic Regression}

One of the goals of this project was to estimate the percentage of person trips by trip purpose, household size, and vehicle count for each of the eligible Census tracts (Table 15). Five trip purpose categories were used: "Home-Based Work," "Home-Based Shopping," "Home-Based Social and Recreational," "Other Home-Based," and "Non Home-Based." Separate estimation models were developed for each of the five geoeconomic clusters.

Table 15. Parameter Specification of Trips by Trip Purpose

\begin{tabular}{|c|c|c|c|c|c|c|c|c|c|}
\hline \multirow{5}{*}{$\begin{array}{l}\text { Vehicle } \\
\text { Count }\end{array}$} & \multicolumn{9}{|c|}{ Household Size } \\
\hline & \multicolumn{5}{|c|}{1} & 2 & 3 & 4 & 5 or more \\
\hline & \multicolumn{5}{|c|}{ Trip Purpose } & & & & \\
\hline & $\mathrm{HB}^{*}$ & HB & HB & Other & Non & & & & \\
\hline & Work & Shopping & $\begin{array}{c}\text { Socio/ } \\
\text { Rec }\end{array}$ & HB & $\mathrm{HB}$ & $\ldots$ & $\ldots$ & .. & $\ldots$ \\
\hline \multicolumn{10}{|l|}{0} \\
\hline \multicolumn{10}{|l|}{1} \\
\hline \multicolumn{10}{|l|}{2} \\
\hline \multicolumn{10}{|l|}{3} \\
\hline 4 & & & & & & & & & \\
\hline
\end{tabular}

Various methods were investigated, including least-squares regression and several types of logistic regression. The least-squares models used the total number of trips, by each trip purpose, as dependent variables. The independent variables were similar to those for estimating total person trips. In addition, three types of logistic regressions were attempted - a proportional odds model, a partial proportional odds model, and a generalized logit.

Logistic regression is most commonly used in the modeling of a binary response, such as a success or failure, as shown below: 


$$
\log \left(\frac{\pi(x)}{1-\pi(x)}\right)=\mathrm{B}_{0}+\mathrm{B}_{1} x_{1}+\mathrm{B}_{2} x_{2}+\ldots+\mathrm{B}_{k} x_{k}+\varepsilon
$$

where $\pi(x)$ is the probability of "success," and the right-hand side represents variables with their coefficients, and the model error term, as in least squares regression ${ }^{19}$. The purpose of logistic regression is commonly used to predict success or failure; the predicted values produced by the model give the probability of success. In this project, logistic regression model was developed to predict the probability of taking a trip for purpose $i$, where $i$ is one of the five trip purpose categories. For modeling trip purpose, a more complicated form of logistic regression was used for the five categories of trip purpose.

One type of logistic regression is the "Proportional Odds" approach. It uses a cumulative logit (the logarithm of odds ratios) function to determine the percentage of trips that have a particular trip purpose ${ }^{20}$. For the five categories of trip purpose, four cumulative logit functions were developed, with identical parameter estimates for each logit. Thus, in modeling trip purpose, the first model would estimate the probability of taking a "Home-Based Work" trip versus the probability of taking a "Home-Based Shopping” trip, "Home-Based Social/Recreational," "Other Home-Based," or "Non Home-Based" trip. The second model would estimate the probability of taking either a "Home-Based Work" or "Home-Based Shopping" trip versus the probability of taking a "Home-Based Social/Recreational," "Other Home-Based," or "Non Home-Based" trip (hence the name "cumulative logit"); and so on for the third and fourth models. Then, using the estimates of the models in conjunction with one another, one can compute the probability of taking a trip of a given purpose. The major assumption of the proportional odds model is that the coefficients are equal for each cumulative logit model. If they are not equal, then a model with different parameter estimates would usually be more

\footnotetext{
${ }^{19}$ Agresti, Alan. “An Introduction to Categorical Data Analysis.” John Wiley \& Sons, Inc. New York, NY. 1996. pp 103.

${ }^{20}$ Agresti, 1996. pp 211-214.
} 
statistically appropriate. Should different parameter estimates be necessary, the model becomes a partial proportional odds model - the second type of logistic regression.

Test results of the proportional odds model reject the assumption of equal coefficients for each level of trip purpose, indicating that the partial proportional odds model was more statistically appropriate. Since the ultimate goal of this study is to identify an estimation method that is superior to other competing methods, emphasis was placed on how well the partial proportional odds model performed with respect to the two competing criteria: the number of "wins" and the mean absolute deviation.

The generalized logit model is typically used with nominal responses, such as trip purpose. The generalized logit uses a "baseline-category" to which one can compare the other categories. The model can be written as

$$
\log \left(\frac{\pi_{j}}{\pi_{J}}\right)=\mathrm{B}_{0}+\mathrm{B}_{1} x_{1}+\mathrm{B}_{2} x_{2}+\ldots+\mathrm{B}_{k} x_{k}+\varepsilon
$$

where $j=1$ to $J-1$ and the right-hand side consists of the traditional coefficients, variables, and error term ${ }^{21}$. In the case of the trip purpose model, $\mathrm{J}$ is 5 . Predicted values are computed for the first $\mathrm{J}-1$ values (i.e., the first four trip purposes) by taking $e$ to the power of the predicted logit function listed above and by dividing by the sum of the predicted value of 1 plus the sum of $e$ to the power of each of the J-1 logit functions. The predicted value for the "baseline-category" is computed using 1 as the numerator with the same denominator as in the 1 to $\mathrm{J}-1$ cases.

Significant independent variables are listed in Table 16. Similar to the leastsquares regression in preceding sections, no inferences should be made to the relationships between significant variables in the model and the propensity of taking a

${ }^{21}$ Agresti, 1996. pp 206-208. 
trip with purpose $i$. Variables in the regressions are restricted to household demographic variables that are available at the Census tract level. For trip purpose, the baseline standard was the percentage of trips by purpose, weighted by the Census-based household distribution by household size and vehicle count.

Table 16. Significant Independent Variables for Estimating Person Trip Distribution by Trip Purpose

\begin{tabular}{|l|c|c|c|c|c|}
\hline \multirow{2}{*}{} & \multicolumn{5}{|c|}{ Geo-Economic Cluster } \\
\cline { 2 - 6 } & $\begin{array}{c}\text { Extreme } \\
\text { Poverty }\end{array}$ & $\begin{array}{c}\text { Mega- } \\
\text { Urban }\end{array}$ & Suburban & Urban & Rural \\
\hline Household Size & + & - & - & - & - \\
\hline No. of Vehicles in Household & - & - & - & + & - \\
\hline MSA size & $\mathrm{x}$ & $\mathrm{x}$ & $\mathrm{X}$ & $\mathrm{x}$ & $\mathrm{X}$ \\
\hline Census Division & $\mathrm{x}$ & $\mathrm{x}$ & $\mathrm{x}$ & $\mathrm{x}$ & $\mathrm{x}$ \\
\hline Life Cycle & - & $\mathrm{x}$ & $\mathrm{X}$ & $\mathrm{x}$ & $\mathrm{x}$ \\
\hline $\begin{array}{l}\text { No. of Workers Who Use Transit to } \\
\text { Work }\end{array}$ & - & & & \\
\hline \% Workers Who Use Transit to Work & & & & & - \\
\hline Urban-Rural & - & & + & + & + \\
\hline No. of Workers & & - & & & - \\
\hline Household Income & & & - & - & \\
\hline Household Buying Power & & + & + & + & \\
\hline No. of Adults & & - & - & & - \\
\hline Home Ownership & & - & & + & + \\
\hline Population Density of the Tract & & & + & & \\
\hline ACCRA Cost of Transportation Index & & & & & - \\
\hline ACCRA Cost of Living Index & & & + & + & + \\
\hline
\end{tabular}

x indicates both "+" and "-“ in various levels of the variable.

\subsection{Assessment of Trip Estimates by Trip Purpose}

The comparison among the competing methods in estimating trip distribution by trip purpose is summarized in Table 17. The logistic regression approach reported in the table is based on the proportional odds model. Assessment results for the partial proportional odds model and for the general logit model are omitted from the table because of their significantly inferior performance. The assessment results suggest that the logistic regression model produces estimates of trip distribution by trip purpose that 
Transferring 2001 National Household Travel Survey

are closest to the baseline in 8 of 9 add-on areas. The "mean absolute deviation" criterion also suggests that the logistic regression model performs significantly better than the competing models.

Table 17. Comparison of Methods to Estimate Trips by Trip Purpose

\begin{tabular}{|l|c|c|c|c|c|c|}
\hline \multirow{2}{*}{ Add-on Areas } & \multicolumn{7}{|c|}{ \% Difference from the Baseline } \\
\cline { 2 - 7 } & $\begin{array}{c}\text { C. Div \& } \\
\text { MSA Size- } \\
\text { based }\end{array}$ & $\begin{array}{c}\text { MSA Size- } \\
\text { based }\end{array}$ & $\begin{array}{c}\text { Census } \\
\text { Division- } \\
\text { based }\end{array}$ & $\begin{array}{c}\text { Census } \\
\text { Region- } \\
\text { based }\end{array}$ & $\begin{array}{c}\text { Logistic } \\
\text { Regression }\end{array}$ & $\begin{array}{c}\text { Least-Squares } \\
\text { Regression }\end{array}$ \\
\hline New York & $1.73 \%$ & $\mathbf{1 . 5 2 \%}$ & $1.72 \%$ & $1.65 \%$ & $1.81 \%$ & $1.93 \%$ \\
\hline Wisconsin & $2.48 \%$ & $2.61 \%$ & $2.41 \%$ & $2.65 \%$ & $\mathbf{0 . 7 6 \%}$ & $2.05 \%$ \\
\hline Texas & $1.28 \%$ & $1.65 \%$ & $1.42 \%$ & $1.57 \%$ & $\mathbf{0 . 5 9 \%}$ & $1.36 \%$ \\
\hline Baltimore & $2.51 \%$ & $2.50 \%$ & $3.02 \%$ & $2.96 \%$ & $\mathbf{0 . 7 8 \%}$ & $2.42 \%$ \\
\hline Lancaster & $2.55 \%$ & $3.14 \%$ & $2.66 \%$ & $2.58 \%$ & $\mathbf{1 . 5 3 \%}$ & $2.80 \%$ \\
\hline Des Moines & $2.86 \%$ & $2.61 \%$ & $3.14 \%$ & $2.58 \%$ & $\mathbf{1 . 1 8 \%}$ & $1.66 \%$ \\
\hline Kentucky & $1.40 \%$ & $1.91 \%$ & $1.72 \%$ & $1.56 \%$ & $\mathbf{0 . 8 5 \%}$ & $1.81 \%$ \\
\hline Hawaii & $1.99 \%$ & $1.82 \%$ & $1.02 \%$ & $1.05 \%$ & $\mathbf{0 . 6 4 \%}$ & $1.44 \%$ \\
\hline Oahu & $3.02 \%$ & $2.58 \%$ & $2.32 \%$ & $2.34 \%$ & $\mathbf{0 . 8 5 \%}$ & $2.29 \%$ \\
\hline $\begin{array}{l}\text { Mean Absolute } \\
\text { Deviation }\end{array}$ & $2.20 \%$ & $2.26 \%$ & $2.16 \%$ & $\mathbf{2 . 1 0 \%}$ & $\mathbf{1 . 0 0 \%}$ & $1.97 \%$ \\
\hline No. of Wins & $0 / 3 *$ & 1 & $0 / 1 *$ & 0 & 8 & 4 \\
\hline
\end{tabular}

\section{CONVERTING TRAVEL ESTIMATES TO TAZ LEVEL}

Many planners express the need to estimate travel rates at the TAZ (Transportation Analysis Zone) level. Unfortunately, there are no direct "cross-walks" between TAZs and Census tracts. As such, one can not explicitly link Census tracts to TAZs. However, since a TAZ consists of blocks and since blocks and Census tracts can be linked, one can presumably link Census tracts and TAZs through blocks.

Travel estimates at the Census tract level were first disaggregated to the block centroid level. The estimates at the block centroid level were then aggregated to the TAZ level. For example, TAZ 01001000299 in Autauga County, Alabama consists of: 3 of the 3 blocks in Census tract 02066 and 3 of the 5 blocks in Census tract 020800 (Table 18). 
Since travel characteristics (i.e., $P T, V T, P M T$, and VMT) are estimated at the Census tract level, travel characteristics for each block within a Census tract are identical. The average number of person trips per household at TAZ 01001000299 is estimated at 10.55 which is derived by taking a weighted average of $P T$ using the number of households in each of the blocks within the TAZ.

Table 18. An Example of Estimating Person Trips at TAZ Level TAZ01001000299

\begin{tabular}{|l|c|c|c|c|c|}
\hline Census tract \# & $\begin{array}{c}\text { Block } \\
\#\end{array}$ & $\begin{array}{c}\text { Part of TAZ } \\
01001000299 ?\end{array}$ & $\begin{array}{c}\text { Estimated Average } \\
P T \text { per Household } \\
(1)\end{array}$ & $\begin{array}{c}\text { No. of } \\
\text { Households } \\
(2)\end{array}$ & Total PT= \\
$(1) \mathrm{x}(2)$
\end{tabular}

Two sets of travel estimates were produced - one at the Census tract level and one at the TAZ level. However, travel estimates at TAZ level can not be categorized by household size and number of vehicles because these data are not publicly available at the block level. To facilitate access to these estimates, a GIS-based web tool was developed (refer to the Tutorial in Appendix 5).

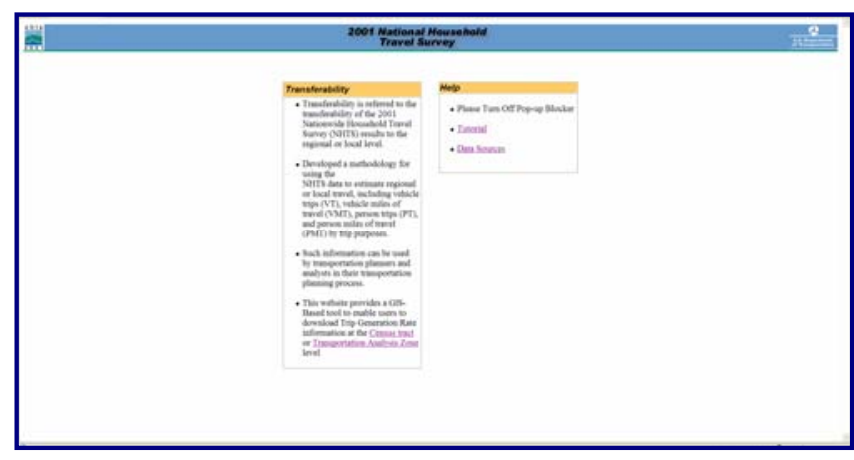




\section{SUMMARY}

The 2001 NHTS sampling scheme defined strata categorized by Census division (e.g., New England, Middle Atlantic, and Pacific), MSA size, and the availability of rail. It is not recommended that the NHTS data be used to estimate travel characteristics for areas smaller than that stratification. The question is whether a method can be developed that integrates the NHTS data and other data to estimate key travel characteristics for small geographic areas such as Census tract and transportation analysis zone, and whether this method can outperform other, competing methods. A set of commonly use methods is outlined in Section 1.

Assessment results based on two different criteria -- the number of "wins" and the mean absolute deviation - suggest that the NHTS data in conjunction with other data sources can be used to estimate key travel parameters for areas smaller than what the NHTS sampling scheme can support. The methods used to transfer NHTS data to smaller areas outperform other, competing methods (Table 19). That said, methods developed in this project have not been assessed against how closely its estimates can reproduce travel estimates based on local household surveys. Instead, they are assessed against other, competing methods in terms of how closely their estimates reproduce the NHTS-based baseline. As such, they should not replace local household surveys which would most likely yield estimates that are more accurate than those based on, or transferred from, other surveys. 
Table 19. Summary of Assessment Results

Based on 2001 NHTS Add-on Area Data

\begin{tabular}{|c|c|c|c|c|c|c|c|}
\hline \multirow[b]{2}{*}{$\begin{array}{l}\text { Daily Travel Estimates per } \\
\text { Household }\end{array}$} & \multirow[b]{2}{*}{ Competing Criteria } & \multicolumn{6}{|c|}{ \% Difference from the Baseline } \\
\hline & & $\begin{array}{l}\text { C.Div \& MSA } \\
\text { Size-based }\end{array}$ & $\begin{array}{l}\text { MSA Size- } \\
\text { based }\end{array}$ & $\begin{array}{c}\text { CENSUS } \\
\text { Division- } \\
\text { based } \\
\end{array}$ & $\begin{array}{c}\text { CENSUS } \\
\text { Region- } \\
\text { based } \\
\end{array}$ & $\begin{array}{c}\text { Regression with } \\
\text { Geo-Economic } \\
\text { cluster } \\
\end{array}$ & $\begin{array}{l}\text { Logistic } \\
\text { Regression }\end{array}$ \\
\hline \multirow{2}{*}{ No. of Person Trips (PT) } & Mean Absolute Deviation & $7.85 \%$ & $10.5 \%$ & $9.04 \%$ & $9.93 \%$ & $3.90 \%$ & - \\
\hline & Number of "Wins" & 2 & 0 & 1 & 0 & 6 & - \\
\hline \multirow{2}{*}{ No. of Vehicle Trips (VT) } & Mean Absolute Deviation & $7.0 \%$ & $10.46 \%$ & $10.04 \%$ & $10.18 \%$ & $5.82 \%$ & - \\
\hline & Number of "Wins” & 2 & $2 / 1^{*}$ & 0 & $1 / 2 *$ & 4 & - \\
\hline \multirow{2}{*}{ Person Miles of Travel (PMT) } & Mean Absolute Deviation & $24.46 \%$ & $23.35 \%$ & $21.81 \%$ & $20.89 \%$ & $7.41 \%$ & - \\
\hline & Number of "Wins” & 1 & 1 & 0 & 1 & 6 & - \\
\hline \multirow{2}{*}{ Vehicle Miles of Travel (VMT) } & Mean Absolute Deviation & $17.24 \%$ & $28.12 \%$ & $20.45 \%$ & $21.16 \%$ & $9.75 \%$ & - \\
\hline & Number of “Wins” & 0 & 1 & 1 & 3 & 4 & - \\
\hline \multirow{2}{*}{ No. of Person Trips by Purpose } & Mean Absolute Deviation & $2.20 \%$ & $2.26 \%$ & $2.16 \%$ & $2.10 \%$ & $1.97 \%$ & $1.00 \%$ \\
\hline & Number of "Wins" & $0 / 3^{*}$ & 1 & $0 / 1^{*}$ & 0 & 4 & 8 \\
\hline
\end{tabular}


Transferring 2001 National Household Travel Survey

\section{APPENDIX 1}

A1 - 1 
Transferring 2001 National Household Travel Survey

\section{APPENDIX 1: TRAVEL CONCEPTS AND GLOSSARY}

PERSON TRIP DEFINITION -A trip by one person in any mode of transportation. This is the most basic and universal measure of personal travel. Each record in the Travel Day and Travel Period files in the NHTS dataset represents one person trip.

EXAMPLES - Two household members traveling together in one car are counted as two person trips. Three household members walking to the store together are counted as three person trips.

PERSON

MILES OF

TRAVEL (PMT)
DEFINITION - The number of miles traveled by each person on a trip.

EXAMPLES - If two people traveling together take a six-mile subway trip to the airport, that trip results in 12 person miles of travel. A four-mile van trip with a driver and three passengers counts as 16 person miles of travel (4 people times 4 miles).

DEFINITION - A trip by a single privately operated vehicle (POV) regardless of the number of persons in the vehicle.

EXAMPLES - Two people traveling together in a car would be counted as one vehicle trip. Four people going to a restaurant in a van is considered one vehicle trip.

NPTS MODE RESTRICTIONS - To be considered a vehicle trip in NHTS, the trip must have been made in a POV, namely a household-based car, van, sport utility vehicle, pickup truck, other truck, recreational vehicle, motorcycle or other POV. The vehicle does not need to belong to the household.

Trips made in other highway vehicles, such as buses, streetcars, taxis, and school buses are collected in the NHTS, but these are shown as person trips by those modes. The design of the NHTS is such that it does not serve as a source for vehicle trips in modes such as buses, because there is no way to trace the movement of the bus fleet throughout the day. Those interested in vehicle trips by buses, taxis, etc. need to use a data source that relies on reports from the fleet operators of those vehicles. The National Transit Database of the Federal Transit Administration is one such source. 
Transferring 2001 National Household Travel Survey

VEHICLE MILES OF TRAVEL (VMT)

\section{VEHICLE OCCUPANCY}

DEFINITION - One vehicle mile of travel is the movement of one privately operated vehicle (POV) for one mile, regardless of the number of people in the vehicle.

EXAMPLES - When one person drives her car 12 miles to work, 12 vehicle miles of travel have been made. If two people travel three miles by pickup, three vehicle miles of travel have been made.

SAME MODE RESTRICTIONS - For NHTS data, vehicle miles are restricted to the same privately-operated vehicles as vehicle trips(see above), that is a household-based car, van, sport utility vehicle, pickup truck, other truck, recreational vehicle, or other POV.

DEFINITION - For NHTS data, vehicle occupancy is generally computed as person miles of travel per vehicle mile (referred to as the travel method). Note that the other commonly-used definition of vehicle occupancy is persons per vehicle trip (referred to as the trip method) .

COMMENTS - Because longer trips often have higher occupancies, the travel method generally yields a higher rate than the trip method. The calculation of the travel method requires that trip miles be reported, thus it is calculated on a slightly smaller number of trips than the trip method.

\section{GLOSSARY}

This glossary provides the most common terms used in the NHTS and definitions of those terms. These definitions are provided to assist the user in the interpretation of the NHTS data.

Adult For NHTS, this is defined as a person 18 years or older.
Baseline Standard
Block Group
In this report, a baseline standard is a travel statistic computed using half of the households in an NHTS sample add-on. The other half of the add-on data is re-weighted and included in estimates using other computational methods (National, MSA Size, Clustering, Regression-based, etc.). A subdivision of a Census tract that averages 1000 to 1100 people, and approximately 400-500 housing units. The source used for the 2001 NHTS was GDT Dynamap 2000 (from Census 2000 TIGER/Line files).


Buying Power

Census Region and Division
The value of money, as measured by the quantity and quality of products and services it can buy ${ }^{22}$. This value accounts for regional and metropolitan differences in the cost of goods and services, and not taking into account taxes.

The Census Bureau divides the states into four regions and nine divisions. Note that the divisions are wholly contained within a region, i.e., region lines do not split division lines. The regions and their component divisions are:

Northeast Region:

New England Division: Connecticut, Maine, Massachusetts, New Hampshire, Rhode Island, Vermont

1. Middle Atlantic Division: New Jersey, New York, Pennsylvania North Central Region:

East North Central Division: Illinois, Indiana, Michigan, Ohio, Wisconsin

West North Central Division: Iowa, Kansas, Minnesota, Missouri, Nebraska, North Dakota, South Dakota

South Region

South Atlantic Division: Delaware, Florida, Georgia, Maryland, North Carolina, South Carolina, Virginia, West Virginia

1) East South Central Division: Alabama, Kentucky, Mississippi, Tennessee

2) West South Central Division: Arkansas, Louisiana, Oklahoma, Texas

West Region

1. Mountain Division: Arizona, Colorado, Idaho, Montana, Nevada, New Mexico, Utah, Wyoming

2. Pacific Division: Alaska, California, Hawaii, Oregon, Washington

Puerto Rico

For the 2001 NHTS the source used for the 2000 Census Region was: http://www.census.gov/geo/www/cob/rg2000.html The source used for the 2000 Census Division was: http://www.census.gov/geo/www/cob/dv2000.html

${ }^{22}$ http://www.investorwords.com/647/buying_power.html 
Transferring 2001 National Household Travel Survey

Census Tract

Child

\section{Consolidated Metropolitan Statistical Area (CMSA)}

Destination

Driver

Education Level

\section{Employed}

Extreme Poverty Area

Household
A small subdivision of a county, containing approximately 4,000 persons. Tracts can range in population from 2,500 to 8,000. The geographic size of the tract may vary considerably, depending on population density. Tracts were designed to be homogeneous in regard to population characteristics, economic status and living conditions when they were first delineated. Since the first tracts were delineated for the 1890 Census, today's tracts may be far from homogeneous. The source used for the 2001 NHTS was GDT Dynamap 2000 (from Census 2000 TIGER/Line files).

A child is normally defined as a person under the age of 18 . An exception to this is for life cycle, where a child can be anyone through the age of 21 who is listed as a child to the household respondent.

A large metropolitan complex of 1 million or more population, containing two or more identifiable component parts designated as Primary Metropolitan Statistical Areas (PMSAs). For example, the Boston CMSA is composed of six PMSAs.

For travel day trips, the destination is the point at which there is a break in travel, except if the break is only to change vehicles or means of transport. For travel period trips, the destination is the farthest point of travel.

A driver is a person who operates a motorized vehicle. If more than one person drives on a single trip, the person who drives the most miles is classified as the principal driver.

The number of years of regular schooling completed in graded public, private, or parochial schools, or in colleges, universities, or professional schools, whether day school or night school. Regular schooling advances a person toward an elementary or high school diploma, or a college, university, or professional school degree.

A person is considered employed if (s)he worked for pay, either full time or part time, during the week before the interview.

A poverty area in which 40 percent or more of the population was poor.

A group of persons whose usual place of residence is a specific housing unit; these persons may or may not be related to each other. The total of all U.S. households represents the total civilian non-institutionalized population. A household does not include group quarters (i.e., 10 or more persons living together, none of whom are related). 
Transferring 2001 National Household Travel Survey

\section{Household Income}

\section{Household Members}

\section{Household Vehicle}

Journey-to-Work Trips (Commute trips)

\author{
Means of \\ Transportation
}

Household income is the money earned by all family members in a household, including those temporarily absent. Annual income consisted of the income earned 12 months preceding the interview. Household income includes monies from all sources, such as wages and salary, commissions, tips, cash bonuses, income from a business or farm, pensions, dividends, interest, unemployment or workmen's compensation, social security, veterans' payments, rent received from owned property (minus the operating costs), public assistance payments, regular gifts of money from friends or relatives not living in the household, alimony, child support, and other kinds of periodic money income other than earnings. Household income excludes in-kind income such as room and board, insurance payments, lump-sum inheritances, occasional gifts of money from persons not living in the same household, withdrawal of savings from banks, tax refunds, and the proceeds of the sale of one's house, car, or other personal property.

Household members include all people, whether present or temporarily absent, whose usual place of residence is in the sample unit. Household members also include people staying in the sample unit who have no other usual place of residence elsewhere.

A household vehicle is a motorized vehicle that is owned, leased, rented or company-owned and available to be used regularly by household members. Household vehicles include vehicles used solely for business purposes or business-owned vehicles, so long as they are driven home and can be used for the home to work trip, (e.g., taxicabs, police cars, etc.). Household vehicles include all vehicles that were owned or available for use by members of the household during the travel period, even though a vehicle may have been sold before the interview. Vehicles excluded from household vehicles are those that were not working and were not expected to be working, and vehicles that were purchased or received after the designated travel day.

Includes travel to and from a place where one reports for work. Does not include any other work-related travel. Does not include any trips for persons who work at home.

A mode of travel used for going from one place (origin) to another (destination). A means of transportation includes private and public modes, as well as walking. 
The following transportation modes, grouped by major mode, are included in the NHTS data.

Private Vehicle

1. Car - A privately owned and/or operated licensed motorized vehicle including cars and station wagons. Leased and rented cars are included if they are privately operated and not used for picking up passengers in return for fare.

2. Van - privately owned and/or operated van or minivan designed to carry 5 to 13 passengers, or to haul cargo.

3. Sport Utility Vehicle - A privately owned and/or operated vehicle that is a hybrid of design elements from a van, a pickup truck and a station wagon. Examples include a Chevrolet Blazer, Ford Bronco, Jeep Cherokee, or Nissan Pathfinder.

4. Pickup Truck - A pickup truck is a motorized vehicle, privately owned and/or operated, with an enclosed cab that usually accommodates 2-3 passengers, and an open cargo area in the rear. Later model pickups often have a back seat that allows for total seating of 4 -6 passengers. Pickup trucks usually have the same size of wheel-base as a full-size station wagon. This category also includes pickups with campers.

5. Other Truck - This category consists of all trucks other than pickup trucks (i.e., dump trucks, trailer trucks, etc.).

6. RV or Motor Home - An RV or motor home includes a self-powered recreational vehicle that is operated as a unit without being towed by another vehicle (e.g., a Winnebago motor home).

7. Motorcycle - This category includes large, medium, and small motorcycles and mopeds.

8. Other POV - A vehicle that cannot be classified into one of the categories above.

Public Transportation

1. Bus - The bus category includes:

a. city to city buses (buses that run from one urban center to the other),

b. mass transit systems (buses that are available to the general public),

c. school buses, and

d. charter/tour buses (private bus operating on a fixed schedule between population centers). 
2. Train - This category includes:

a. Amtrak and intercity train (heavy passenger rail that runs form one urban center to another),

b. Subway and elevated rail (also know as rail rapid transit is a high capacity system operated on a fixed rail or guide way system on a private right of way), and

c. Trolley/streetcars (vehicles that run on a fixed rail system powered by electricity obtained from an overhead power distribution system), and commuter trains and passenger trains.

Other Modes

1. Airplane - Airplanes include commercial airplanes and smaller planes that are available for use by the general public in exchange for a fare. Private and corporate planes and helicopters are also included.

2. Ship - This includes travel by ships, cruise ships, passenger lines and ferries, sailboats, motorboats and yachts.

3. Taxi - Taxis include the use of a taxicab by a passenger for fare. The taxi category does not include rental cars if they are privately operated.

4. Limousine - Includes the use of a limousine by passenger for fare. The limousine category does not include rental cars if they are privately operated.

5. Hotel/Airport Shuttle - This includes privately operated shuttle buses that are operated between a limited number of points for a fare.

6. Bicycle - This category includes bicycles of all speeds and sizes that do not have a motor.

7. Walk. - This category includes walking and jogging.

8. Other - Includes any types of transportation not previously listed, e.g. skate boards.

Metropolitan Statistical Area (MSA)

\section{Motorized Vehicle}

Except in the New England States, a Metropolitan Statistical Area is a county or group of contiguous counties which contains at least one city of 50,000 inhabitants or more or "twin cities" with a combined population of at least 50,000 . In addition, contiguous counties are included in an MSA if, according to certain criteria, they are socially and economically integrated with the central city. In the New England States, MSAs consist of towns and cities instead of counties. The source used for the 2001 NHTS was 1999 Metropolitan Areas: Cartographic Boundary Files. File ma99_99.shp from http://www.census.gov/geo/www/cob/ma1999.html.

Motorized vehicles are all vehicles that are licensed for highway driving. 
Occupancy

\section{Origin \\ Overlap Trip}

Passenger

Person Miles of Travel (PMT)

\section{Person Trip}

POV

Poverty Area

Seasonal Variation

Transferability
Occupancy is the number of persons, including driver and passenger(s) in a vehicle. NHTS occupancy rates are generally calculated as person miles divided by vehicle miles.

Origin is the starting point of a trip.

A travel period trip that occurs on travel day, and is thus collected in both portions of the NHTS questionnaire. To ensure that this trip is not counted twice, eliminate overlap trips from travel day data when travel day and travel period data will be added together.

For a specific trip, a passenger is any occupant of a motorized vehicle, other than the driver.

PMT is a primary measure of person travel. When one person travels one mile, one person mile of travel results. Where 2 or more persons travel together in the same vehicle, each person makes the same number of person miles as the vehicle miles. Therefore, four persons traveling 5 miles in the same vehicle results in 20 person miles $(4 \times 5=20)$.

A person trip is a trip by one or more persons in any mode of transportation. Each person is considered as making one person trip. For example, four persons traveling together in one auto are counted as four person trips.

A privately-owned vehicle or privately-operated vehicle. Either way, the intent here is that this is not a vehicle available to the public for a fee, such as a bus, subway, taxi, etc.

Census tracts or block numbering areas (BNA's) where at least 20 percent of residents were poor ${ }^{23}$. Also see Extreme Poverty Area.

Season is defined as:

\section{Winter: December through February; Spring: March through May; Summer: June through August; \\ Fall: September through November.}

In this report, transferability refers to the process of using statistical analysis on survey data sampled at one level (in the case of NHTS, the Census Division-MSA Size-Rail level) to estimate travel statistics at finer levels, such as state or local. To say that the data is "transferable" means that estimates resulting from the transferability process are statistically valid.

\footnotetext{
${ }^{23}$ http://www.census.gov/population/socdemo/statbriefs/povarea.html
} 
Travel Day

Travel Day Trip

Travel Day Trip Purpose
A travel day is a 24-hour period from 4:00 a.m. to 3:59 a.m. designated as the reference period for studying trips and travel by members of a sampled household.

A travel day trip is defined as any time the respondent went from one address to another by private motor vehicle, public transportation, bicycle, walking, or other means. However, a separate trip is not counted in two instances:

1. When the sole purpose for the trip is to get to another vehicle or mode of transportation in order to continue to the destination.

2. Travel within a shopping center, mall or shopping areas of 4-5 blocks is to be considered as travel to one destination.

A trip purpose is the main reason that motivates a trip. There are 36 travel day trip purposes used in the 2001 NHTS.

For the 2001 Survey, trip purposes were collected using a From-To approach. For each trip, the origin and destination are on the file in generic terms, e.g. from work to shopping. The 36 trip reasons are defined as follows, and shown with their coded trip purpose number.

1. To Home - Travel to home after leaving for some reason.

11. Go to Work - The first trip to the work location on travel day.

12. Return to Work - A trip to work that is not the first trip to work on the travel day.

13. Attend Business Meeting/Trip - A work related trip whose purpose is to attend a business meeting.

14. Other Work Related - A work related trip whose purpose is not specifically to attend a business meeting.

20. Other School/Religious Activity - School and religious activities not covered by categories 21 through 23 below.

21. Go to School as a Student - A trip whose purpose is to go to school as a student.

22. Go to Religious Activity - A trip whose purpose is to go to a place to attend a religious activity.

23. Go to Library, School Related - A trip whose purpose is to go to the library as part of a school related activity.

24. Go to Daycare - A trip whose purpose is to attend day care.

30. Medical/Dental Services - A trip made for medical, dental, or mental health treatment, or other related professional services. 
40. Shopping/Errands - Shopping/errand trips not covered by categories 41 through 43 below.

41. Buy Goods, (e.g., groceries/clothing/hardware store) - A shopping trip whose purpose is to purchase commodities for use or consumption elsewhere. This purpose also includes window-shopping and trip made to shop even if nothing is purchased.

42. Buy Services, (e.g., video rentals/dry cleaning/post office/car service/bank) - The category includes the purchase of services other than medical/dental or other professional services.

43. Buy Gas - A trip made specifically to get gas.

50. Social/Recreational - Includes social and recreational trips not covered by categories 51 through 55 below.

51. Go to the Gym/Exercise/Play Sports - A trip made for exercise or to participate in a sport.

52. Rest or Relaxation/Vacation.

53. Visit Friends/Relatives - The social/recreational trip whose purpose is to visit with family and friends.

54. Go out/Hang out, Entertainment/Theater/Sports Event/Go to Bar - The purpose of the trip is entertainment or hanging out with friends.

55. Visit Public Place, Historical Site/Museum/Park/Library.

60. Family Personal Business/Obligations - A trip for personal business not covered by categories 61 through 65 below.

61. Use Professional Services, Attorney/Accountant - A trip made for professional services other than for medical/dental purposes.

62. Attend Funeral/Wedding - A personal trip to attend a funeral or a wedding.

63. Use Personal Services, Grooming/Haircut/Nails - A trip for personal services such as to a hairdresser.

64. Pet Care, Walk the dog/Vet visits.

65. Attend Meeting, PTA/Home Owners Association/Local Government The purpose of the trip is to attend a non-work related meeting, such as a community meeting.

70. Transport Someone - Trips with a passenger that are related to picking up or dropping off someone but not covered by categories 71 through 73 below.

71. Pickup Someone.

72. Take and Wait - A trip made to take someone to a destination and then wait with them at the destination and return together.

73. Drop Someone Off. 
80. Meals - A trip whose purpose is to eat or get a meal but not covered by categories 81 through 83 below.

81. Social Event - A trip whose purpose is to eat a meal at a social event.

82. Get/Eat Meal - A trip whose purpose is to get and eat a meal but not at a social event.

83. Coffee/Ice Cream/Snacks - A trip whose purpose is to get/eat a snack or drink, something less than a meal.

91. Other - A trip purpose not covered by categories above.

Travel Period A travel period consists of a four-week period ending with the travel day.

Travel Period A travel period trip is a trip where the farthest destination is at least 50 miles Trip from home. The outgoing portion of this trip can take place at any time, but the return must be within the four-week travel period. The four-week travel period ends on and includes the assigned travel day.

Travel Period Trip Purpose

Urban

Urbanized Area
A trip purpose is the main reason that motivates a trip. There were 18 travel period trip purposes in the 2001 NHTS. The main reason and all other reasons for the trip were collected.

A Census tract is classified as urban if more than $50 \%$ of households in a tract live in an Urbanized area. Also see Urbanized Area. [NOTE THIS MAY BE UNNECESSARY IF WE DON'T INCLUDE INITIAL ANALYSIS BEFORE BUYING CLARITAS DATA]

An urbanized area consists of the built up area surrounding a central core (or central city), with a population density of at least 1,000 persons per square mile. Urbanized areas do not follow jurisdictional boundaries thus it is common for the urbanized area boundary to divide a county.

For the 2001 NHTS, Urban Areas were calculated two ways.

1. Variable URBAN uses the 2000 Urbanized Areas: Cartographic Boundary Files. File ua00_d00.shp from http://www.census.gov/geo/www/cob/ua2000.html. Two codes are used: $0=$ Not in Urban Area, $1=$ in Urban Area.

2. Variable URBAN1 uses the 2000 Urbanized Areas: Cartographic Boundary Files. File ua00_d00.shp from http://www.census.gov/geo/www/cob/ua2000.html. Three codes are used: $0=$ Not in Urban Area, $1=$ in Urban Cluster, $2=$ in Urban Area, 3 $=$ in area surrounded by urban areas.

The 2001 NHTS, the term vehicle includes autos, passenger vans, sport utility 
vehicles, pickups and other light trucks, RV's, motorcycles and mopeds owned or available to the household.

Vehicle Miles of Travel (VMT)

Vehicle Occupancy

Vehicle Trip

Vehicle Type
VMT is a unit to measure vehicle travel made by a private vehicle, such as an automobile, van, pickup truck, or motorcycle. Each mile traveled is counted as one vehicle mile regardless of the number of persons in the vehicle.

Vehicle occupancy is the number of persons, including driver and passenger(s) in a vehicle; also includes persons who did not complete a whole trip. NHTS occupancy rates are generally calculated as person miles divided by vehicle miles.

A trip by a single privately-operated vehicle (POV) regardless of the number of persons in the vehicle.

For purposes of the 2001 NHTS, one of the following:

1. Automobile (including station wagon)

2. Van

3. Sport Utility Vehicle

4. Pickup Truck (including pickup with camper)

5. Other Truck

6. RV or Motor Home

7. Motorcycle

8. Other 
Transferring 2001 National Household Travel Survey

\section{APPENDIX 2}

A2 - 1 


\title{
APPENDIX 2: KEY CHANGES IN THE 2001 NHTS SURVEY METHODOLOGY AND CONTENT
}

\author{
(Source: Exhibit 3-1, 2001 NHTS User's Guide)
}

\begin{tabular}{|c|c|c|c|}
\hline TOPIC & FROM & TO & PROBABLE IMPACTS \\
\hline $\begin{array}{l}\text { What is } \\
\text { collected? }\end{array}$ & $\begin{array}{l}\text { Two separate } \\
\text { surveys - the NPTS } \\
\text { and the ATS }\end{array}$ & $\begin{array}{l}\text { Combined survey } \\
\text { that collects both } \\
\text { travel day and travel } \\
\text { period information }\end{array}$ & $\begin{array}{l}\text { Enables analysis of } \\
\text { relationship between daily } \\
\text { and long-distance travel } \\
\text { characteristics of each person }\end{array}$ \\
\hline $\begin{array}{l}\text { Which } \\
\text { household } \\
\text { members are } \\
\text { eligible? }\end{array}$ & $\begin{array}{l}\text { Household members } \\
\text { age } 5 \text { and older }\end{array}$ & $\begin{array}{l}\text { All household } \\
\text { members }\end{array}$ & More complete trip reporting \\
\hline $\begin{array}{l}\text { When proxy } \\
\text { needed? }\end{array}$ & $\begin{array}{l}\text { Proxy for household } \\
\text { members } 5 \text { to } 13 \\
\text { years }\end{array}$ & $\begin{array}{l}\text { Proxy for household } \\
\text { members under } 16 \\
\text { years }\end{array}$ & $\begin{array}{l}\text { - Increase in number of } \\
\text { interviews by proxy } \\
\text { - Obtain parental approval } \\
\text { when speaking with } 14 \text { and } \\
15 \text { year olds }\end{array}$ \\
\hline $\begin{array}{l}\text { Respondent } \\
\text { Contact }\end{array}$ & Advance letter & $\begin{array}{l}\text { Advance letter with a } \\
\$ 5 \text { cash incentive and } \\
\text { a brochure }\end{array}$ & $\begin{array}{l}\text { - Improved response } \\
\text { - Legitimizes the survey } \\
\text { with respondents }\end{array}$ \\
\hline $\begin{array}{l}\text { Use of a } \\
\text { diary for } \\
\text { long trips }\end{array}$ & $\begin{array}{l}\text { The ATS used a } \\
\text { diary to record long- } \\
\text { distance trips }\end{array}$ & $\begin{array}{l}\text { No travel period } \\
\text { diary included }\end{array}$ & $\begin{array}{l}\text { Lower respondent burden and } \\
\text { reduce the possibility of } \\
\text { confusion due to the mailing } \\
\text { of both a travel day and } \\
\text { travel period diary }\end{array}$ \\
\hline $\begin{array}{l}\text { Travel day } \\
\text { trip } \\
\text { definition }\end{array}$ & $\begin{array}{l}\text { Any stop from one } \\
\text { address to the next is } \\
\text { a separate trip }\end{array}$ & $\begin{array}{l}\text { Basically the same - } \\
\text { stops only to change } \\
\text { a mode of } \\
\text { transportation } \\
\text { excluded }\end{array}$ & $\begin{array}{l}\text { - May improve reporting of } \\
\text { trips by public } \\
\text { transportation as subjects } \\
\text { were specifically reminded } \\
\text { about these trips } \\
\text { - No change mode trips } \\
\text { were recorded except } \\
\text { where public } \\
\text { transportation was } \\
\text { involved }\end{array}$ \\
\hline
\end{tabular}


Transferring 2001 National Household Travel Survey

\begin{tabular}{|c|c|c|c|}
\hline TOPIC & FROM & TO & PROBABLE IMPACTS \\
\hline $\begin{array}{l}\text { Walk and } \\
\text { bike trips on } \\
\text { travel day }\end{array}$ & $\begin{array}{l}\text { No specific mention } \\
\text { of walk and bike } \\
\text { trips }\end{array}$ & $\begin{array}{l}\text { Specific reminder to } \\
\text { include walk, bike } \\
\text { rides and trips that } \\
\text { started and ended in } \\
\text { the same place }\end{array}$ & $\begin{array}{l}\text { Will increase the reporting of } \\
\text { walk and bike trips }\end{array}$ \\
\hline $\begin{array}{l}\text { Travel day } \\
\text { trip purpose }\end{array}$ & $\begin{array}{l}\text { There were } 17 \text { trip } \\
\text { purpose categories }\end{array}$ & $\begin{array}{l}\text { There are } 36 \text { trip } \\
\text { purpose categories }\end{array}$ & $\begin{array}{l}\text { The new categories more } \\
\text { accurately capture responses }\end{array}$ \\
\hline $\begin{array}{l}\text { Most recent } \\
\text { long distance } \\
\text { trip }\end{array}$ & Not collected & Collected & $\begin{array}{l}\text { Facilitate the imputation of } \\
\text { trips for persons with no } \\
\text { reported long distance trips in } \\
\text { travel period }\end{array}$ \\
\hline $\begin{array}{l}\text { Odometer } \\
\text { readings }\end{array}$ & $\begin{array}{l}\text { Readings collected } \\
\text { by contacting the } \\
\text { respondent by phone } \\
\text { or by mail }\end{array}$ & $\begin{array}{l}\text { Data collection } \\
\text { modes also included } \\
\text { the Internet, fax, and } \\
\text { a toll-free } 800 \\
\text { number }\end{array}$ & Improved response \\
\hline Geo-coding & $\begin{array}{l}\text { Limited use of } \\
\text { manual geo-coding }\end{array}$ & $\begin{array}{l}\text { Extensive use of } \\
\text { manual geo-coding }\end{array}$ & $\begin{array}{l}\text { Higher geo-coding success } \\
\text { rates and more accurate geo- } \\
\text { coding }\end{array}$ \\
\hline $\begin{array}{l}\text { Travel } \\
\text { period length } \\
\text { and travel } \\
\text { period trip } \\
\text { definition }\end{array}$ & $\begin{array}{l}\text { The NPTS included } \\
\text { trips of } 75 \text { miles or } \\
\text { more and used a 2- } \\
\text { week recall period. } \\
\text { The ATS included } \\
\text { trips of } 100 \text { miles or } \\
\text { more taken over a } \\
\text { full year (4 } \\
\text { interviews). }\end{array}$ & $\begin{array}{l}\text { The travel period was } \\
\text { a four-week period. } \\
\text { Trips of } 50 \text { miles or } \\
\text { more from home } \\
\text { were defined as long } \\
\text { distance. }\end{array}$ & $\begin{array}{l}\text { Four-week travel period and } \\
\text { shorter criterion distance } \\
\text { provides information on a } \\
\text { larger sample of long- } \\
\text { distance trips than NPTS and } \\
\text { better recall of trips than ATS } \\
\text { (if not recorded in ATS } \\
\text { diary), but a smaller sample } \\
\text { of trips and greater difficulty } \\
\text { estimating annual long- } \\
\text { distance trip rates than ATS. } \\
\text { The 4-week travel period } \\
\text { may have increased the } \\
\text { potential for telescoping (i.e., } \\
\text { bringing trips into the travel } \\
\text { period). }\end{array}$ \\
\hline $\begin{array}{l}\text { Splitting } \\
\text { walk and } \\
\text { bike trips at } \\
\text { the end of } \\
\text { travel day }\end{array}$ & Not conducted & Conducted & $\begin{array}{l}\text { Walk and bike trip rates may } \\
\text { be higher than on past NPTSs }\end{array}$ \\
\hline
\end{tabular}


Transferring 2001 National Household Travel Survey

\begin{tabular}{|l|l|l|l|}
\hline \multicolumn{1}{|c|}{ TOPIC } & \multicolumn{1}{|c|}{ FROM } & \multicolumn{1}{c|}{ TO } & \multicolumn{1}{c|}{ PROBABLE IMPACTS } \\
\hline $\begin{array}{l}\text { Adding trips } \\
\text { not reported } \\
\text { by household } \\
\text { members } \\
\text { interviewed } \\
\text { earlier }\end{array}$ & Not conducted & Conducted & More complete trip reporting \\
& totals & & \\
\hline Weighting & Raking to control $^{24}$ & $\begin{array}{l}\text { Several stages of } \\
\text { separate nonresponse } \\
\text { adjustment and } \\
\text { trimming as well as } \\
\text { raking. }\end{array}$ & $\begin{array}{l}\text { Presently unknown. } \\
\text { conducted. }\end{array}$ \\
& & $\begin{array}{l}\text { Changes to cells used } \\
\text { for raking. }\end{array}$ & \\
\hline
\end{tabular}

24 In raking, one adjusts estimates to agree to one set of controls (e. g., ethnicity), then adjusts estimates to a second set of controls (e. g., region), etc. This process is then repeated until all estimates are simultaneously close to the full set of controls. 
Transferring 2001 National Household Travel Survey

\section{APPENDIX 3}

A3 - 1 
Transferring 2001 National Household Travel Survey

\section{APPENDIX 3: ADJUSTMENT OF INCOME BY THE ACCRA COST OF LIVING INDEX}

The ACCRA Cost of Living index (http://www.coli.org/) is perhaps the most widely used index to estimate city-to-city variability between the prices of goods. The buying power variable used in this report was calculated for both NHTS household income (using the midpoint of the \$5,000 range) and for all Census tracts' median household income by simply dividing income by the buying power index, where 1.00 equaled the national average. The ACCRA data used was the average of all quarters of 2001, which seemed a reasonable compromise given the sampling window of the 2001 NHTS.

ACCRA data was available for some, but not all, MSAs in the U.S. In addition, some MSAs had multiple records for different cities or other boundaries within the MSA. If there was more than one entry per MSA, households and tracts were matched on the name of the city used for an ACCRA record. If a household or tract was in the MSA but not in a particular city listed, a default record (usually the largest city in the MSA for which data was available) was chosen for that MSA and its data was used. If a household or tract was in an MSA but no ACCRA data existed for that MSA, or was not in an MSA, data for the closest MSA, determined by great circle distance, was assigned. Hawaiian tracts were assigned 3rd quarter 2002 ACCRA values found at http://www.missourieconomy.org/indicators/cost_of_living/col3qu2002.stm , since no data for Hawaii was available for 2001.

Rural tracts, as defined where $50 \%$ or more households in a tract is rural according to Census data, were investigated for whether they had a lower cost of living. Since no definitive national data was available that proves a universally lower cost of living in rural areas, the relationship between person and vehicle trips and buying power using several rural adjustment factors was investigated. No significant differences in Rsquared existed between the adjustment factors attempted $(0.9,1.06,1.16)$, so no adjustment was made to rural tracts. 
Transferring 2001 National Household Travel Survey

\section{APPENDIX 4}

A4 - 1 
Transferring 2001 National Household Travel Survey

\section{APPENDIX 4: DETERMINATION OF 19 “MEGA-URBAN” MSAs}

Transit availability can have an effect on mobility. Urban areas can differ greatly in their availability of transit. Thus, the decision was made to separate urban areas into those with widely available transit (termed "Mega-Urban" areas, since these tend to be cities such as New York and Los Angeles), and those with transit not as widely available in relative terms (simply referred to as "Urban"). The method of splitting urban areas into these two groups used data on transit service hours and actual transit use.

\section{Service Hours}

A measure of service hours was computed from the 2001 National Transit Database using the sum of annual totals of rail and non-rail hours (variables ITHOURS and IVHOURS, respectively, from Form 406. This sum was summarized over each Urbanized Area (UZA), which is similar to Metropolitan Statistical Area (MSA) classifications. For purposes of this procedure, differences between MSAs and UZAs are not important.

\section{Transit Use}

Since data on national transit use on a city by city basis is not readily available, a proxy of actual transit use was computed using journey-to-work data from the 2000 Decennial Census. More specifically, the percentage of users by census tract that used public transit on their journeys-to-work was computed, and average percentages were computed for each MSA.

\section{Selection Procedure}

MSAs/UZAs were ranked by each of the two measures described above, with the MSA/UZA having the highest number of service hours or percentage transit use being ranked 1, the second highest 2, etc. The two ranks were then added, and MSAs were then sorted on the combined sum. For instance, New York MSA has both the highest number of service hours and highest percent transit use, so their ranks for each measure would be 1 , giving them a combined score of 2 , which is the lowest possible combined score.

These combined rankings were then used to find the top MSAs in transit availability and use that have a combined population of at least 100 million persons. The number 100 million was decided upon so that the data for urban areas would be roughly split into two equal halves- those with transit available and widely used, and those without transit. In all, nineteen MSAs were selected. Below are the top MSAs, with all relevant data. 


\begin{tabular}{|c|c|c|c|c|c|c|c|}
\hline $\begin{array}{l}\text { Overall } \\
\text { Rank }\end{array}$ & MSA/UZA & $\begin{array}{c}\text { Service } \\
\text { Hours } \\
(000 s)\end{array}$ & Rank & $\begin{array}{l}\text { Transit } \\
\text { Use }\end{array}$ & Rank & $\begin{array}{l}\text { Com- } \\
\text { bined } \\
\text { Score }\end{array}$ & $\begin{array}{l}\text { Total } \\
\text { Pop. } \\
\text { (000s) }\end{array}$ \\
\hline 1 & $\begin{array}{l}\text { New York-Newark, NY- } \\
\text { NJ-CT }\end{array}$ & 35,206 & 1 & $24.0 \%$ & 1 & 2 & 21,200 \\
\hline 2 & Chicago, IL-IN & 11,055 & 4 & $11.6 \%$ & 2 & 6 & 9,158 \\
\hline 3 & $\begin{array}{l}\text { San Francisco--Oakland-- } \\
\text { San Jose, CA }\end{array}$ & 11,177 & 3 & $8.9 \%$ & 4 & 7 & 7,039 \\
\hline 4 & $\begin{array}{l}\text { Washington--Baltimore, } \\
\text { DC--MD--VA--WV }\end{array}$ & 9,134 & 5 & $10.9 \%$ & 3 & 8 & 7,608 \\
\hline 5 & $\begin{array}{l}\text { Philadelphia, PA-NJ-DE- } \\
\text { MD }\end{array}$ & 6,599 & 6 & $8.4 \%$ & 7 & 13 & 6,188 \\
\hline 6 & Boston, MA-NH-RI & 4,715 & 9 & $8.2 \%$ & 8 & 17 & 5,819 \\
\hline 7 & Seattle, WA & 6,187 & 7 & $6.0 \%$ & 12 & 19 & 3,555 \\
\hline 8 & $\begin{array}{l}\text { Los Angeles-Long Beach- } \\
\text { Santa Ana, CA }\end{array}$ & 14,980 & 2 & $5.2 \%$ & 18 & 20 & 16,374 \\
\hline 9 & Pittsburgh, PA & 3,855 & 12 & $7.9 \%$ & 9 & 21 & 2,359 \\
\hline 10 & Miami, FL & 5,524 & 8 & $4.6 \%$ & 20 & 28 & 3,876 \\
\hline (tie) & Portland, OR-WA & 2,914 & 17 & $6.0 \%$ & 11 & 28 & 2,265 \\
\hline 12 & Honolulu, HI & 1,895 & 24 & $8.8 \%$ & 5 & 29 & 876 \\
\hline 13 & Minneapolis-St. Paul, MN & 3,593 & 13 & $5.3 \%$ & 17 & 30 & 2,969 \\
\hline (tie) & Atlanta, GA & 2,976 & 15 & $5.8 \%$ & 15 & 30 & 4,112 \\
\hline 15 & Milwaukee, WI & 2,317 & 21 & $7.2 \%$ & 10 & 31 & 1,690 \\
\hline 16 & Cleveland, $\mathrm{OH}$ & 2,546 & 19 & $5.8 \%$ & 14 & 33 & 2,946 \\
\hline 17 & New Orleans, LA & 1,485 & 28 & $8.7 \%$ & 6 & 34 & 1,338 \\
\hline 18 & Denver-Aurora, CO & 3,369 & 14 & $4.4 \%$ & 24 & 38 & 2,582 \\
\hline 19 & Houston, TX & 4,063 & 10 & $3.6 \%$ & 31 & 41 & 4,670 \\
\hline & $\begin{array}{l}\text { TOTAL POPULATION } \\
\text { (000s) }\end{array}$ & & & & & & 106,622 \\
\hline
\end{tabular}


Transferring 2001 National Household Travel Survey

\section{APPENDIX 5}

A5 - 1 


\section{APPENDIX 5. TUTORIAL TO USE THE GIS-BASED WEB TOOL}

\section{Purpose:}

To show the user how to use this website.

\section{Web Site Objective}

To provide a GIS-Based web application to enable users to download Trip Generation Rate information at the Census tract and Transportation Analysis Zone (TAZ) level. Such information can be used by transportation planners and analysts in their transportation planning process.

Trip Rate Information is generated based on information from the 2001 National Household Travel Survey (NHTS). More information on NHTS can be found at the following agency's sites:

- $\quad$ Bureau of Transportation Statistics

- Office of Highway Policy Information, Federal Highway Administration

This tutorial is prepared for download trip rates by Census tract. Procedures to download trip rates by TAZ are the same as the procedures outlined in this tutorial.

\section{Web Page Layout}

The web page is divided into the following major areas:

- Page Title

- Navigation/Selection Control

- Map Layer Control

- Map Display

- $\quad$ Trip Rate Table Control

A Sample Web page is depicted in the next figure. 


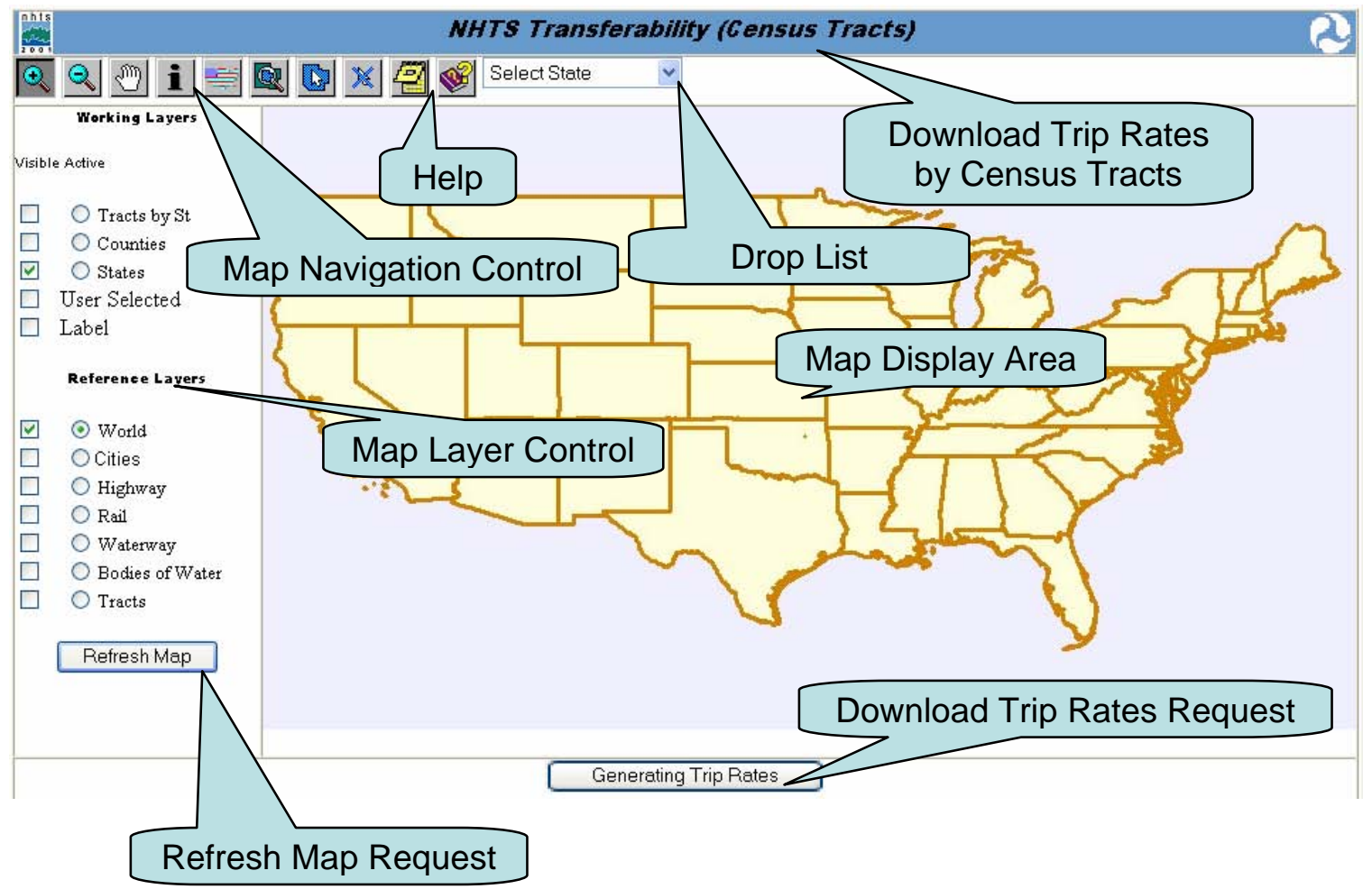

\section{Capability:}

This web site provides the user with the following capability:

- Navigation

o Zoom In

- Zoom In to Any Location(s)

- Zoom In to a State and County

o Zoom Out

o Pan

o Identify Feature Within Active Map Layer

o Reset Map to Original Map Extent

- Help Information

o Data Source

o Tutorial

- Map Layer Visibility/Activated Layer Control

- Set Visibility of Each Map Layer

- Set a Map Layer as The Active Layer

o Set Visibility of the User Selected Tract(s) 
o Set Visibility of the Label for the Active Map Layer

- Select Tracts for the Trip Rates Table

o Select by Drop Lists

o Select by a Point Within The Area Boundary

- Clear Selected Tract(s)

o Reset Drop Lists

- Trip Rate Table

o Generate Trip Rate Table for The User Selected Tracts

o Display Trip Rate Table

o Download Trip Rate Table

- Microsoft Excel File Format

- ESRI Shape File Format

\section{Map Layers}

- Working (or Essential) Map Layer

o US State Boundary Layer

o US County Boundary Layer

o User Selection Layer

o Census Tract Boundary

- Tracts (National)

- Tracts by State

Or

o Transportation Analysis Zone (TAZ) Layer

- TAZ

- TAZ by State

- Reference (or Background) Layers

o CTA National Highway Network

o CTA National Railroad Network

o National Waterways Network with attached global seaways (part of the CTA Intermodal Transportation Network)

o Bodies of Water

o World Country Boundary

\section{Important Tips}

- $\quad$ Pop-up Blocker

- Active Content Blocker

- Tract Selection and Download

- Map Layers 


\section{Navigation/Selection Control}
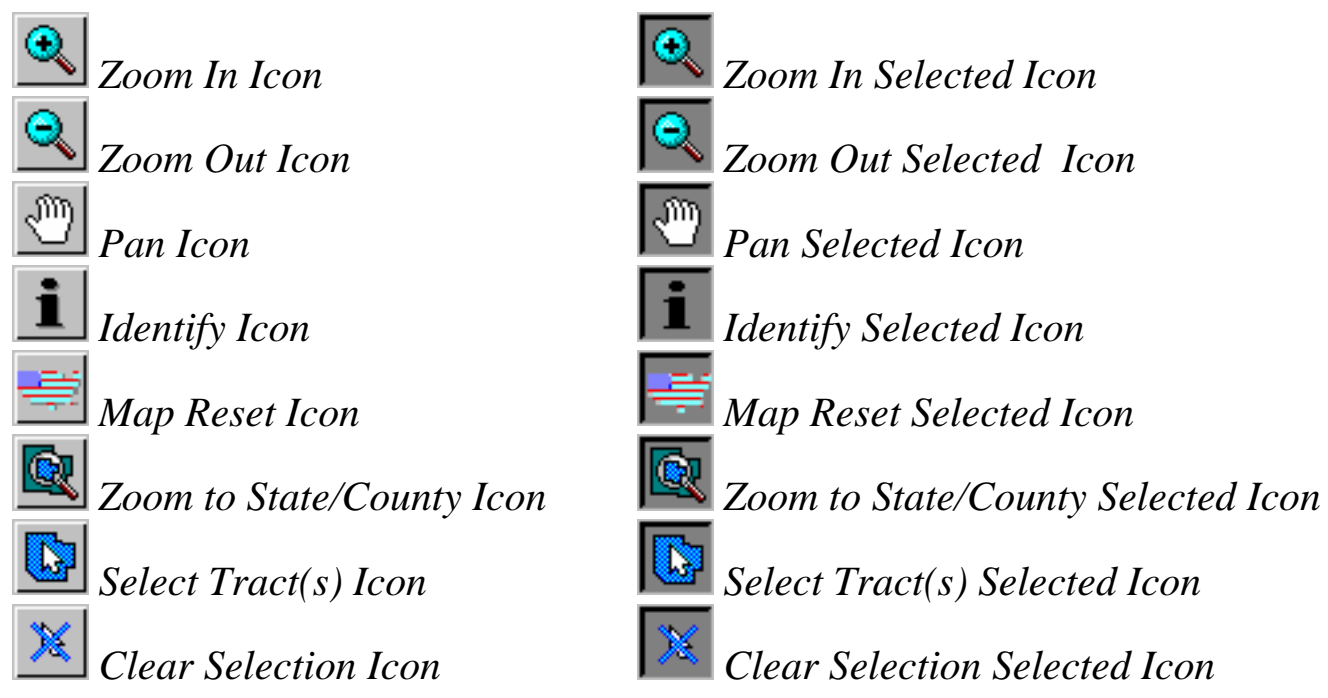

The above navigation/selection controls require users to click on the map display for the web-application to execute the selected control.

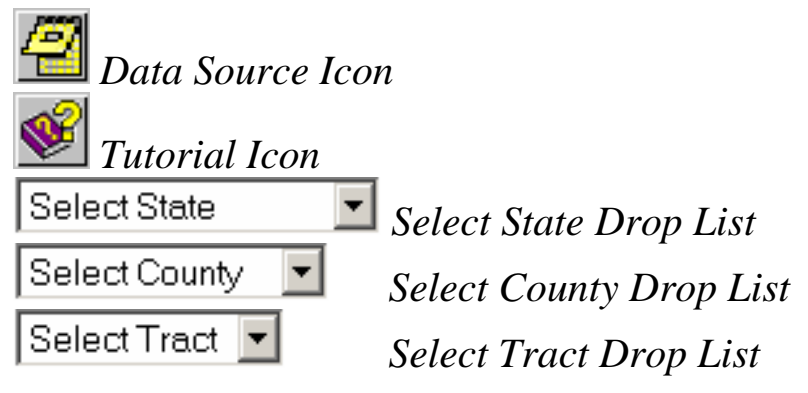

In stead of Select Tract Drop List, Select TAZ Drop List will be shown for trip rates download by TAZ.

\section{Map Layer Control}

The map layer control layout is shown in the following figure. In general, there is one check box per map layer to set the layer's visibility and one radio button per map layer to set the map layer as the Active Map Layer.

There is one visibility check box for the User Selected tract map layer and one check box for the visibility of the identification label of the Active Map Layer.

More than one layer can be "visible." However, only one layer can be "active" at any time. 


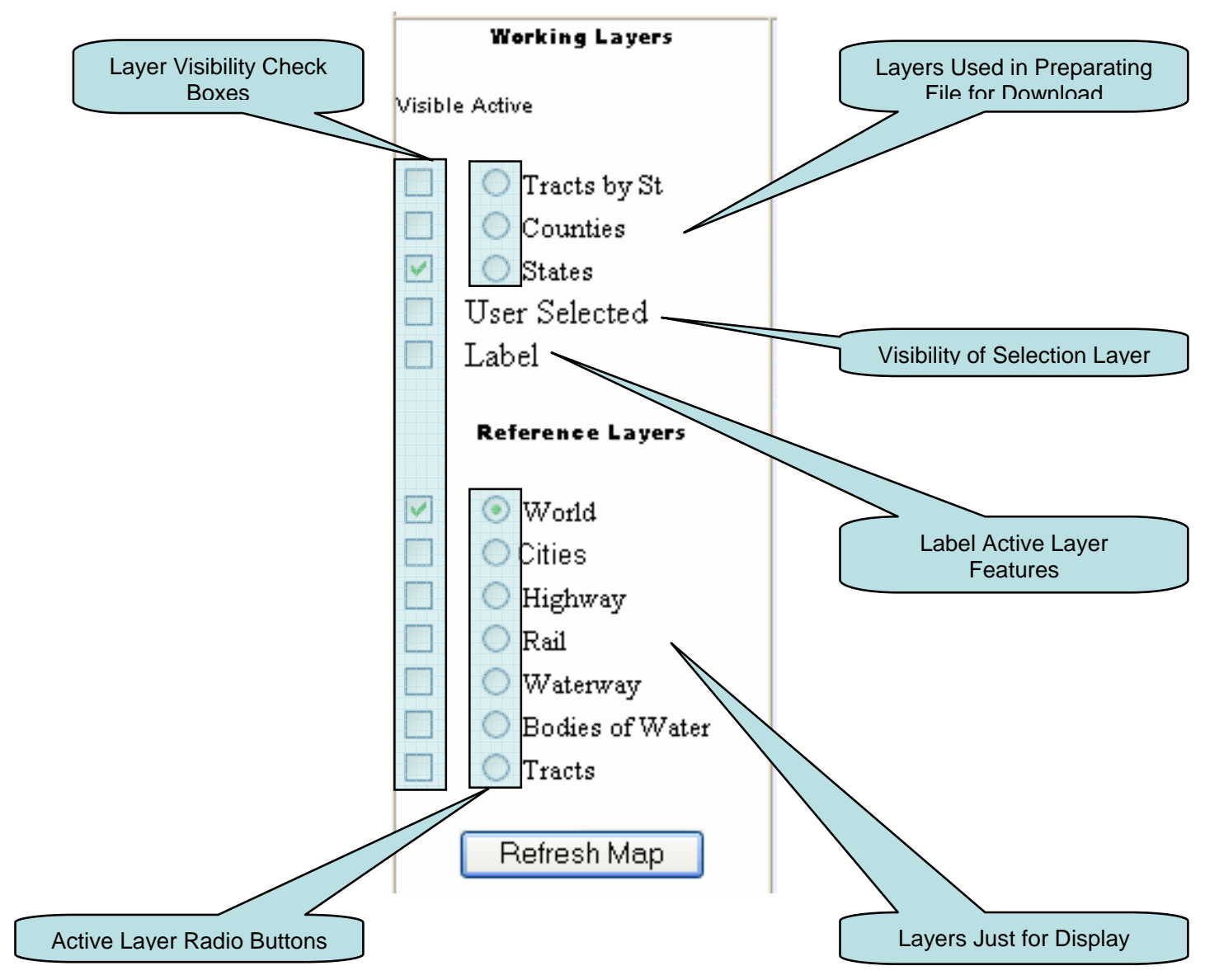

The user can use the cursor to check or un-check the check box of a map layer to set the visibility of the map layer. You can check or un-check more than one map layer visibility check box before refreshing the Map Display. After finishing the map layer visibility selection process, you can either proceed to set the Active Map Layer or click on the Refresh Map command button to refresh the Map Display.

There is one radio button for each map layer included in the system. You can set the Active Map Layer by clicking on the radio button of the map layer. You can select only one map layer as the active layer at any time. 
The following functions within the system will only work with the Active Map Layer:

- Identify i

- Label Visibility

- Zoom to State and County

- Select Tracts by a Point Within The Boundary 圈

Instead of Tracts and Tracts by St map layers, TAZs and TAZs by St map layers will be shown for trip rates download by TAZ.

\section{Trip Rate Table Control}

After the user has selected the desired tracts, the system will generate the corresponding Trip Rate Table by clicking on the command button.

\section{Generating Trip Rates}

\section{Zoom In to Any Location(s)}

1. Click on $\stackrel{\oplus}{\oplus}$, the icon will change to $\oplus$.

2. Move the cursor to the Map Display area. The cursor will change to firy over the Map Display Area.

3. Click on the desired point on Map Display.

4. The new Map Display will center at the clicked location with the map scale at $50 \%$ of the previous Map Display.

The following figure shows the user clicked the ${ }^{+}$icon and moved the cursor to the eastern Tennessee area. 


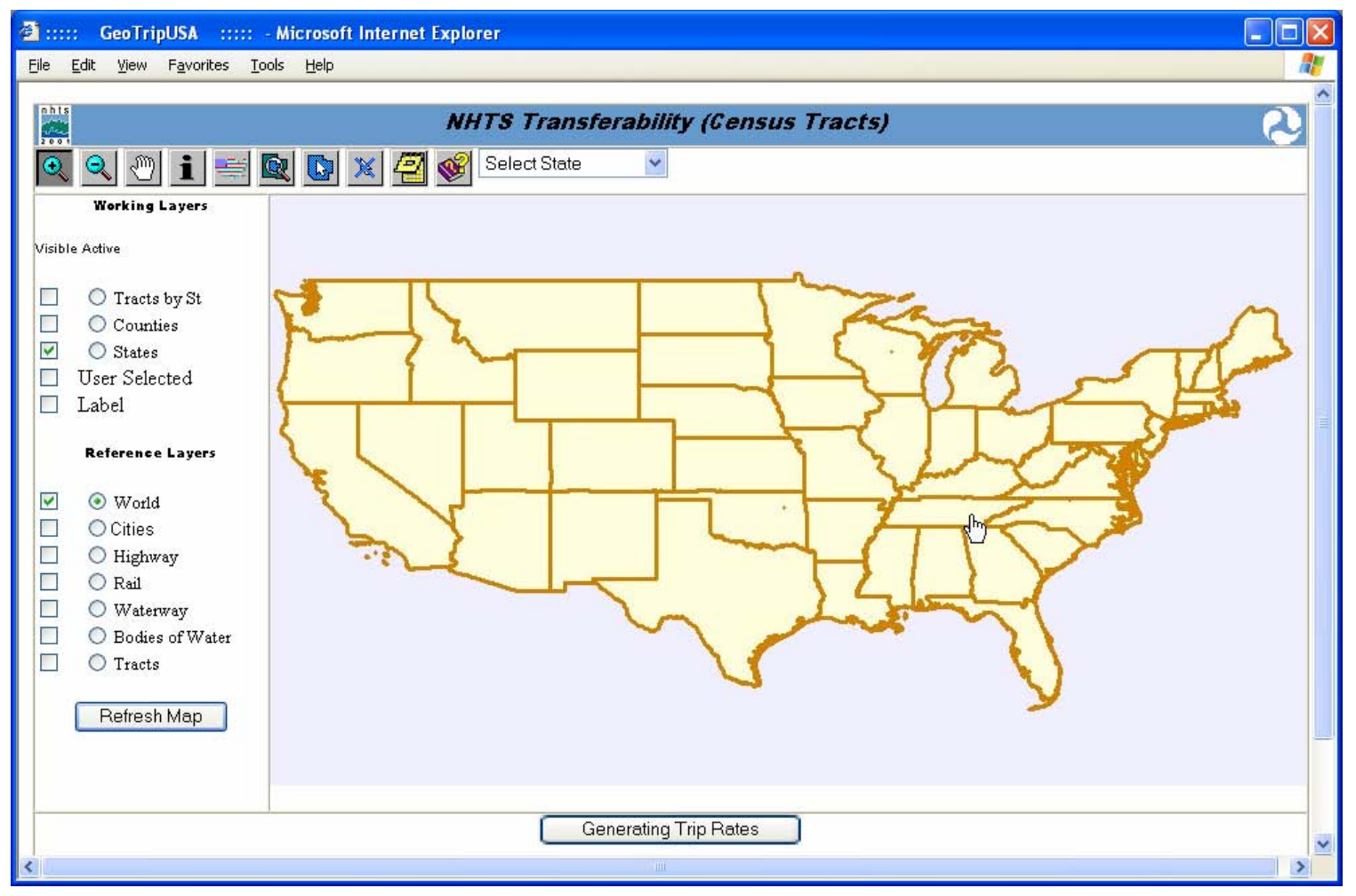

The next figure shows the Map Display centered in eastern Tennessee and the Map Display scale at $50 \%$ of the previous Map Display scale. 


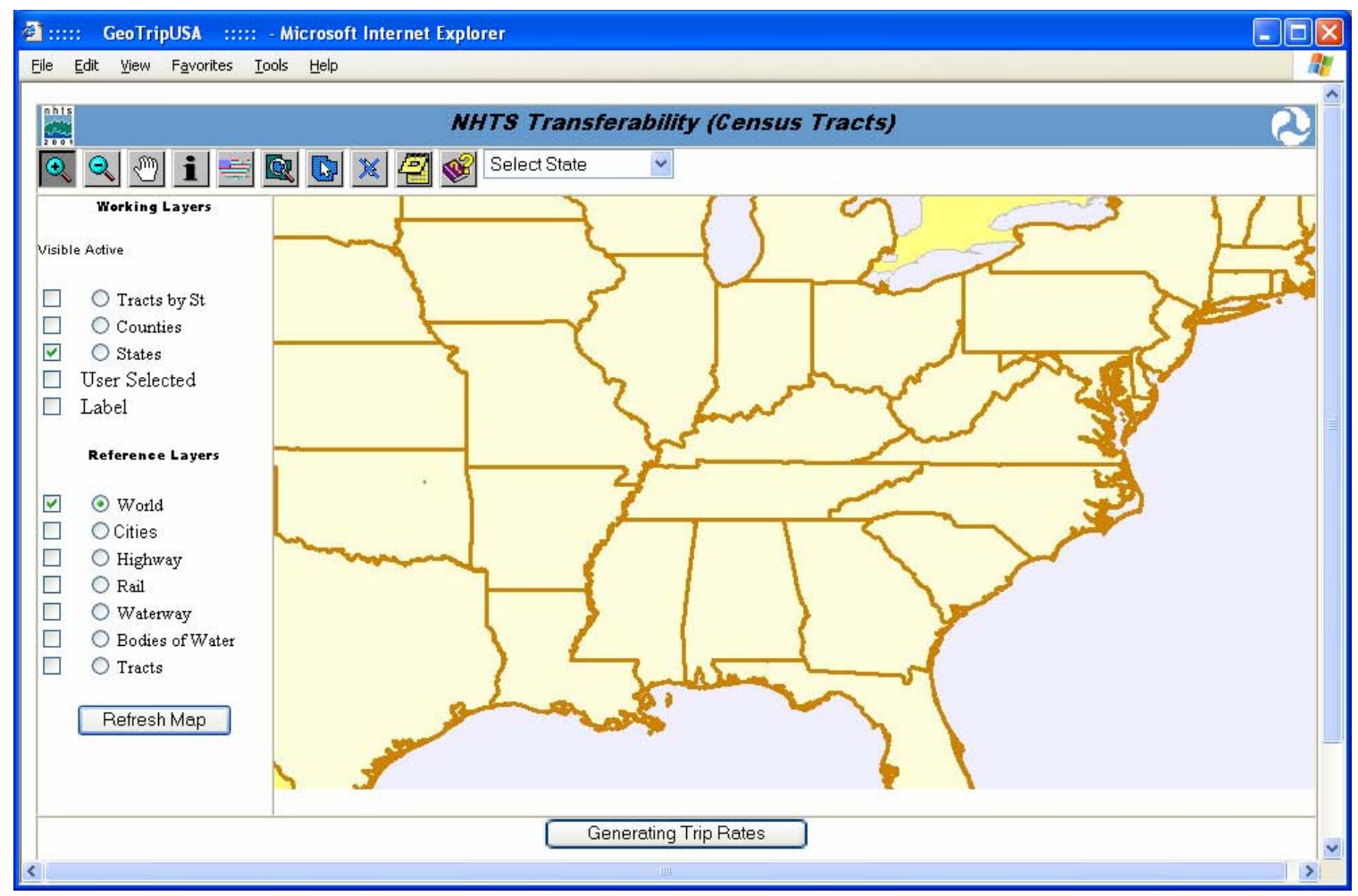

\section{Zoom In to a State, Then to a County}

1. Make either the State Boundary Map Layer or the County Boundary Map Layer as the visible Active Map layer. Otherwise, the system will show a Reminding Message.

2. Click on<smiles>C1=CC2=CC1=C2</smiles>
, the icon will change to

3. Move the cursor to the inside of the desired state (county) and click on the Map Display.

4. The new Map Display will zoom to the selected state (county) with state (county) name labeled.

5. The above-mentioned Reminding Message will be trigged again if the user

a. changes the visibility check boxes and active layer radio buttons but 
b. icon

Under this circumstance, the user should select a different icon and click the Refresh Map button and refreshed the screen.

The flowing figure shows the user set the visibility to "on" and set the State Boundary Map Layer as the Active Map Layer. The user moved the cursor to the interior of Alabama.

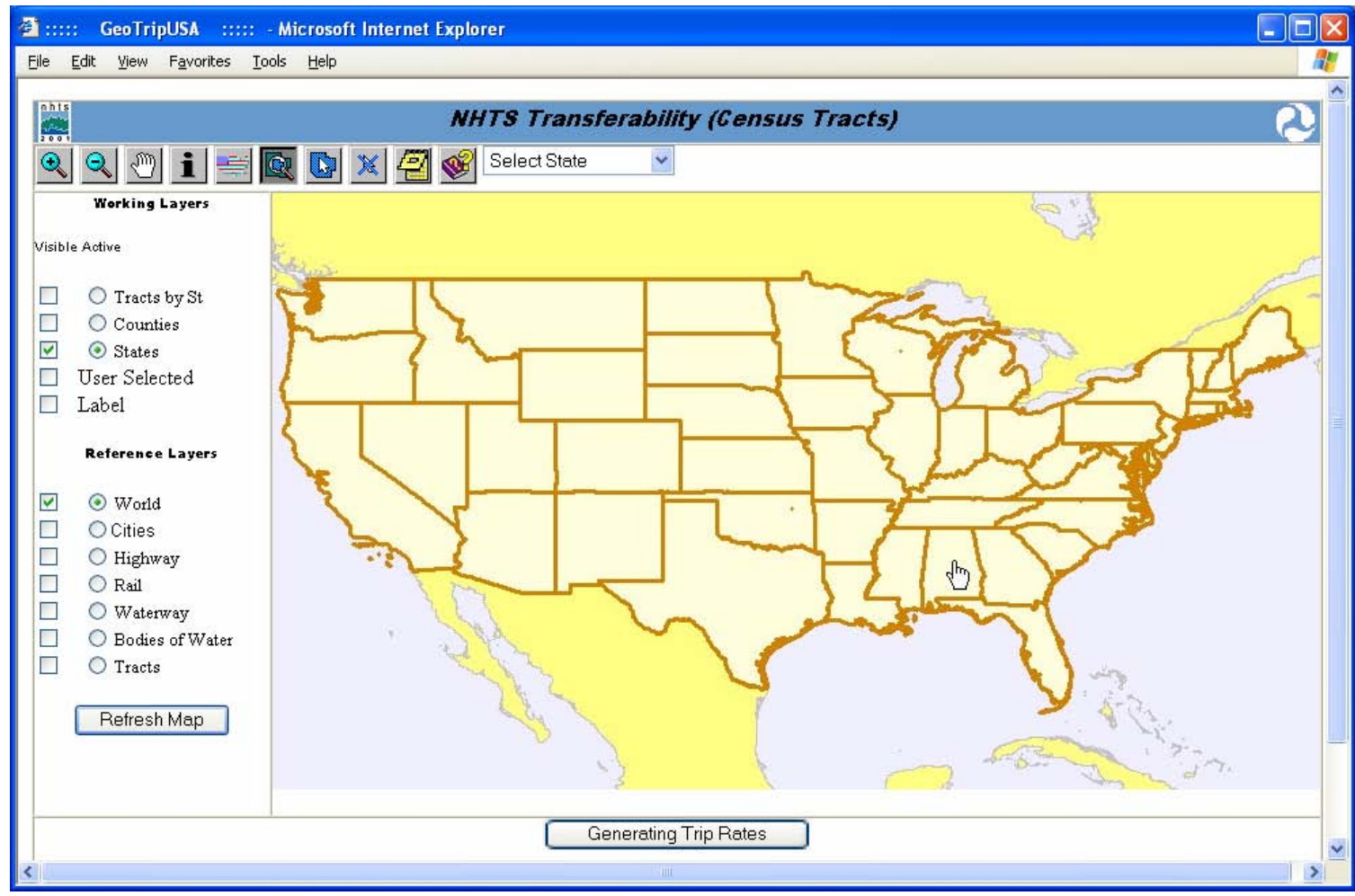

After the user has clicked on the interior of Alabama, the system reloads a new Map Display that is zoomed in to Alabama with the state name labeled. 


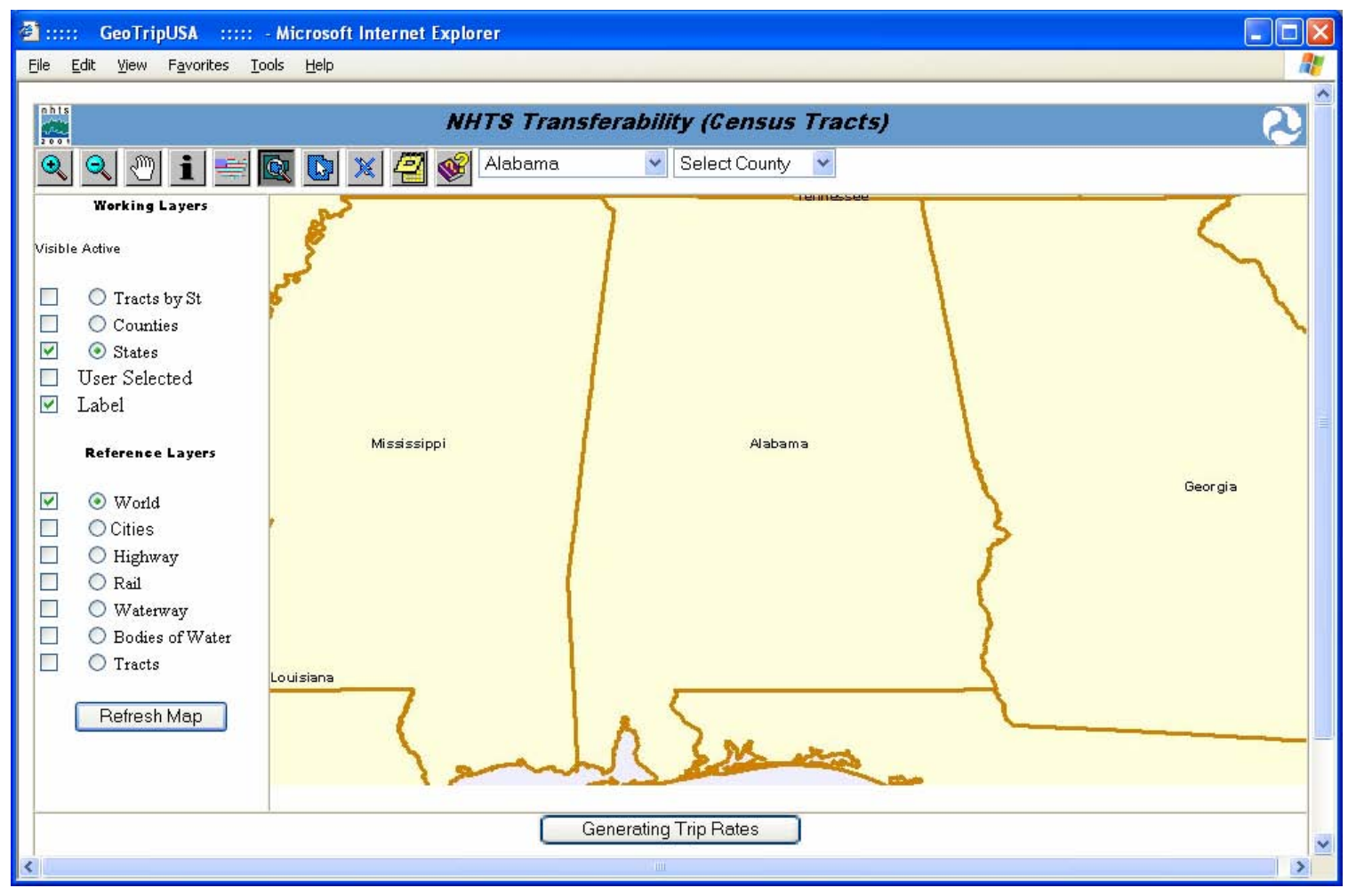

The user can reset the Map Layers Control options and zoom in to a county within Alabama. In the next figure, the user has set the County Boundary Map Layer as the Active Map Layer and set the visibility to "on." The user has also set the visibility of Label to "off." 


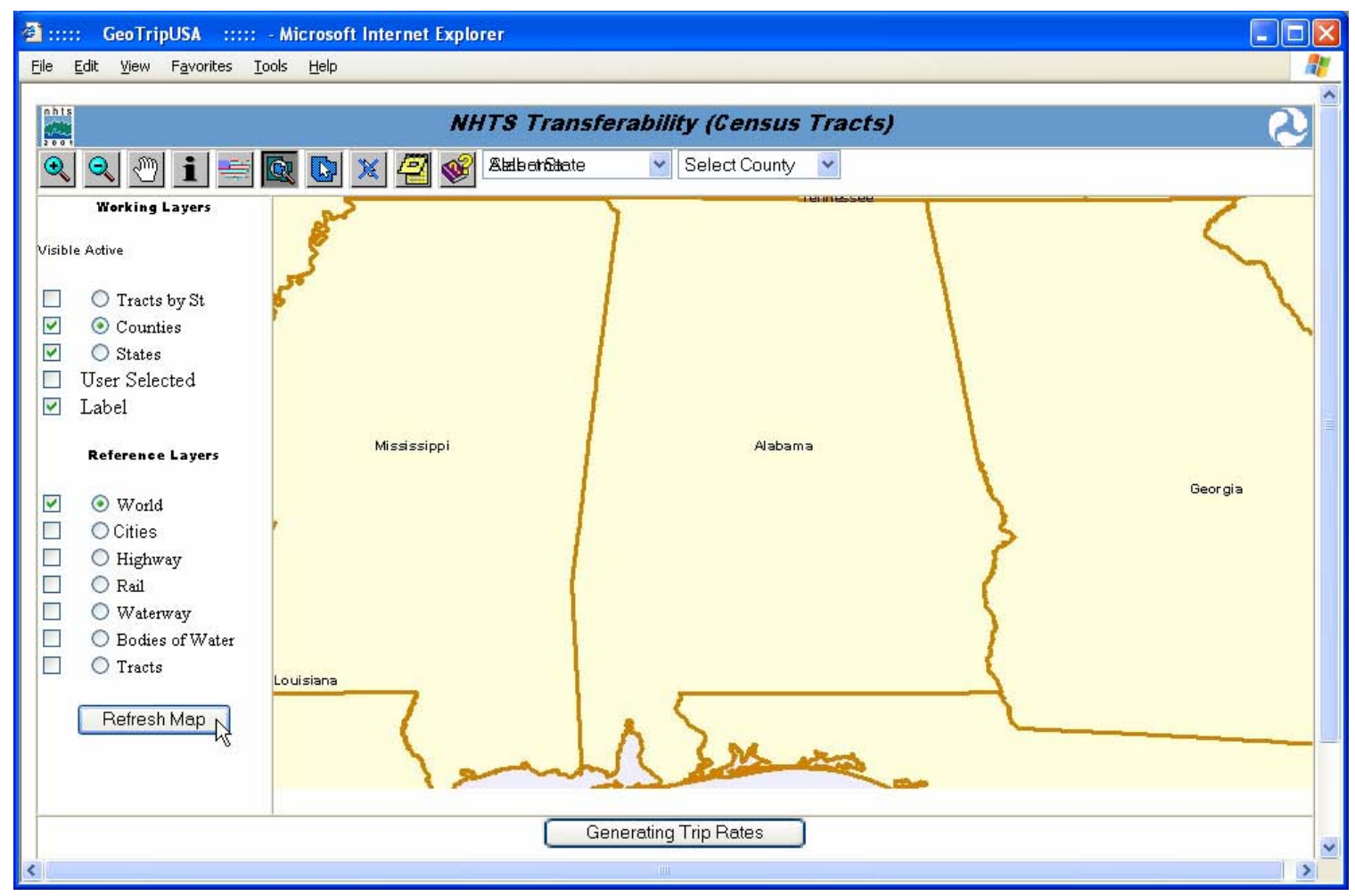

After the user has clicked the Refresh Map command button Refresh Map, the newly refreshed Map Display is shown in the following figure. 


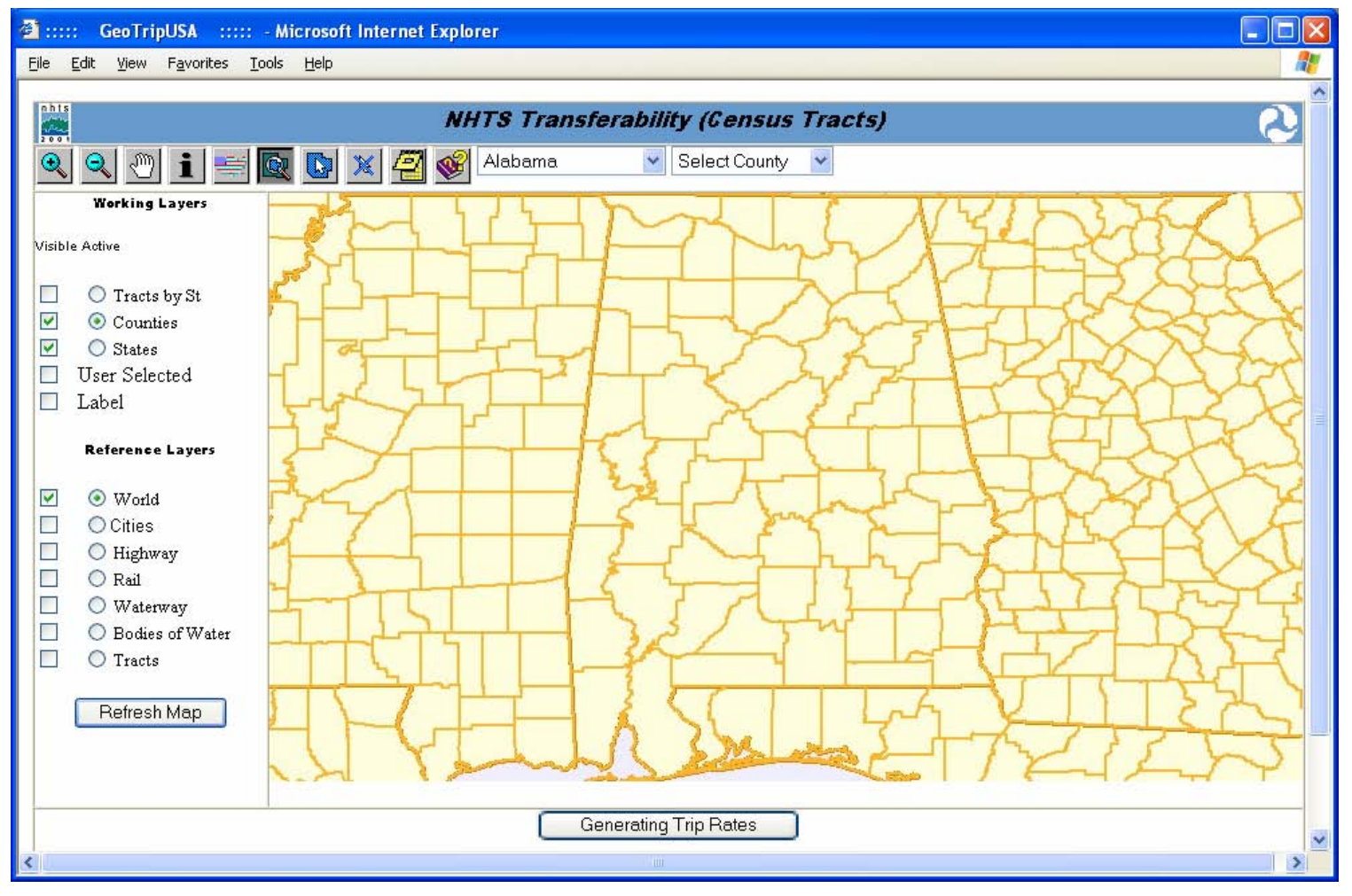

Then the user moves the cursor to the interior of Montgomery County, Alabama. 


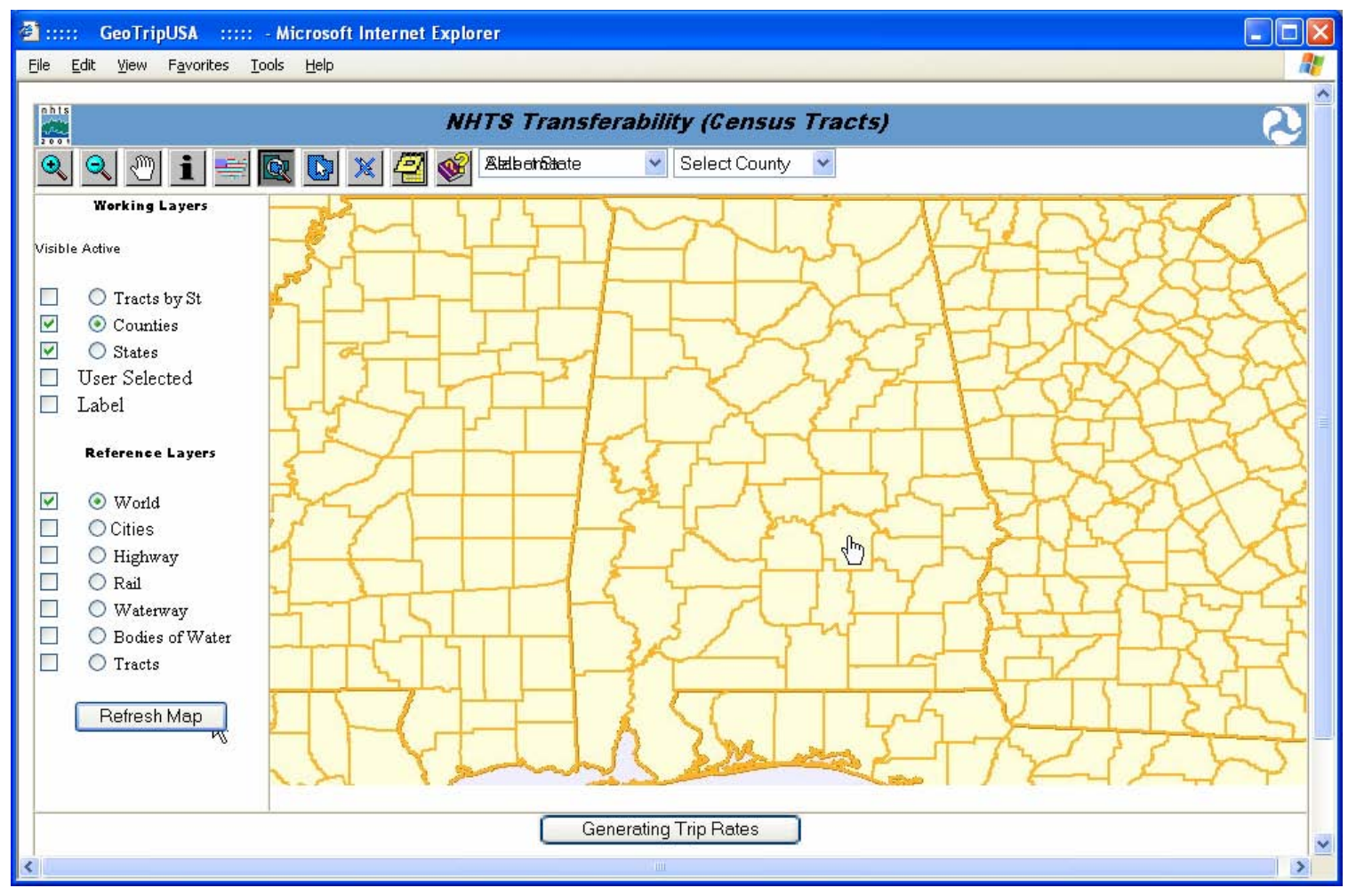

After the user has clicked on the interior point of Montgomery County, Alabama, the system will zoom to Montgomery County, Alabama with the county name labeled. 


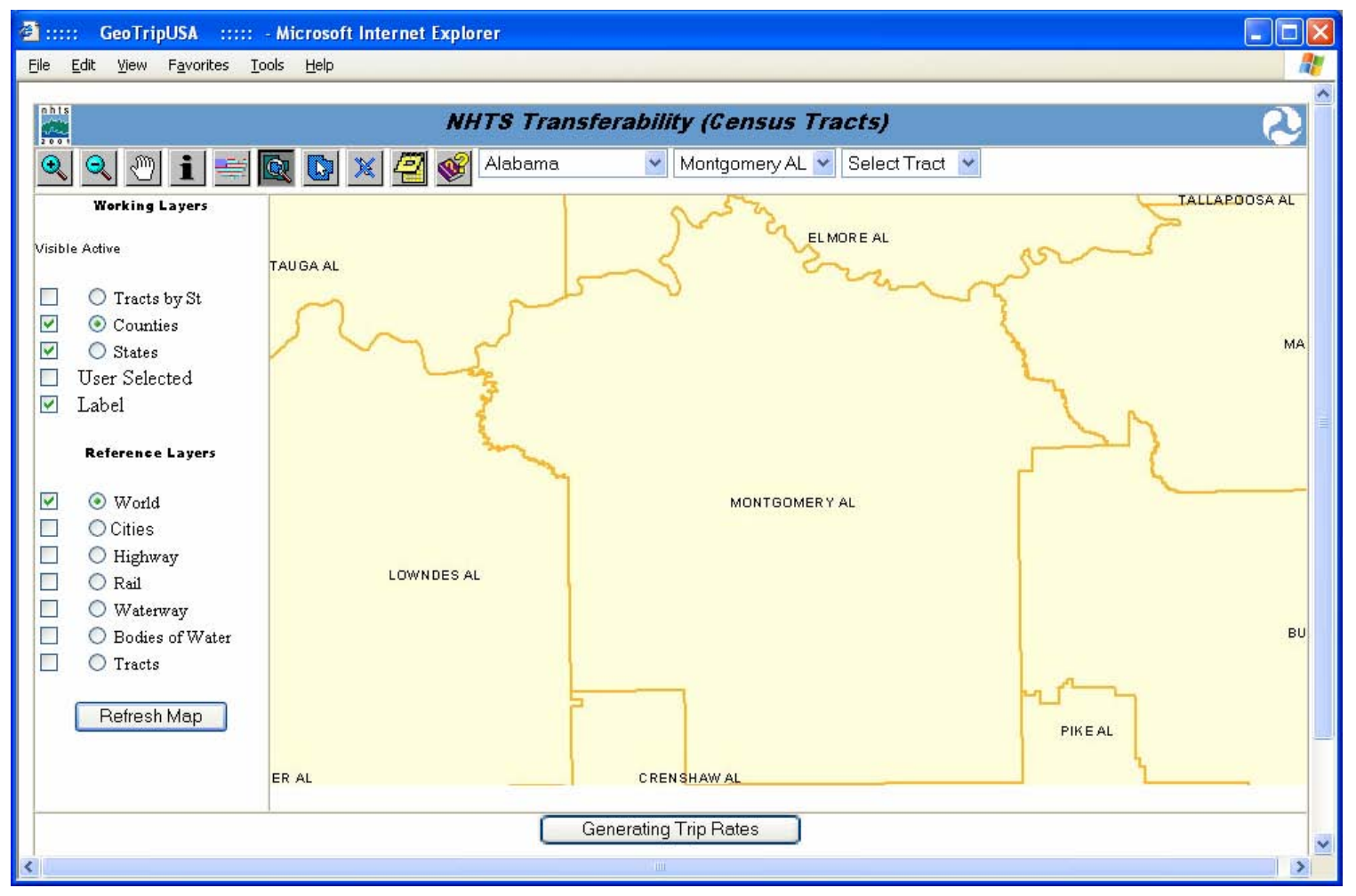

The user can click on any interior point within the neighboring county to zoom to the selected county. The next example shows the user moved the cursor to Elmore County, Alabama. 


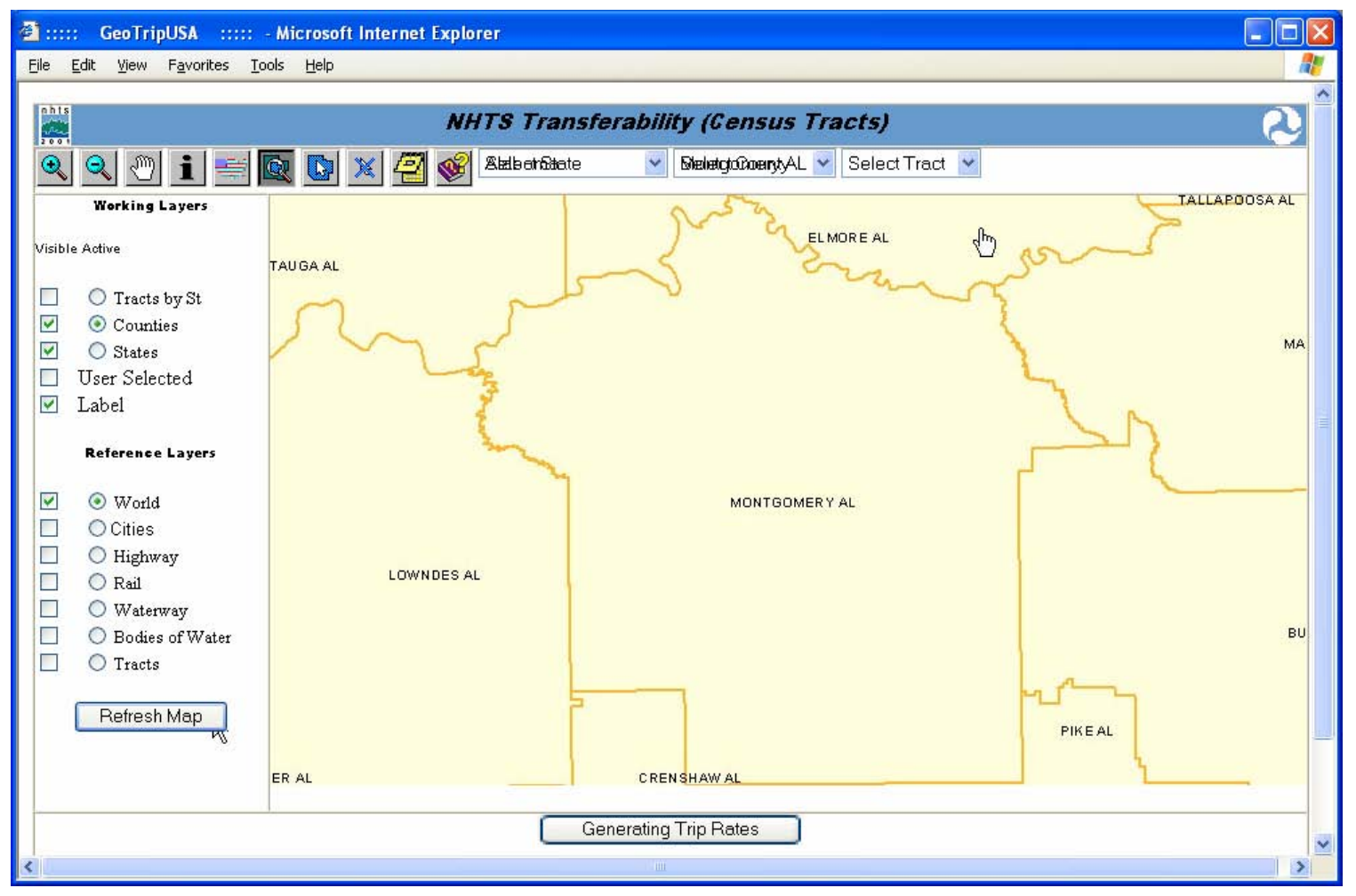

After the user has clicked on the interior point of Elmore County, Alabama, the system will reload with a new Map Display zoomed to Elmore County, Alabama with the county name labeled. 


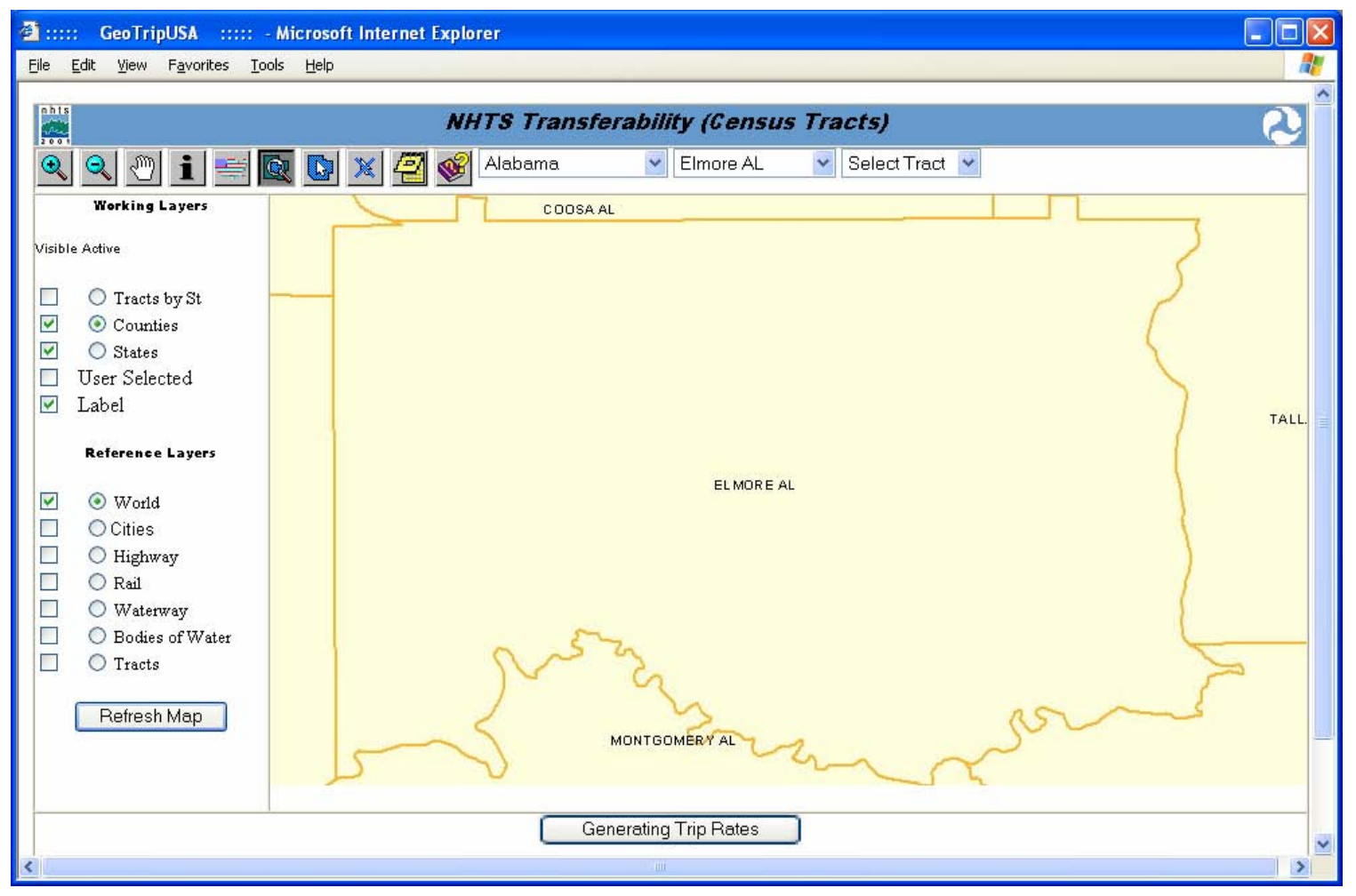

The Select State, Select County drop lists Select State $\quad \nabla$, Select County $\quad \nabla$ will display the selected state and selected county accordingly.

You are not required to zoom to a state and then zoom to a county. You can zoom to a county directly, as long as the County Boundary Map Layer is visible and is the Active Map Layer.

\section{Zoom Out}

1. Click on $Q$, the icon will change to $Q$.

2. Move the cursor and click on the desired point in the Map Display.

3. The new Map Display will be centered at the clicked location with the map scale at $200 \%$ of the previous map scale.

The following figure shows a user has selected the 1 option and moved the cursor to the middle Kansas area. 


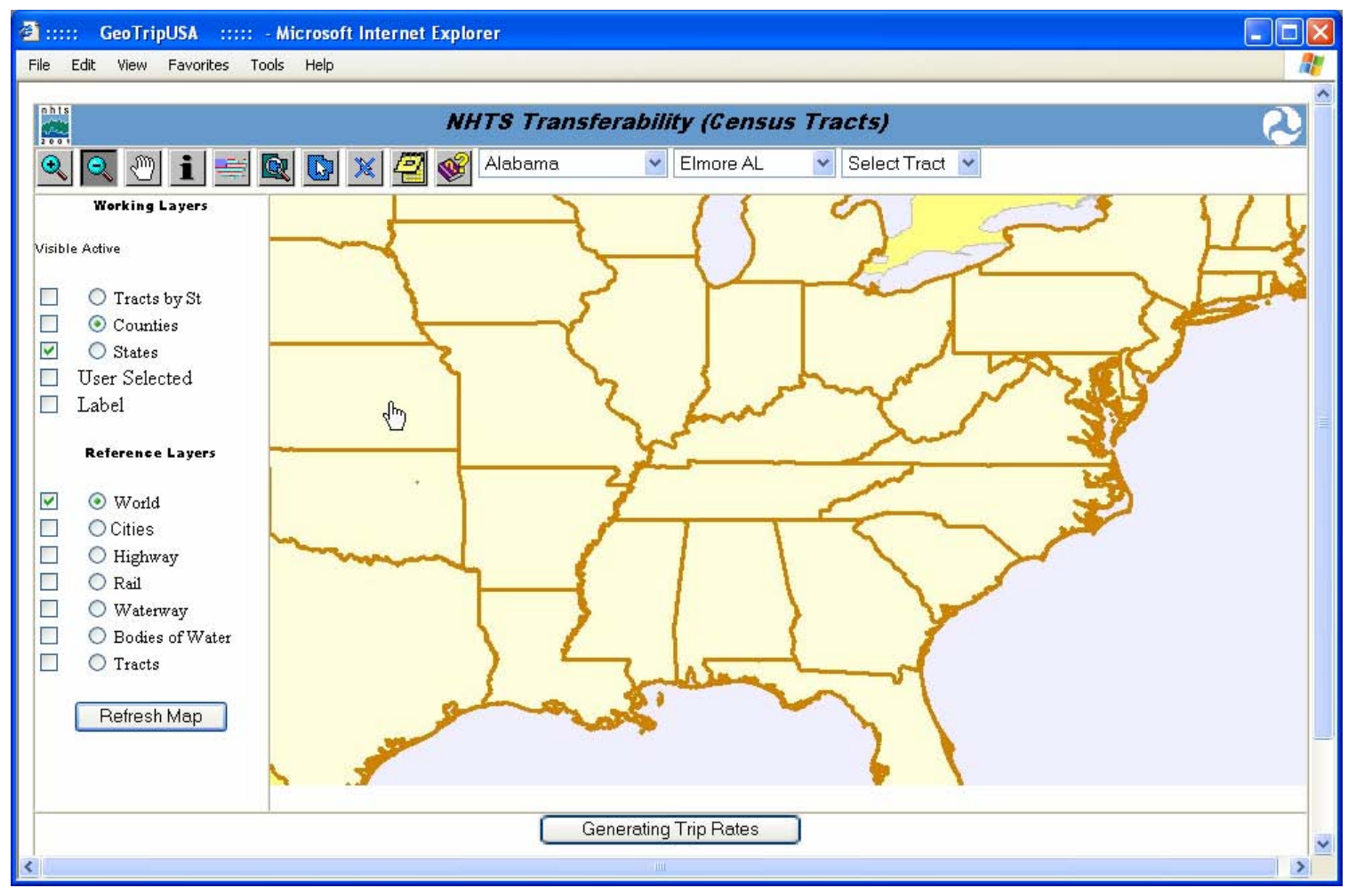

The next figure shows the Map Display centered in central Kansas and the Map Display scale at $200 \%$ of the previous Map Display scale. 


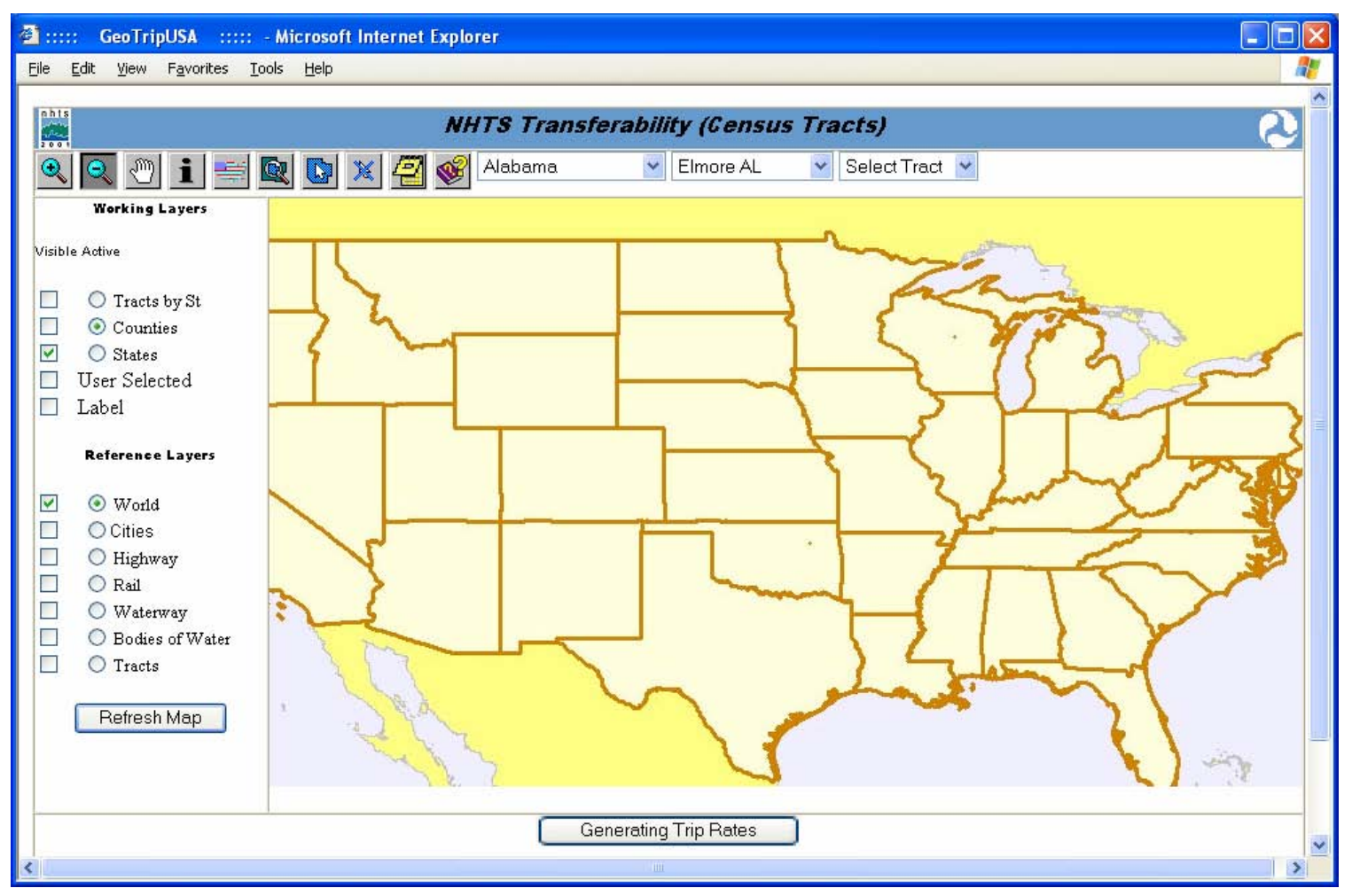

\section{Pan}

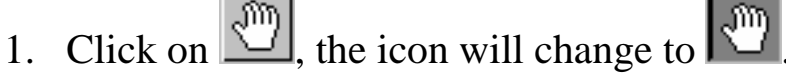

2. Move the cursor and click on the desired point in the Map Display.

3. The new Map Display will center at the clicked location with the same map scale.

The following figure shows the user selected the Pan option and moved the cursor to the southern California area. 


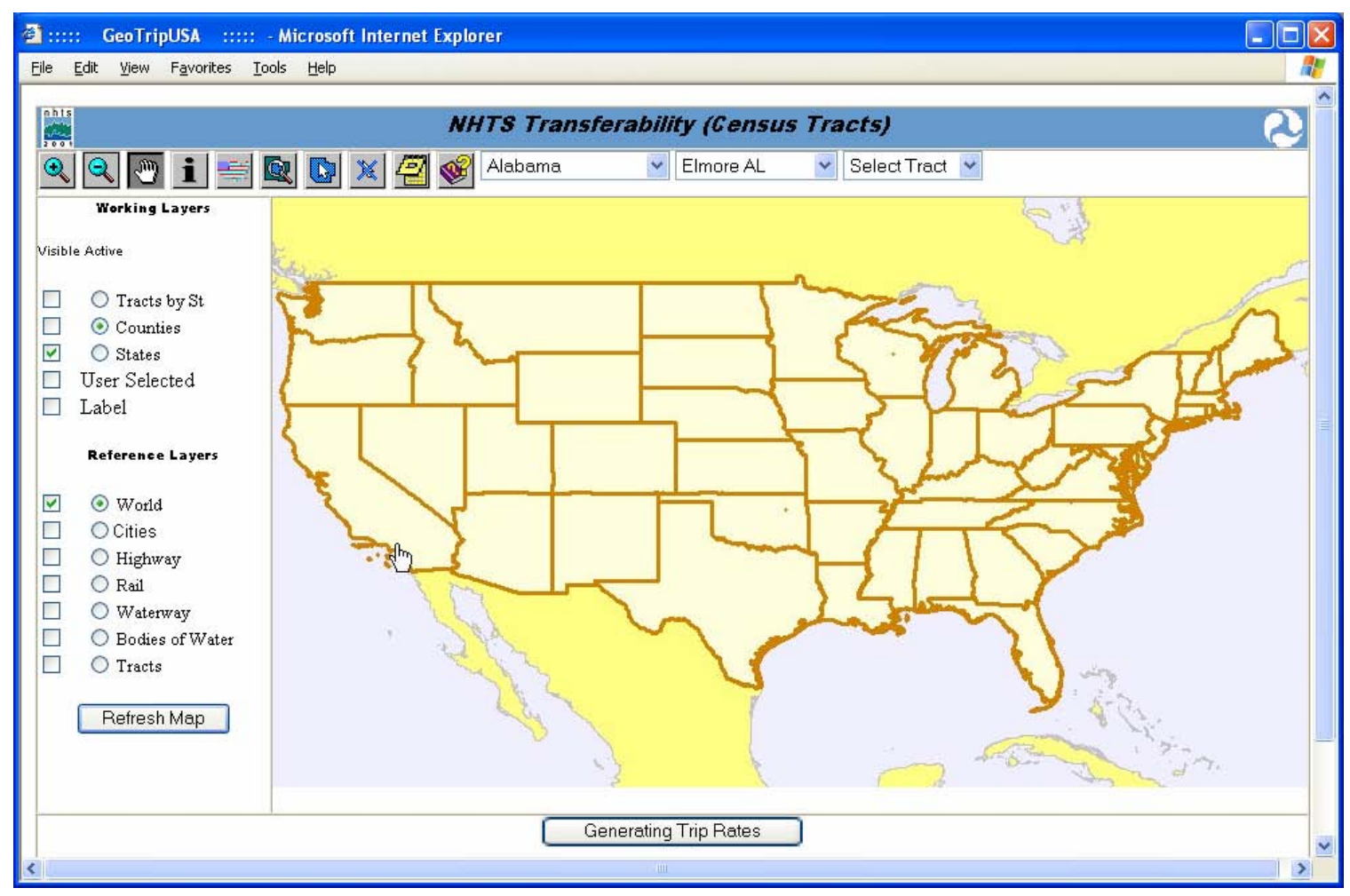

After the user has clicked on a point in southern California, the system will reload with the new Map Display centered at the point the user has selected with the same map scale. 


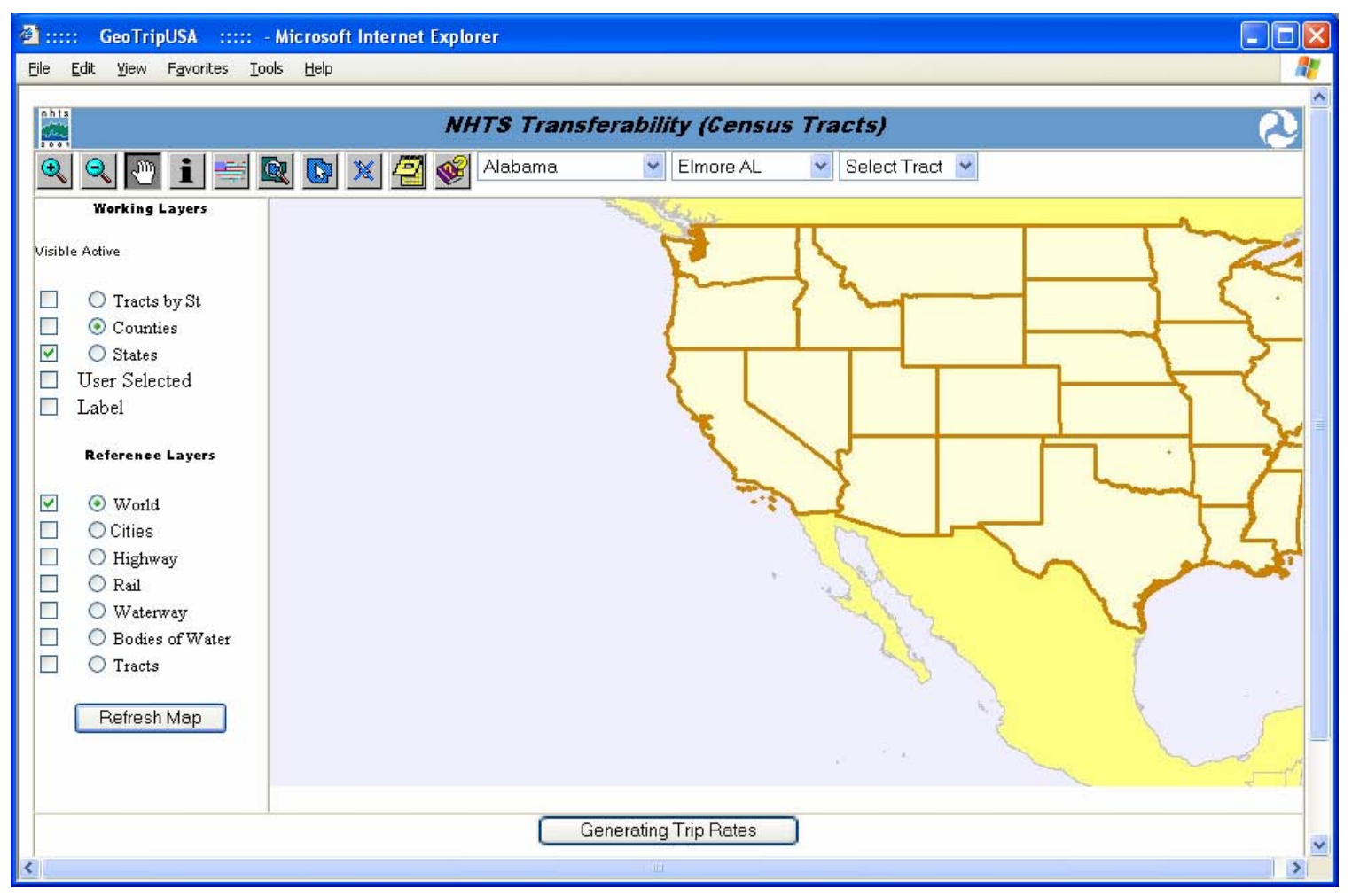

\section{Identify Feature within Active Map Layer}

1. Set target map layer as the visible Active Map Layer.

2. Click on $\underline{\mathbf{i}}$, the icon will change to $\mathbf{i}$.

3. Move the cursor to the desire geographic element in the Map Display and click.

4. The selected element will be highlighted with identification information.

The following figure shows the user has set the target map layer as the State Boundary map layer. The user has also selected the Identify option and moved the cursor to a location inside of Nebraska. 


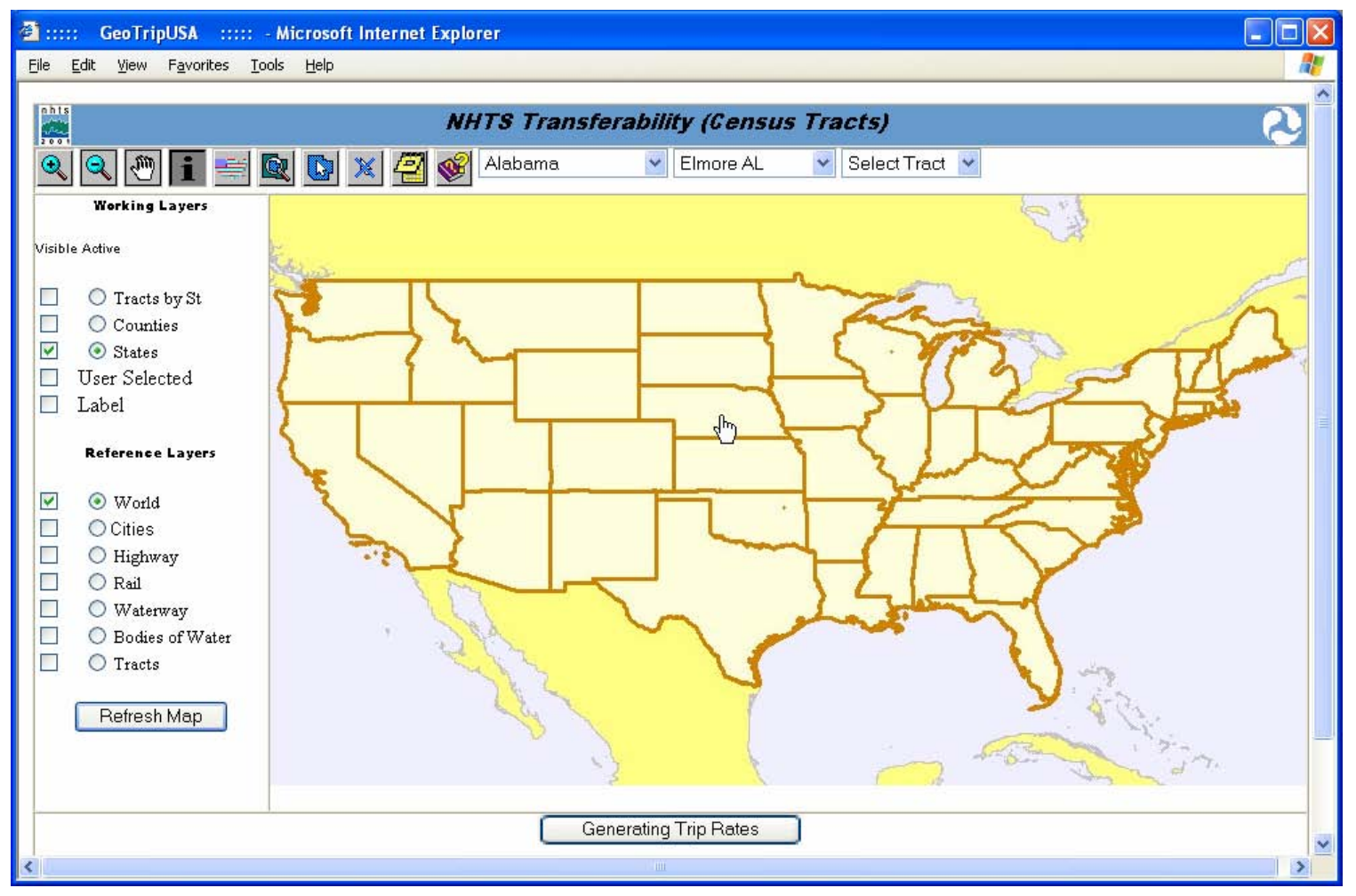

After the user has clicked on Nebraska, the new Map Display depicts the same Map Display with Nebraska highlighted with a call-out box labeled with the state name. 


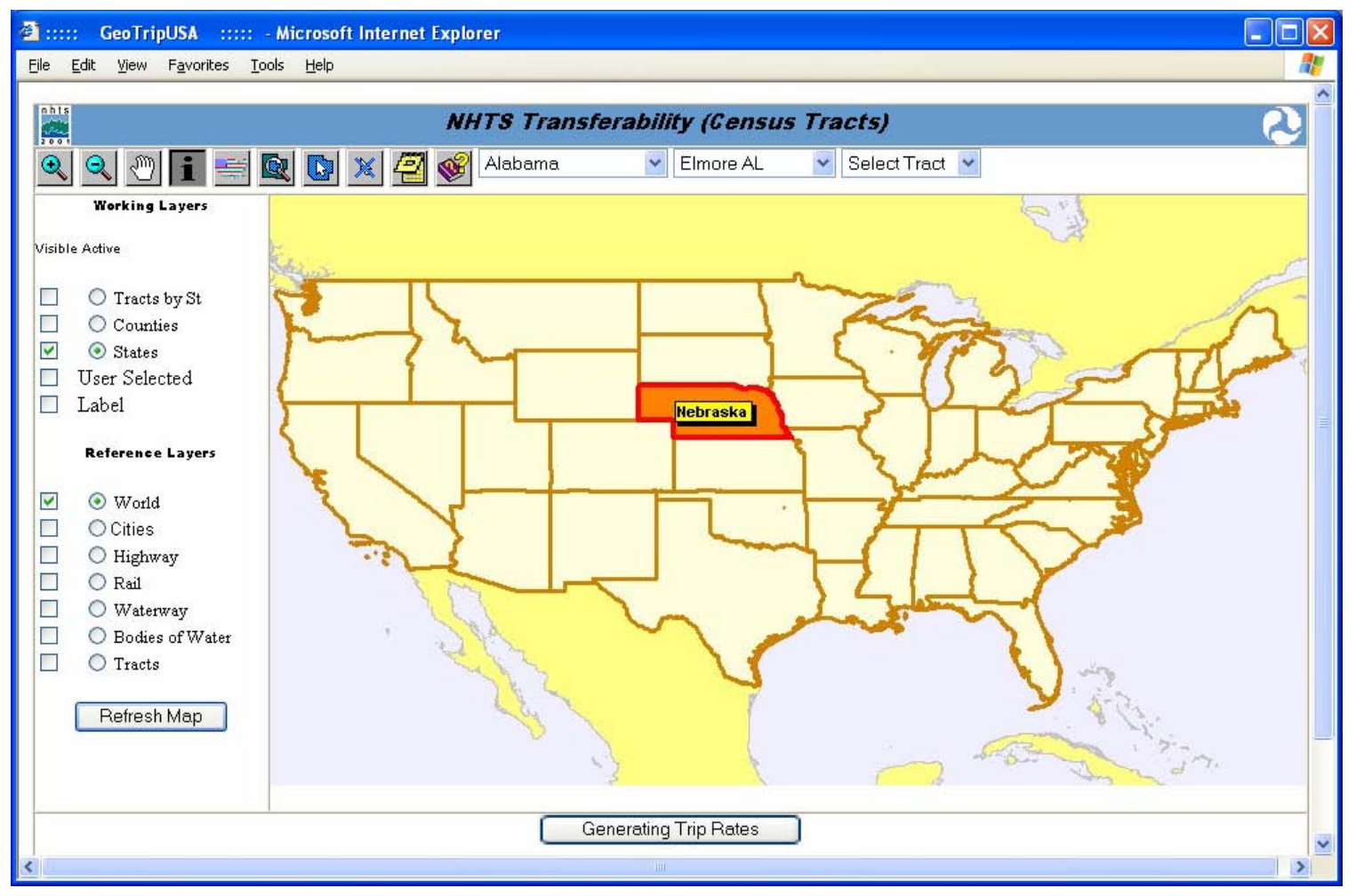

The next figure shows the user has set the Highway, Body of Water, County, State, and World Boundary layers visible. However, the Highway map layer is the target map layer which is also the visible Active Map Layer. The Map Display has already zoomed to the Atlanta, Georgia area and the user has moved the cursor to the northern part of the I-285 loop. 


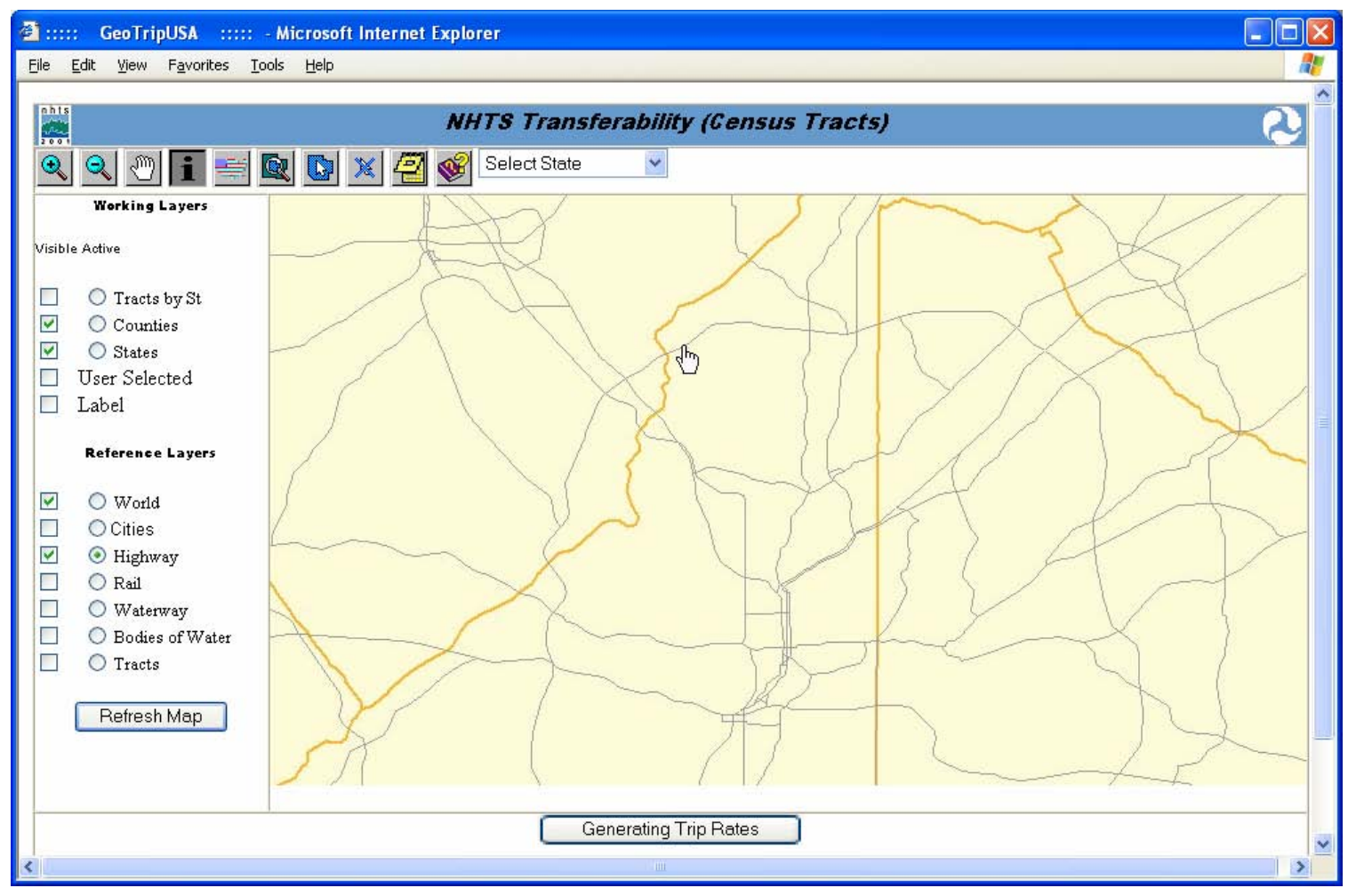

After the user has clicked on the highway link, the new Map Display is the same as the previous Map Display but with the user selected highway link highlighted with the highway identification information labeled. 


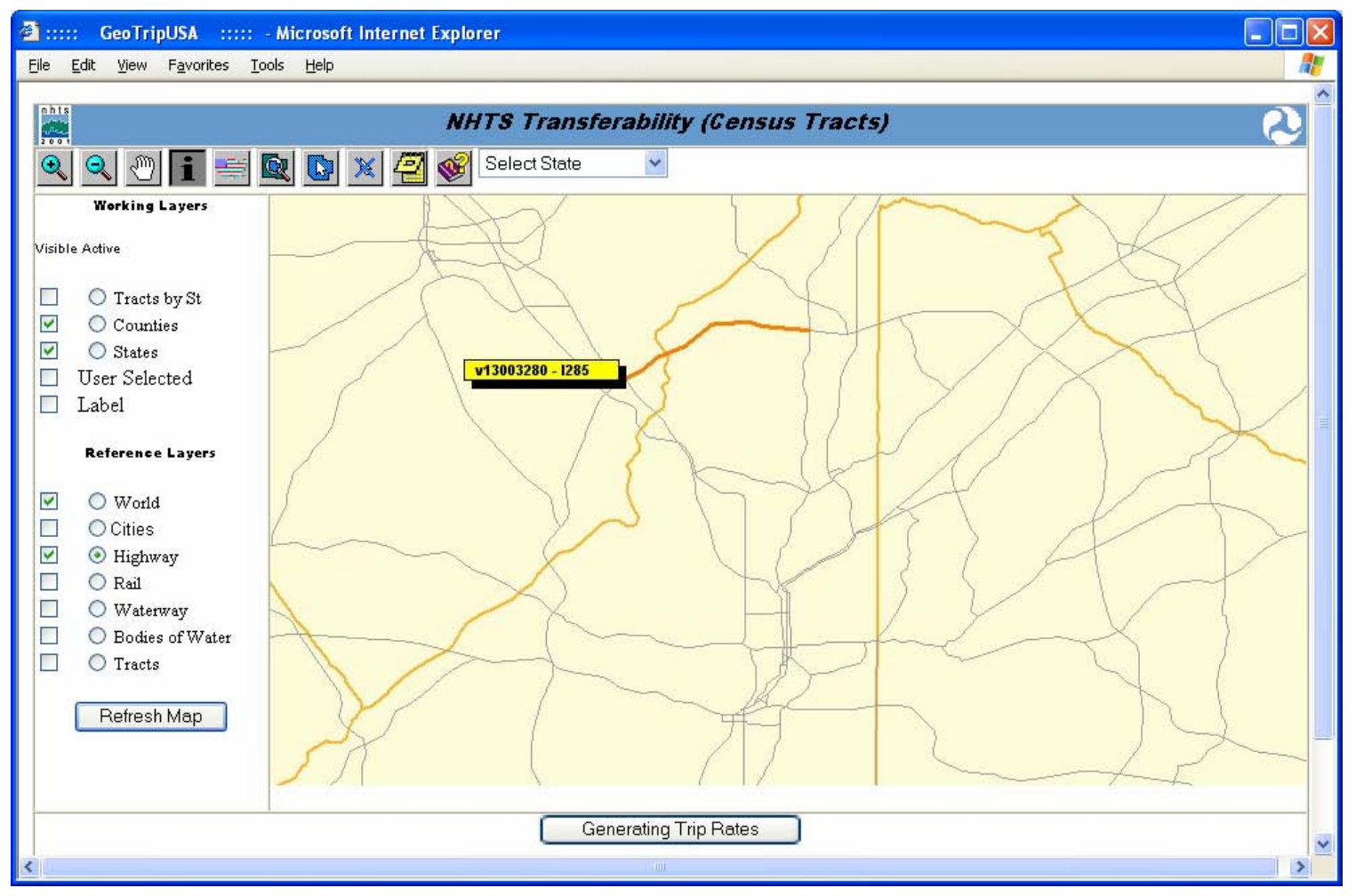

\section{Reset Map to Original Map Extent}

1. Click on the icon will change to

2. Move the cursor and click on any location in the Map Display.

3. The new Map display shows the original Map Display.

The following figure shows the user has set the State Boundary and World Country map layers to visible. The user has also selected the Reset option and moved the cursor to a location in the Map Display. 


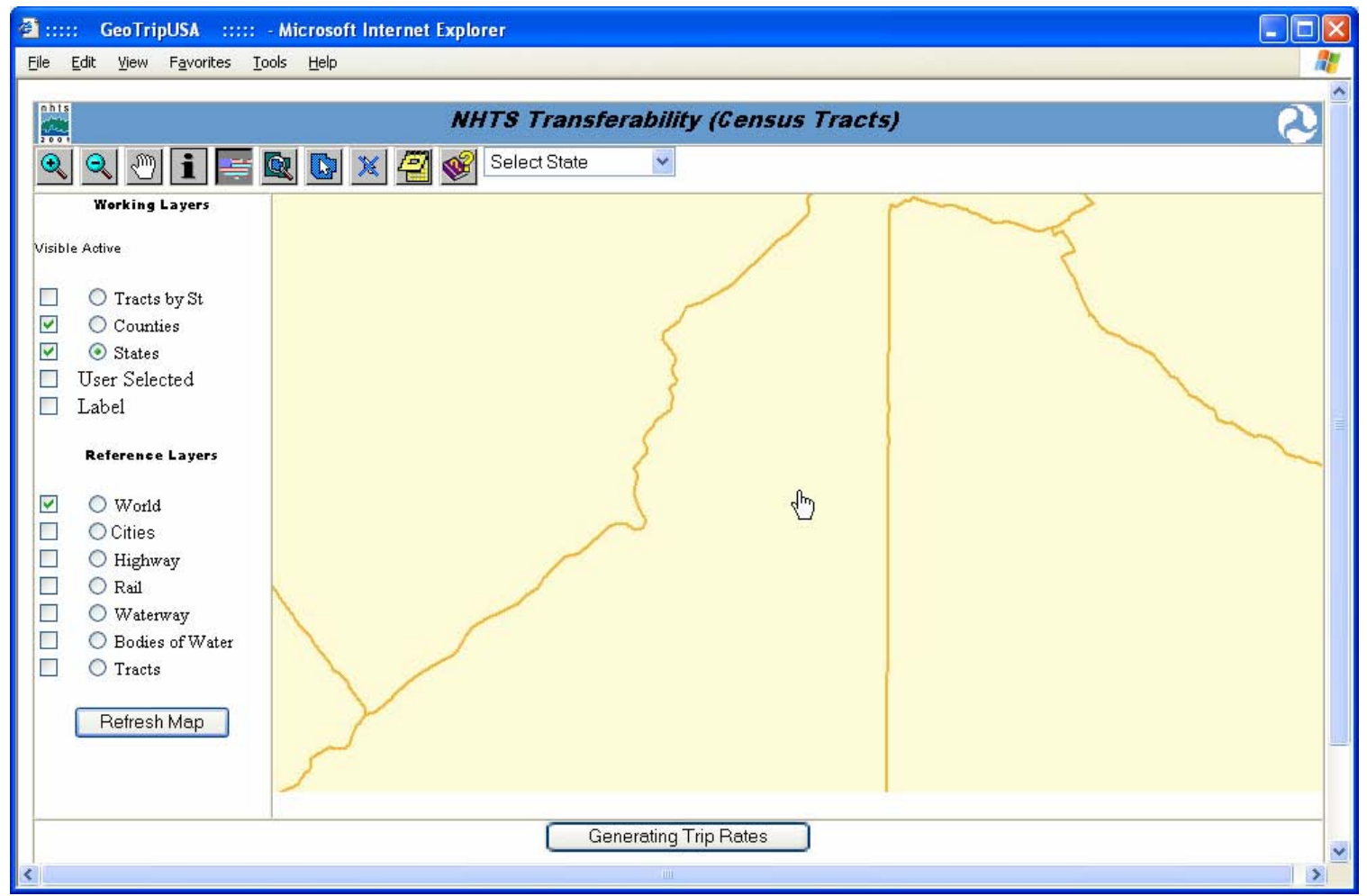

After the user has clicked on the Map Display, the new Map Display depicts the lower forty-eight continental States. 


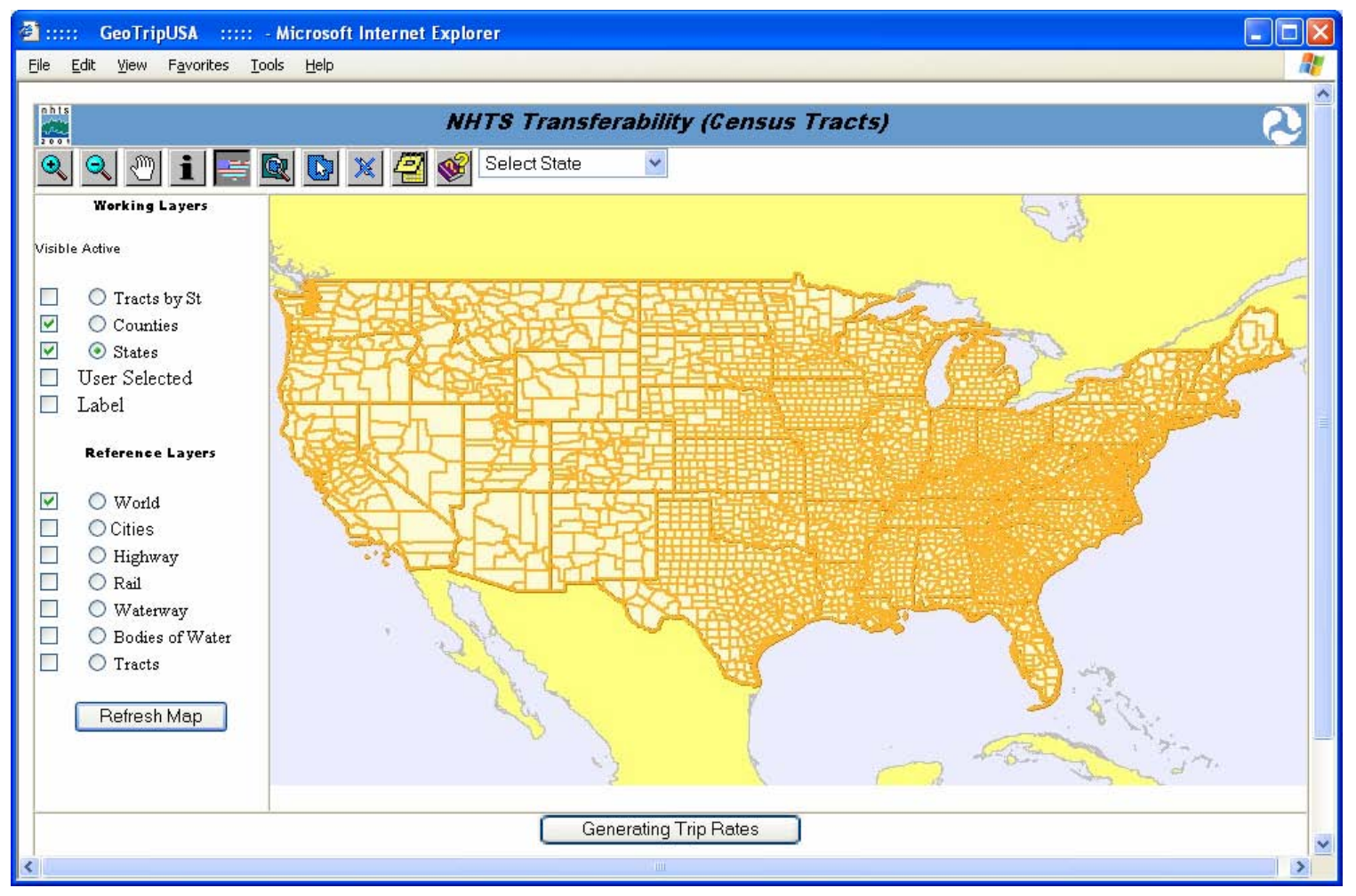

\section{Select Tracts for the Trip Rates Table by Clicking on Map}

1. Make Tract Boundary map layer as the visible Active Map Layer. Otherwise, the system set Tract Boundary map layer as the visible Active Map Layer, User Selected layer visible, and Label visibility to off for the user and refreshes the map.

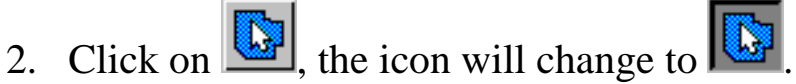

3. Move the cursor to the inside of the desired county or tract and click.

4. The new Map Display will be the same as the previous Map display, but with the selected tract(s) highlighted.

5. The above-mentioned automatic setting will be repeated if the user

a. changes the visibility check boxes and active layer radio buttons but

b. icon is still selected.

Under this circumstance, the user should select a different icon and click the Refresh Map button and refreshed the screen. 
The next figure shows the user has already zoomed to Knox County, Tennessee with the Tract by St Boundary map layer as the visible Active Map layer. The User Selected map layer is also set to visible. The user has moved the cursor to Tract 47093006500 which is on the eastern part of Knox County, Tennessee.

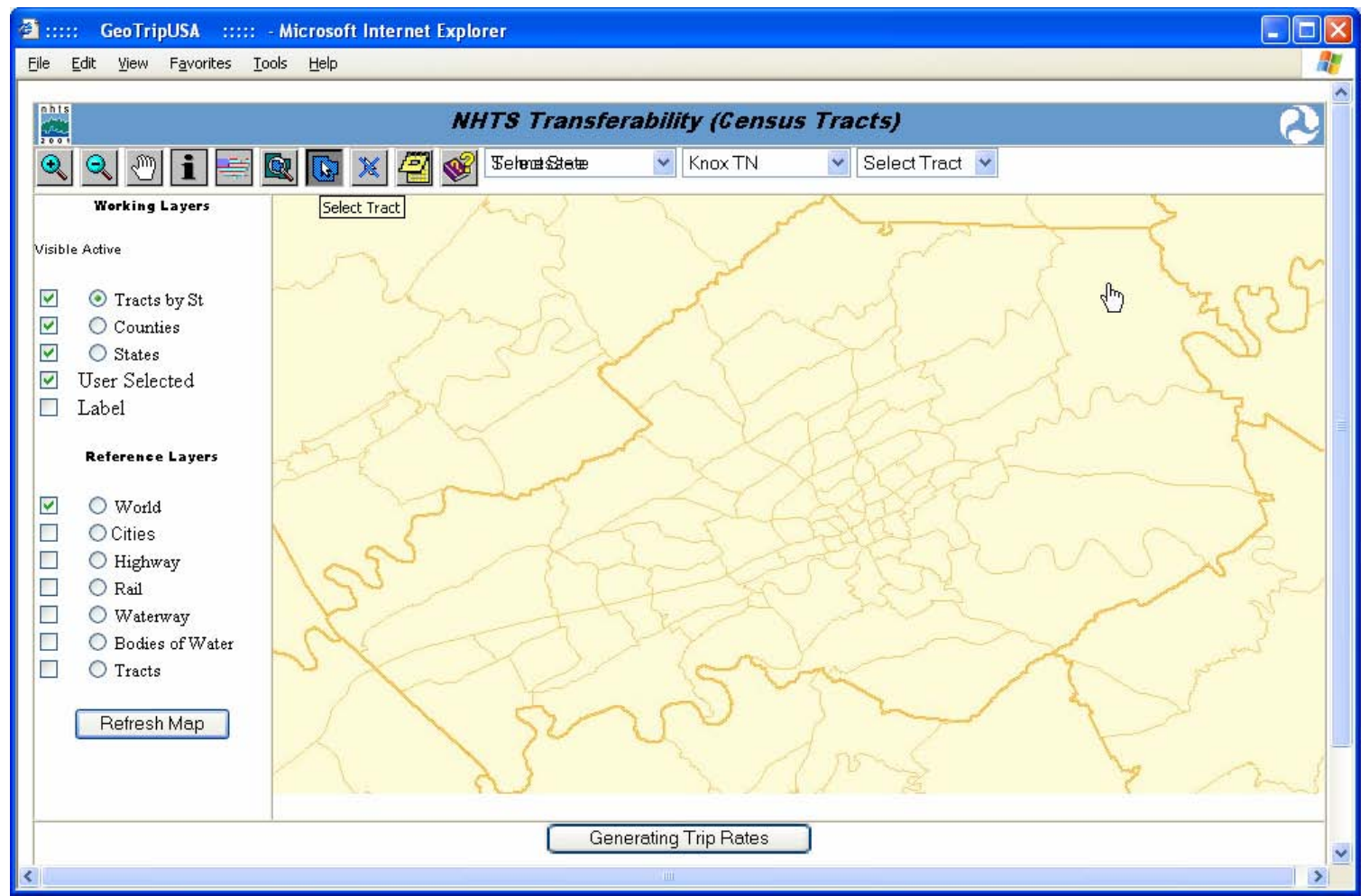

After the user has clicked on Tract 47093006500, the new Map Display is the same as the previous Map Display, but with the selected Tract 47093006500 highlighted. Selected tract(s) will be highlighted if the visibility of the User Selected map layer is “on”. 


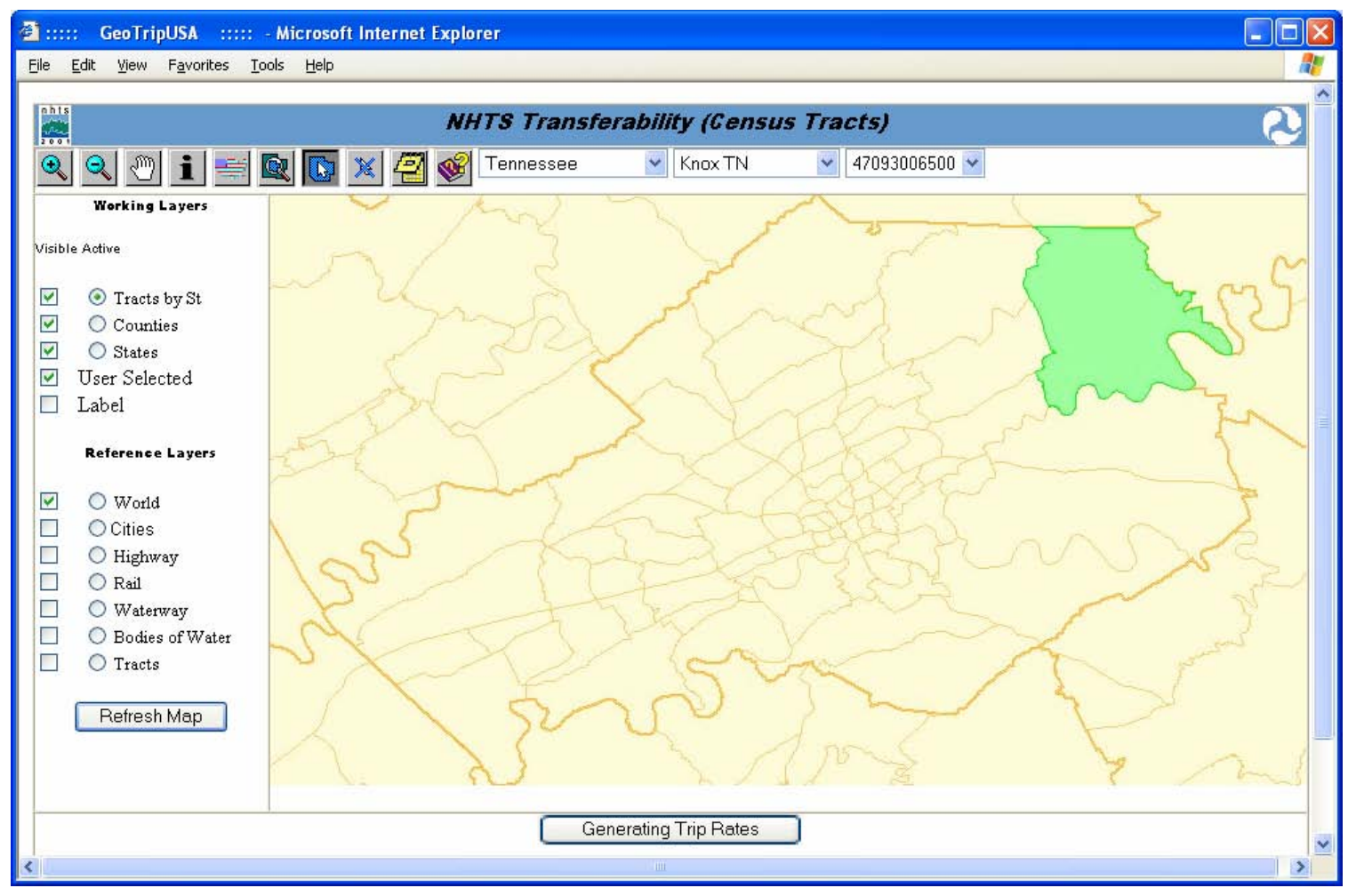

More tracts can be selected by repeating the selection process.

\section{Clear Selected Tract(s)}

1. Click on $\stackrel{\mathscr{X}}{\mathscr{3}}$, the icon will change to

2. Move the cursor to any part of the Map Display and click on the Map Display.

3. The User Selected tract database will contain no record.

\section{Reset Drop Lists}

1. Click on the down arrow on the right side of the Select State drop List Select State $\quad-$ The drop list will show a list of all states and Washington DC.

2. Navigate to the "Select State" option using the scroll bar on the right side of the list.

3. Click on the "Selected State".

4. The new page will only display the Select State drop List. 
The following example shows a web page with drop lists are displayed which shows Tract 47093006500 in Knox County, Tennessee is selected.

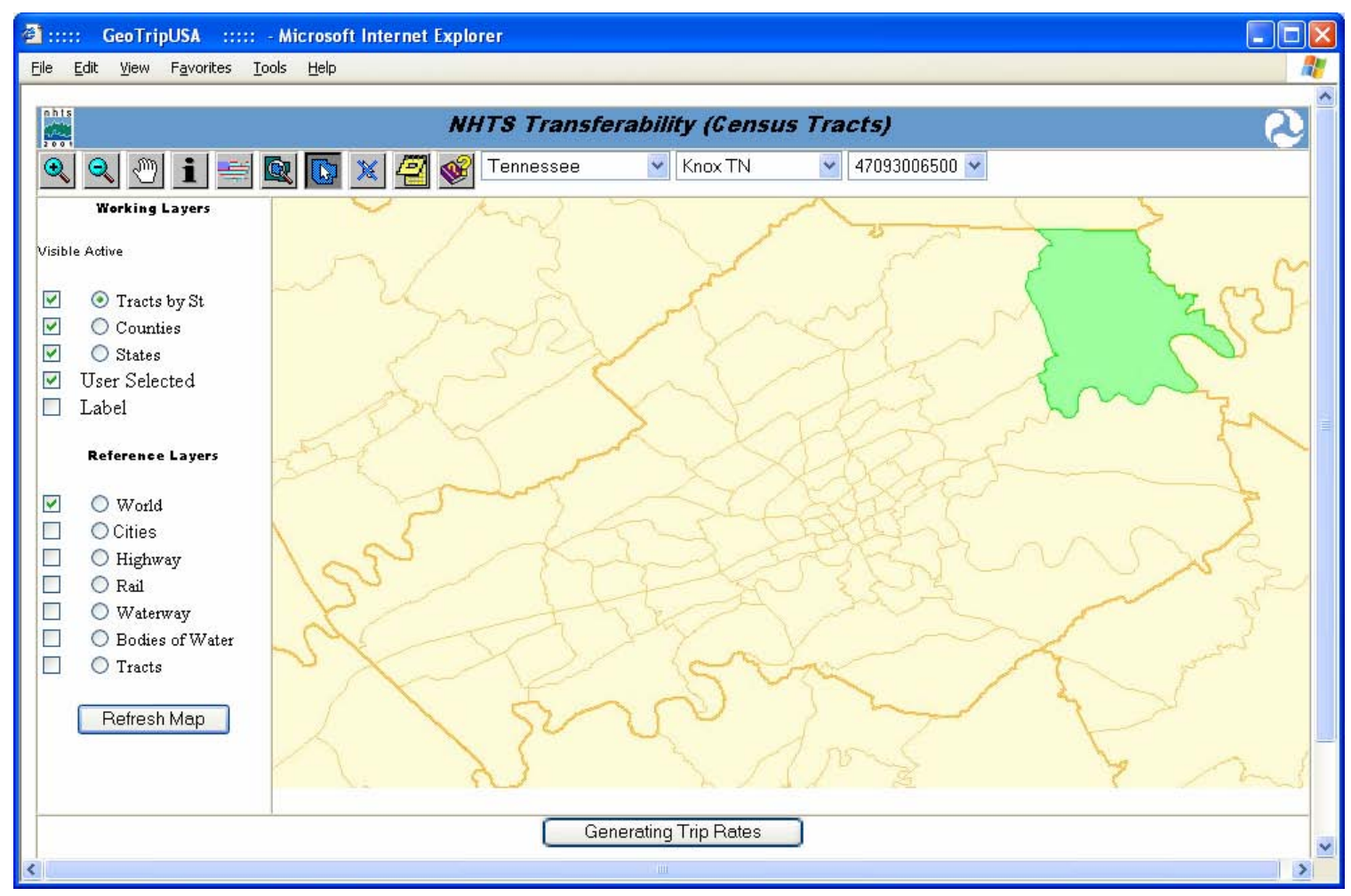

The next screen shows the "Select State" option in the Select State drop List has been highlighted. 


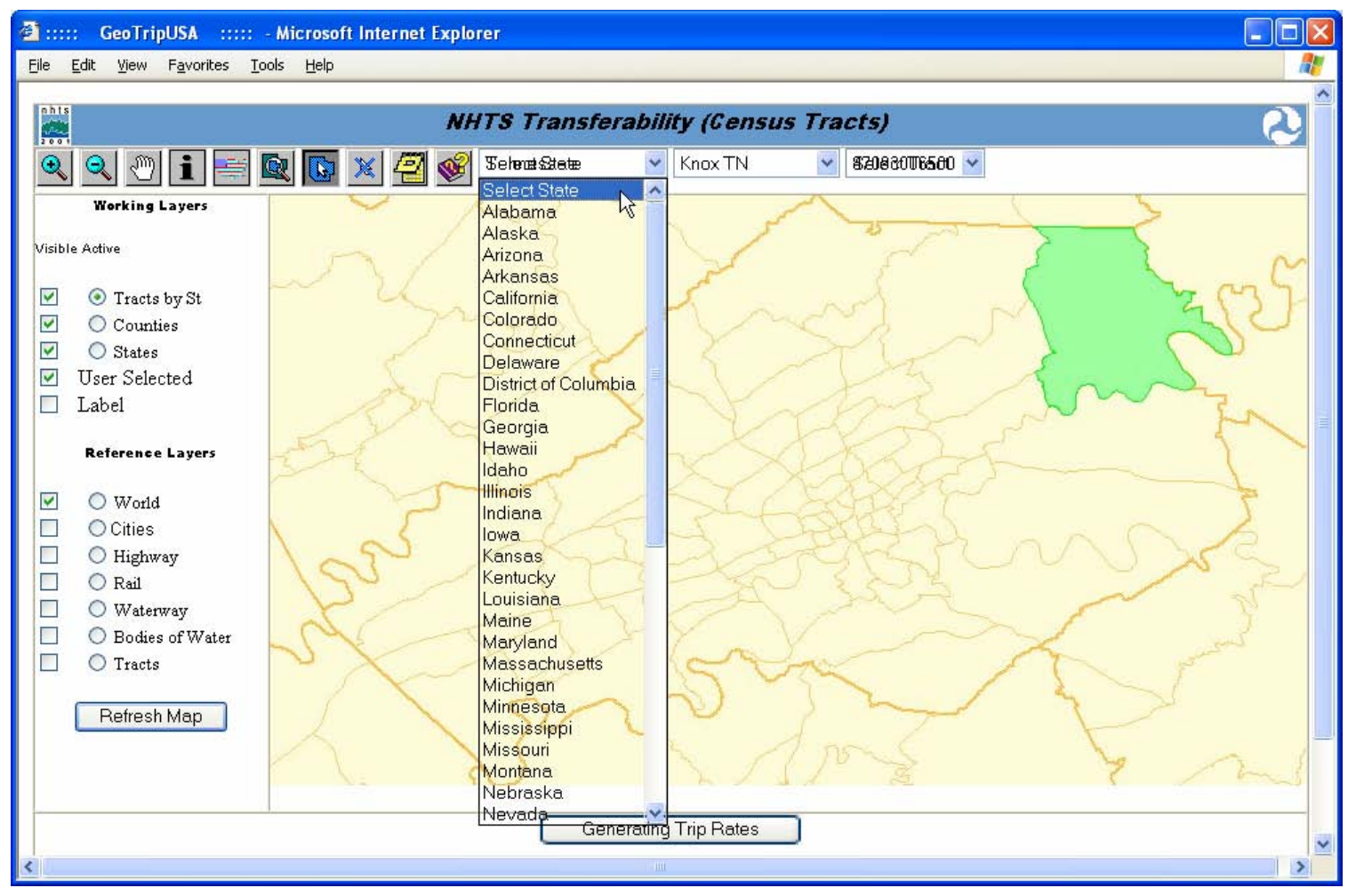

After user has clicked on the "Select State" option, the web page will only show Select State drop List. 


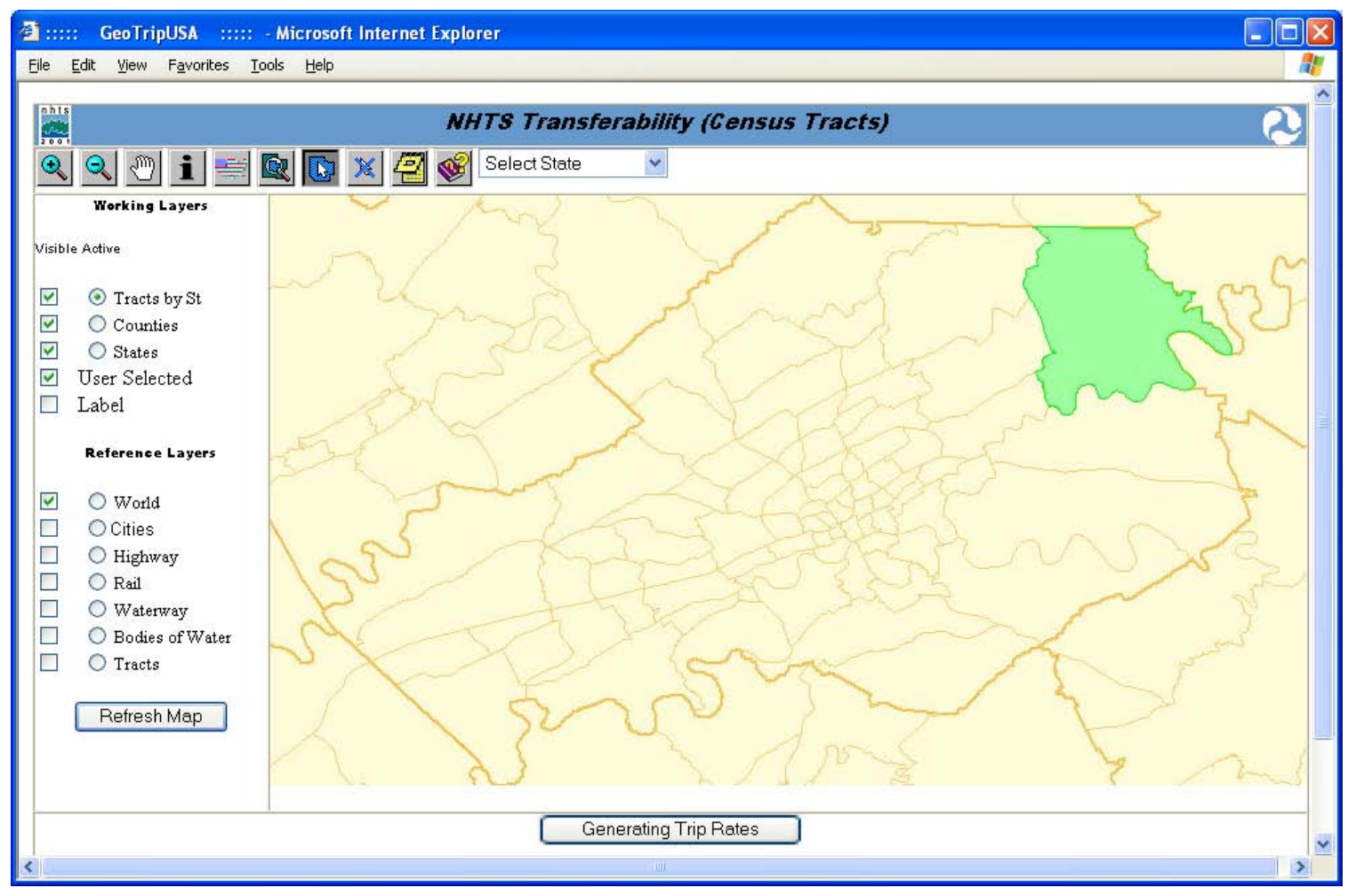

\section{Set Map Layer Visibility}

1. Set the target map layer's visibility check box to "checked"

2. Click on

\section{Refresh Map}

3. The new Map Display will show the target map layer.

The following example shows Knox County, Tennessee with the ORNL Highway map layer visible and active. Since the Label check box is checked, highway route information is displayed. 


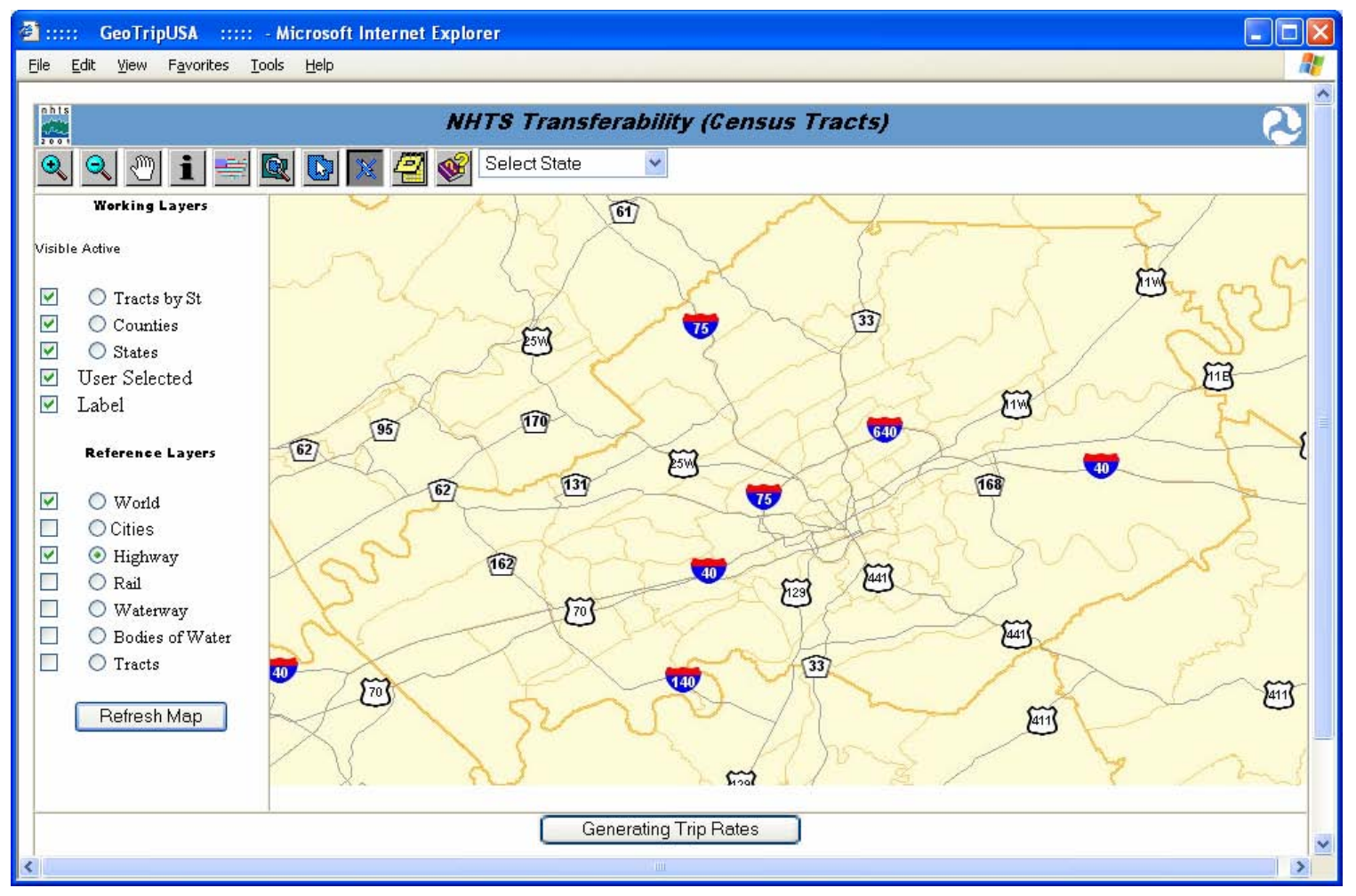

\section{Set Active Map Layer}

Click on the radio button of the target map layer which is already visible.

\section{Display Label for the Active Map Layer}

1. Click of the Label check box and click on Refresh Map.

2. Depending on the map layers, no label will be displayed until the map scale has reached a pre-specified limit.

The following example shows the Label check box has been checked and the State Boundary map layer is visible and set as the Active Map Layer. 


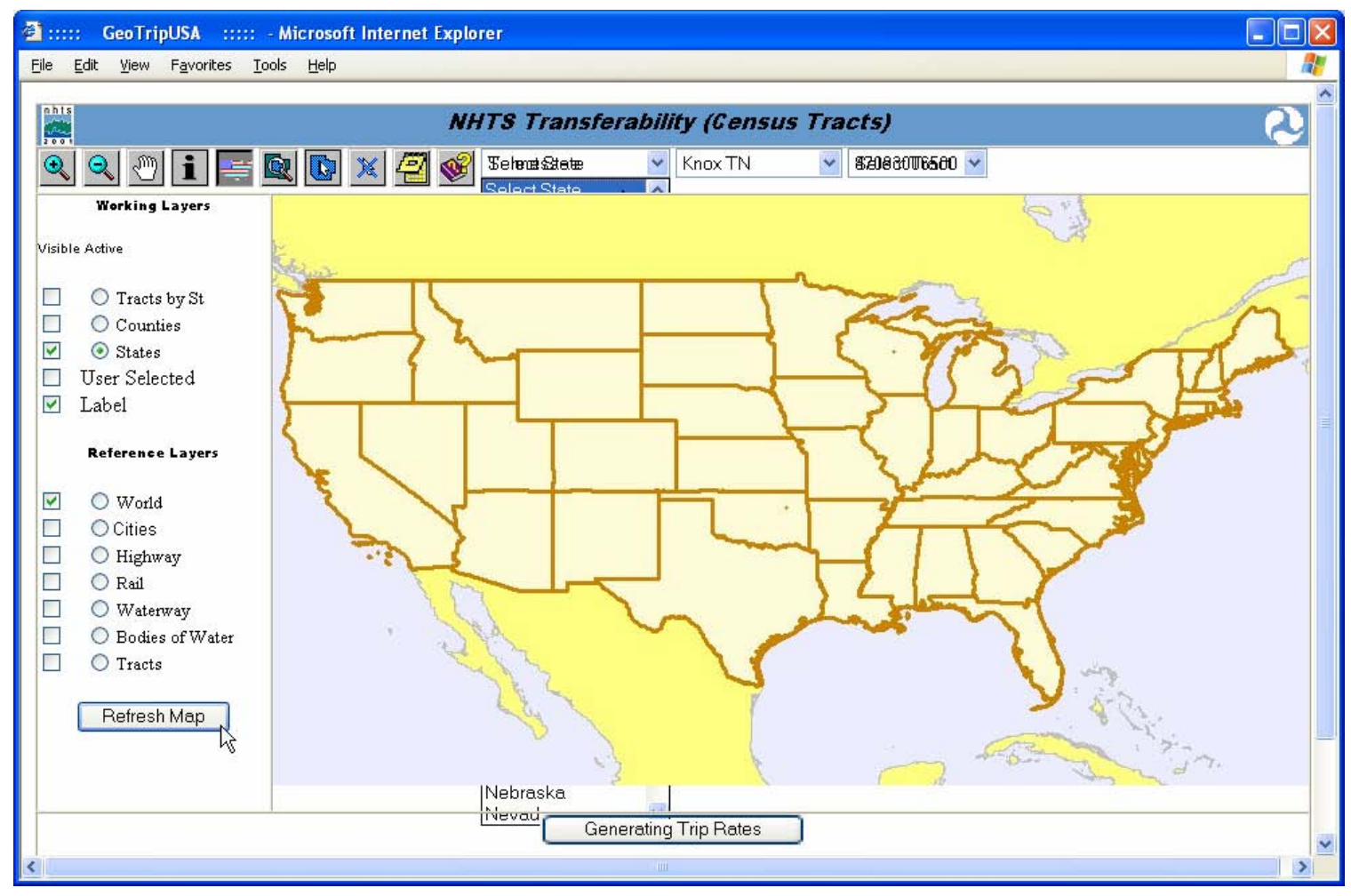

After the user has clicked on the Refresh Map command button, the system will refresh the Map Display with a new page with the State Boundary map layer labeled with the state name. 


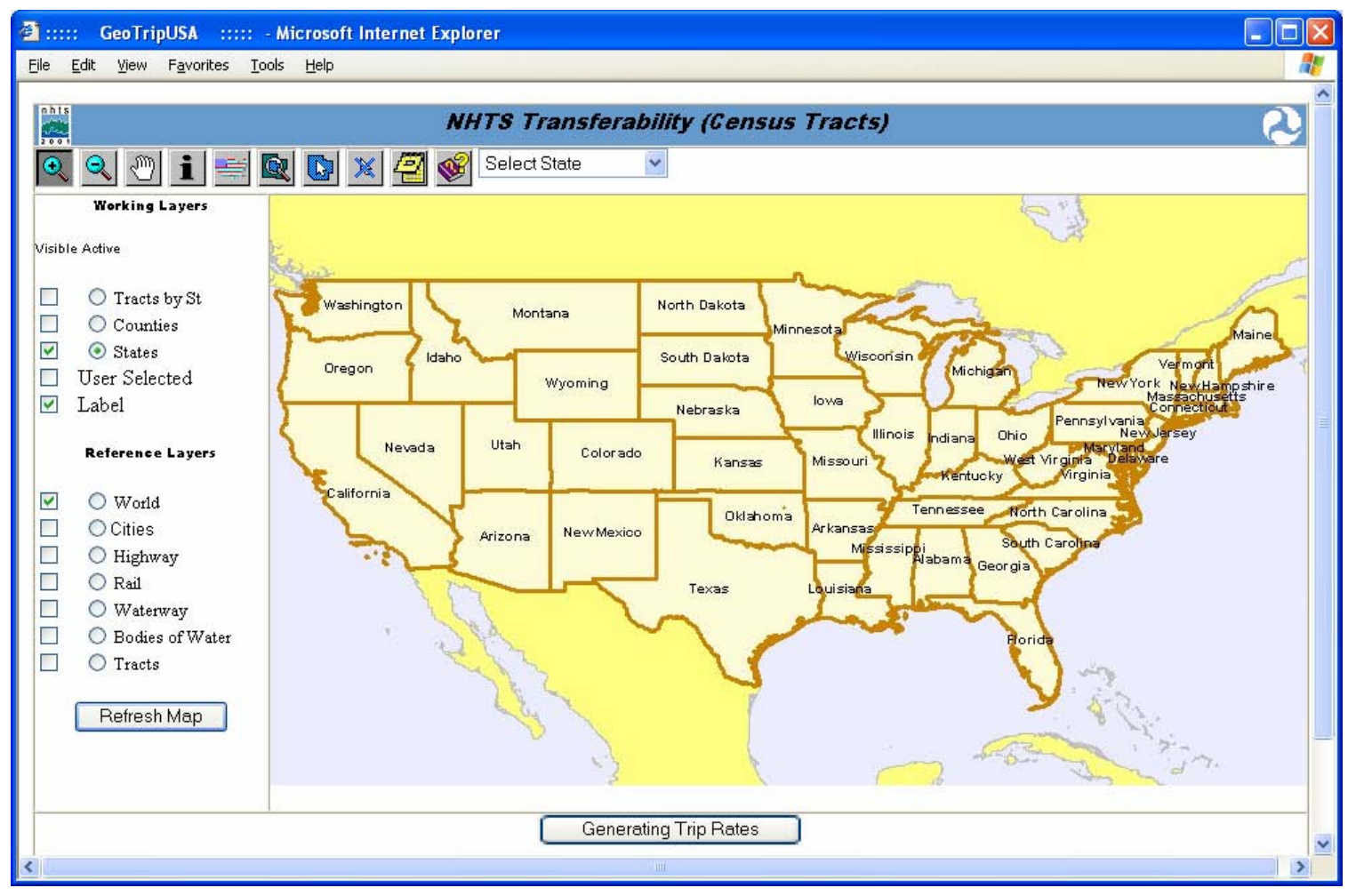

\section{Set Visibility of the User Selected Tract Map Layer}

1. Click of the check box for the User Selected map layer and

$$
\text { click Refresh Map. }
$$

2. The user selected tract(s) will be highlighted.

The following example shows four of the selected tracts within Baldwin County, Alabama that are superimposed on the Map Display with the Tract by State Boundary, County Boundary, State Boundary, and World Country Boundary map layers visible. The County Boundary map layer is the Active Map Layer. Since the Label check box is not checked, no county label is displayed. 


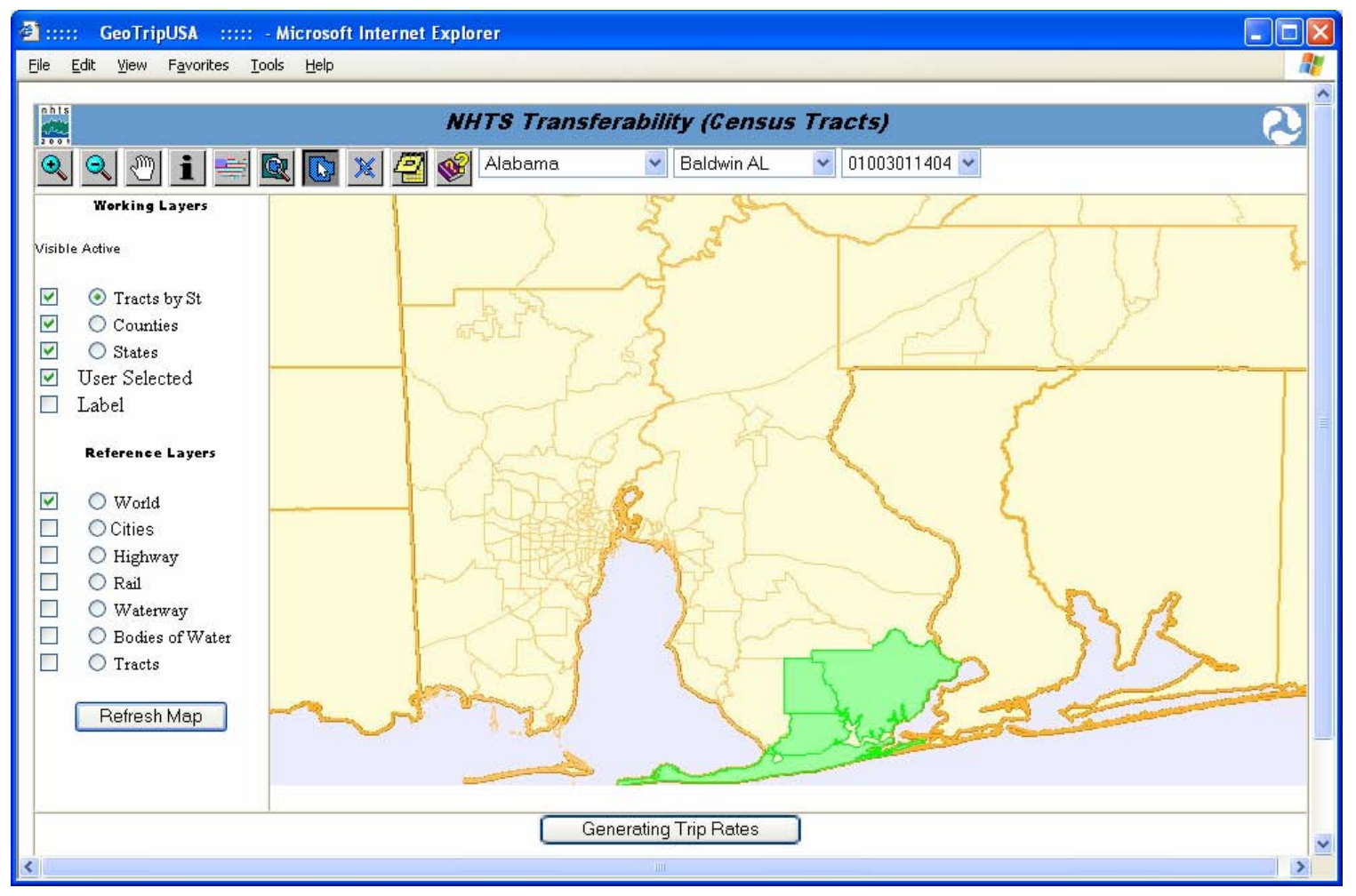

\section{Select Tract(s) Through Drop Lists}

1. Click on the down arrow on the right side of the Select State drop List Select State The drop list will show a list of all states and Washington DC.

2. Navigate to the target state using the scroll bar on the right side of the list.

3. Click on the target state.

4. The new Map Display will zoom in to the selected state with the state labeled. The Select County drop list Select County $\neg$ will appear.

5. Repeat the procedure to select a county.

6. The new Map Display will zoom to the selected county with the county name labeled. The Select Tract drop list Select Tract - will appear.

7. Repeat the procedure to select a tract or all tracts within the county.

8. The system will automatically set the User Selected check box, Tracts by St map layer visibility check box, and refresh the Map Display to show the user selected tract or tracts.

9. To select another set of tracts, clear the user selection and reset the drop lists.

The next example shows the user has selected "Tennessee”. 


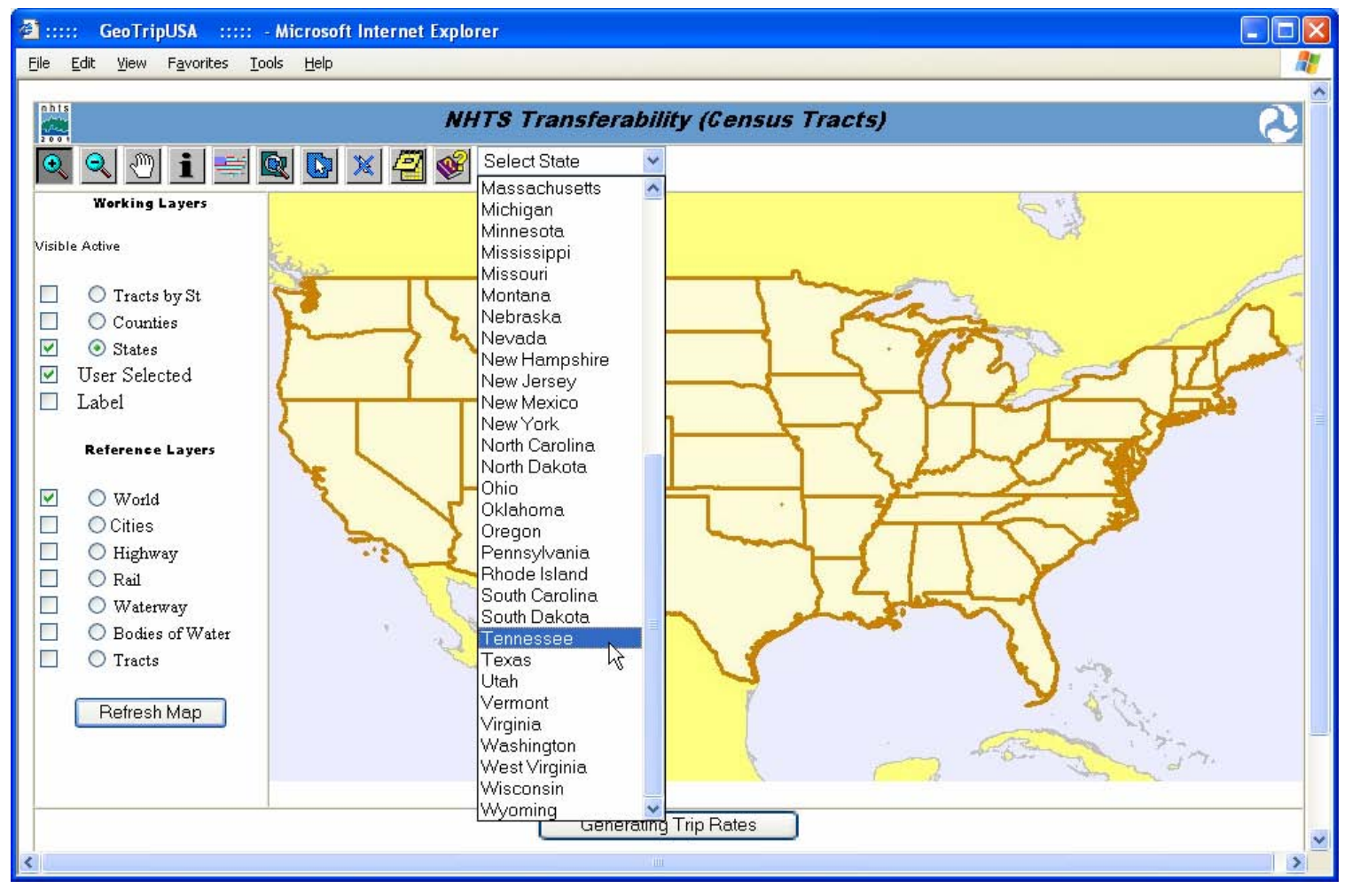

After the user has clicked "Tennessee", the system will reload a new page with the Map Display zoomed to Tennessee with the state labeled. An additional Select County drop list appears. 


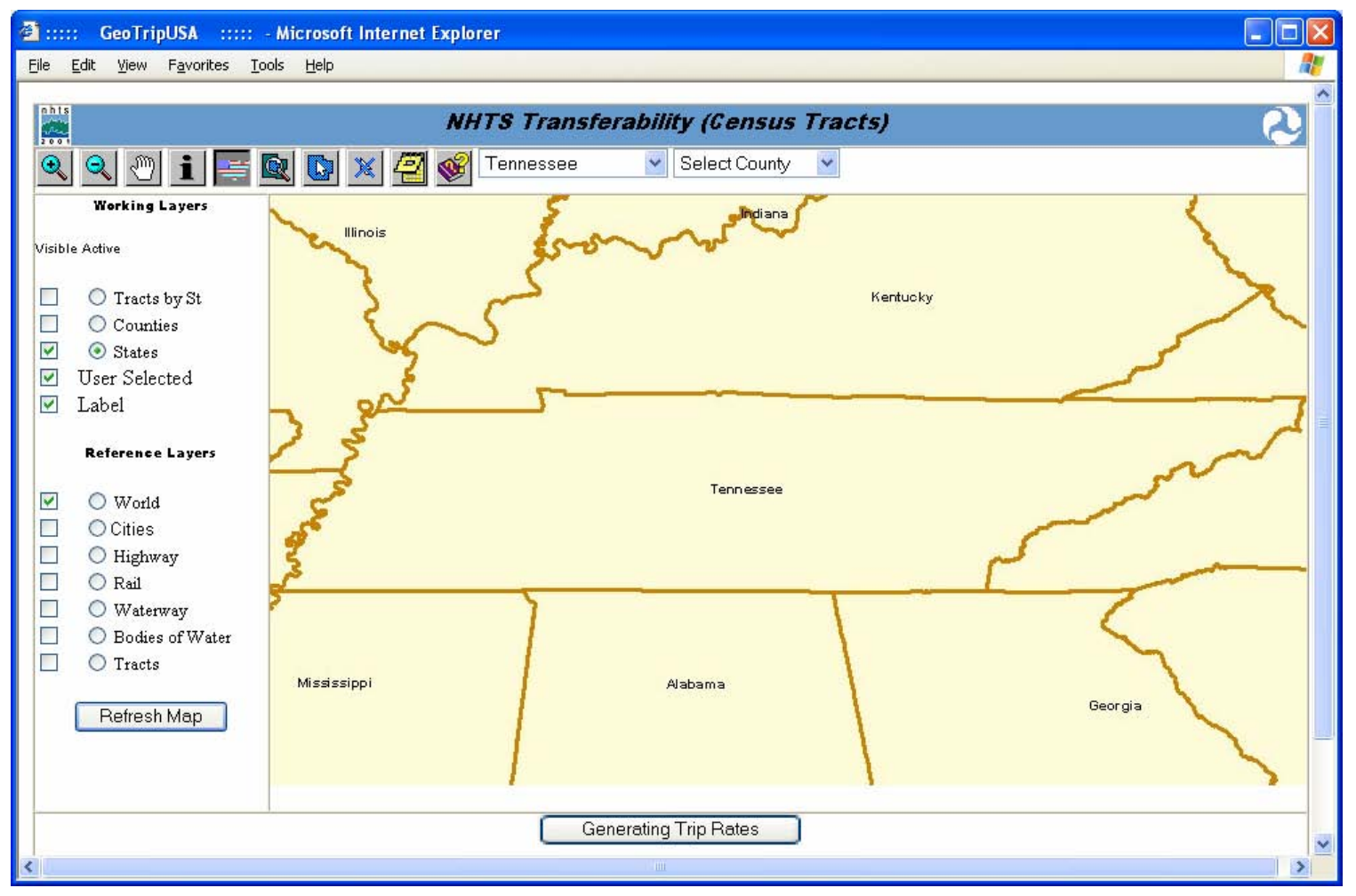

Similar to the Select State drop list, the user can get a list of county names within Tennessee by clicking on the down arrow on the right. The user can navigate to the desired county by using the scroll bar to the right of the drop list. The next example shows Knox County, Tennessee has been selected. 


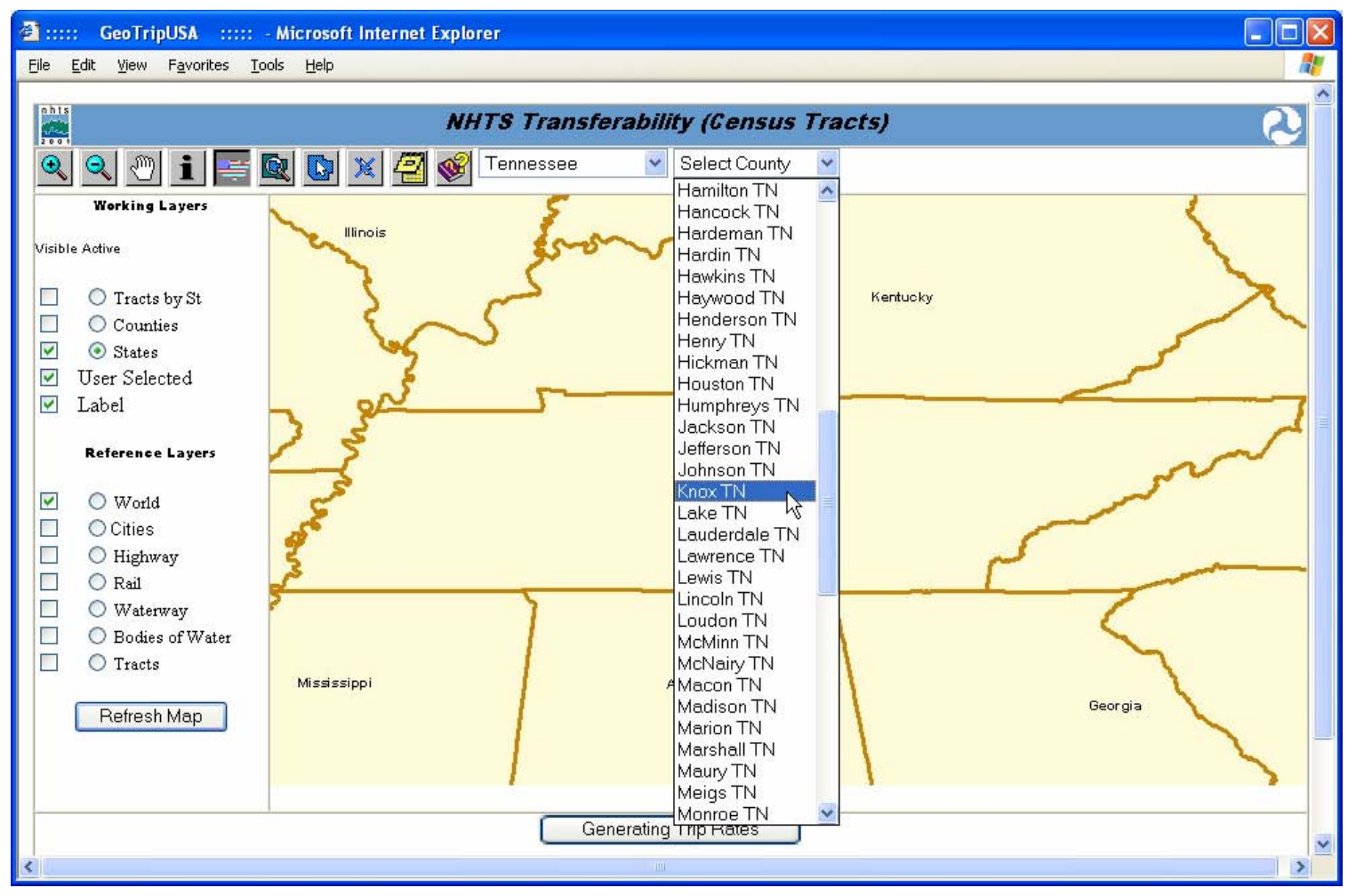

After the user has clicked "Knox, TN", the system will reload a new page with the Map Display zoomed to Knox County, Tennessee with the county labeled. An additional Select Tract drop list appears next to the Select County drop list. 


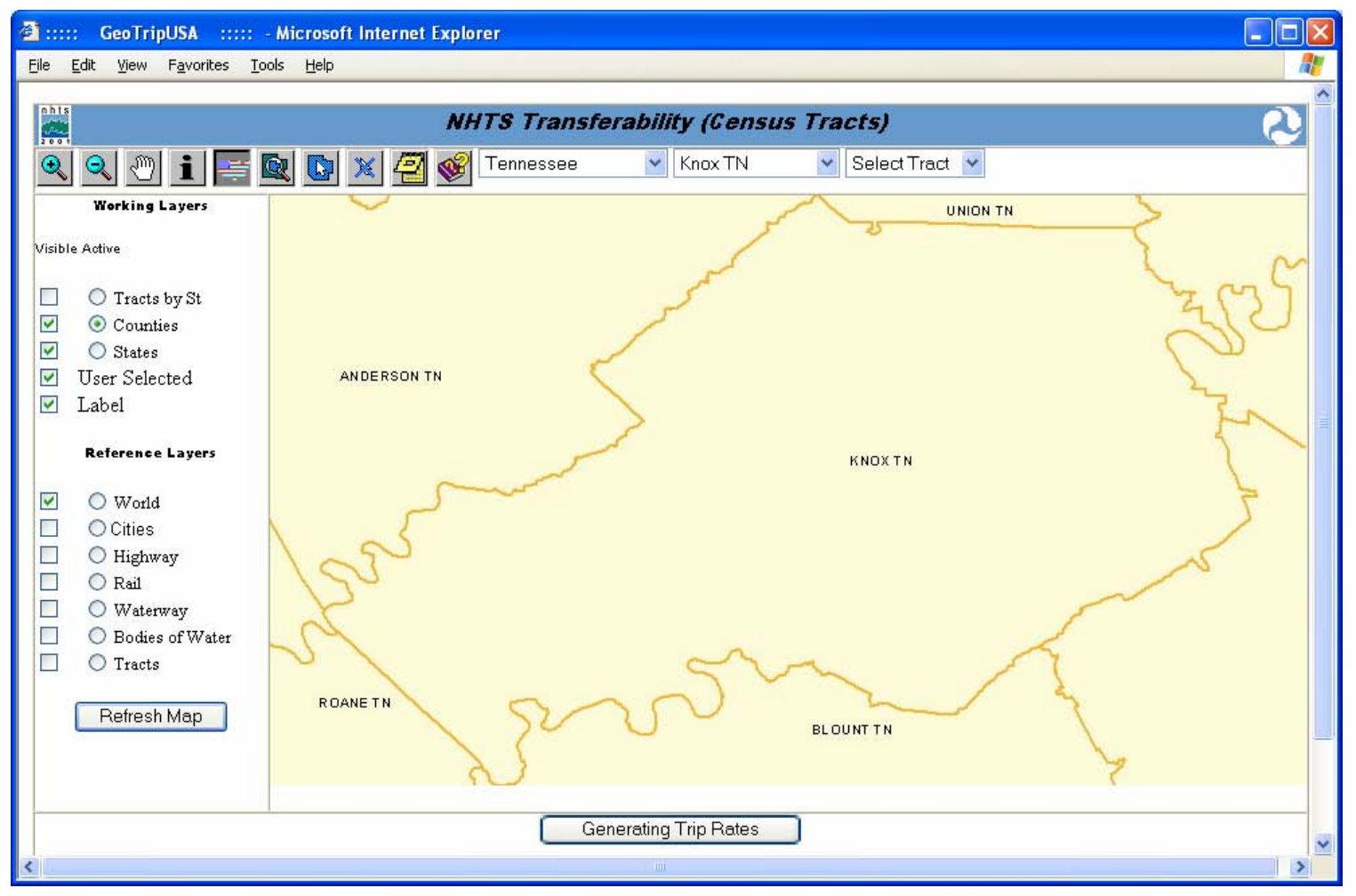

Similar to the Select County drop list, the user can get a list of tract Identification Numbers within Knox County, Tennessee by clicking on the down arrow on the right. The user can navigate to the desired tract by using the scroll bar to the right of the drop list. The next example shows Tract 47093006500 in Knox County, Tennessee has been selected. 


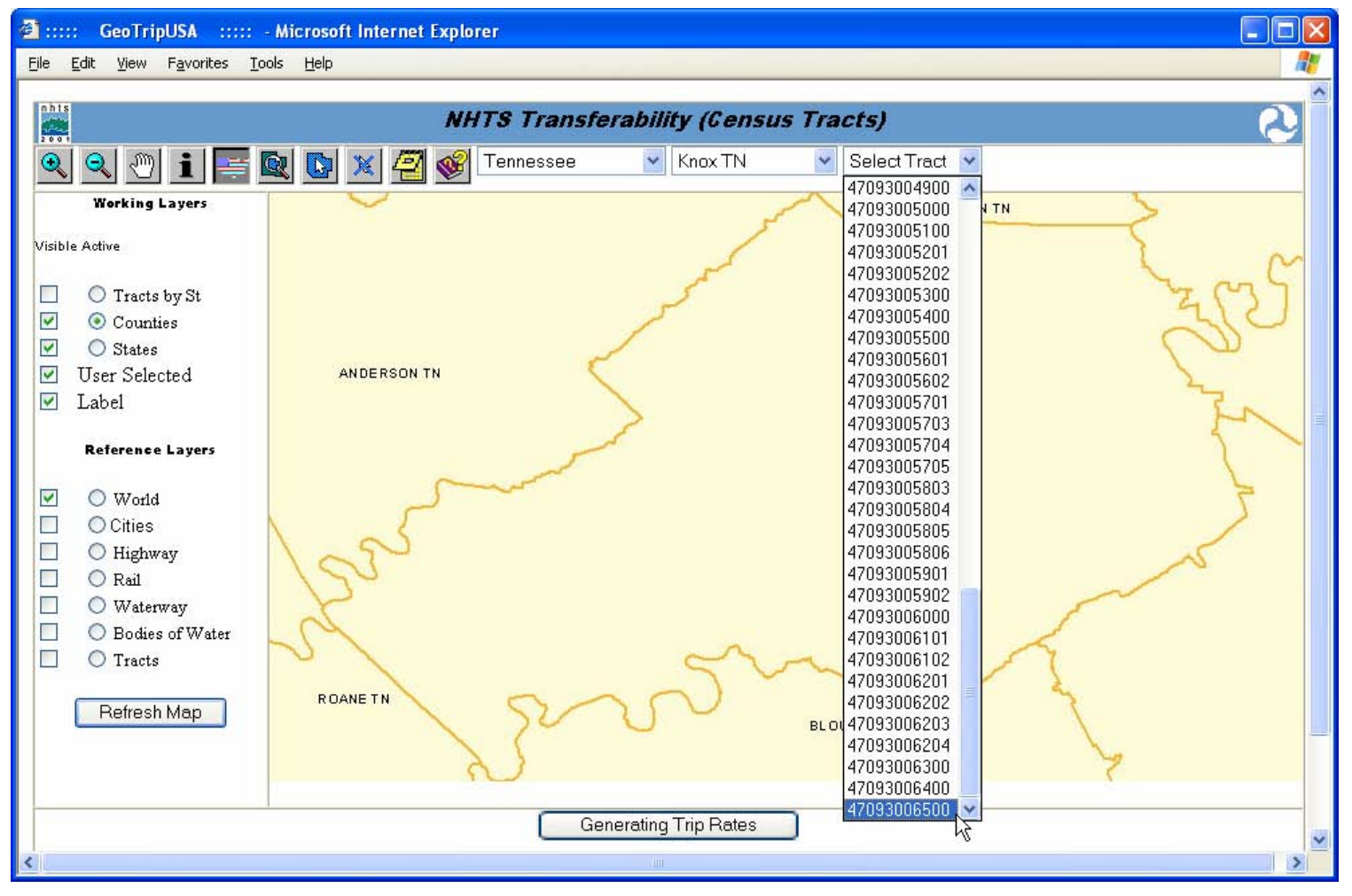

After the user has clicked the Tract 47093006500 in Knox County, Tennessee, the system will reload with a new page. The Map Display will show the user selected tract or tracts if the User Selected check box is checked. The next example shows the selected Tract 47093006500 in Knox County, Tennessee is super-imposed on the Map Display. 


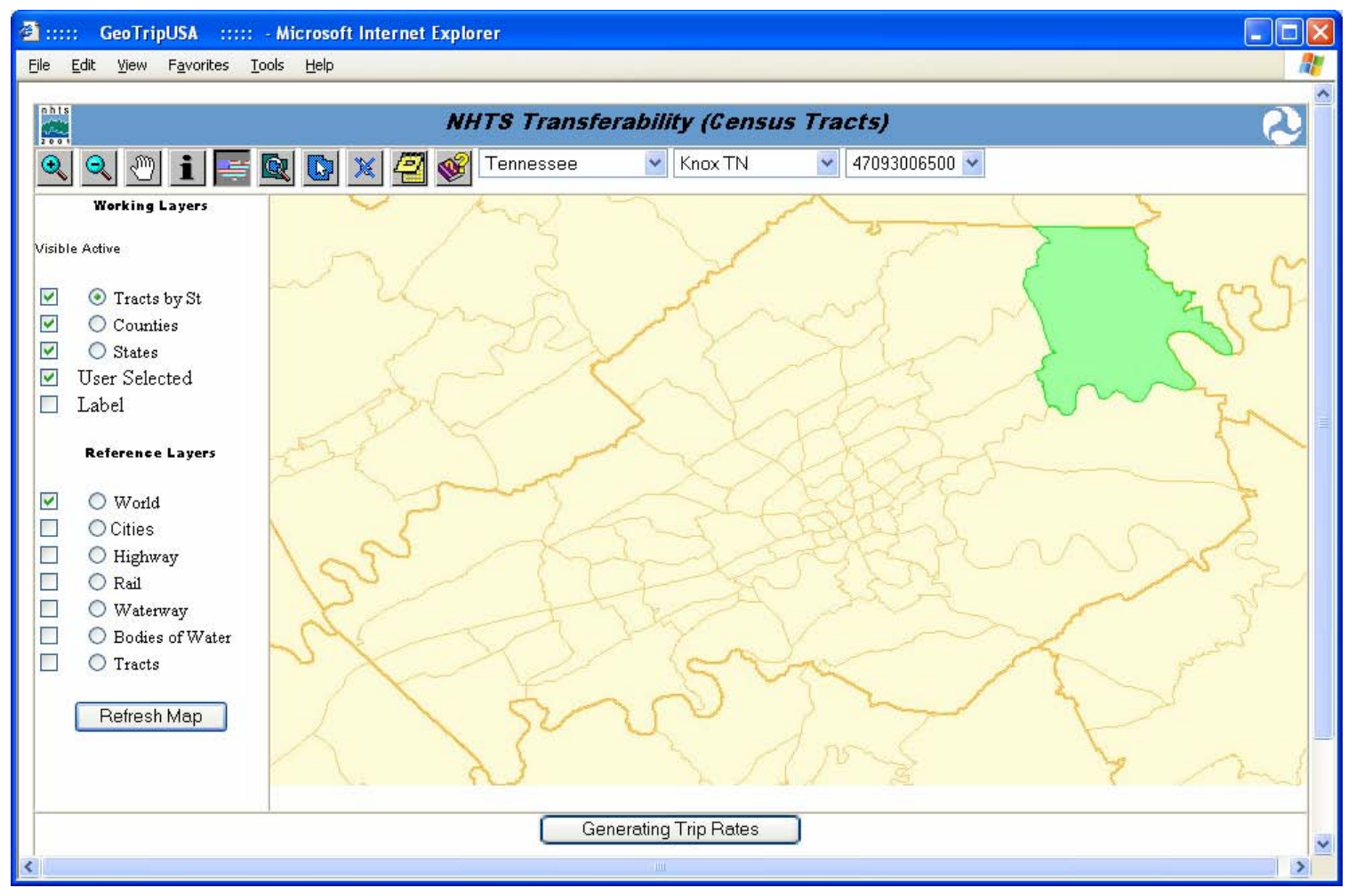

By repeating the selection process, additional tracts can be added to the selection.

The user can also select all tracts within a county by clicking on the "All Tracts" option in the Select Tract drop list.

\section{Generate Trip Rate Table}

1. Select desired tract(s).

2. Make sure the user's Internet Explorer allows Pop-ups.

3. Click on Generating Trip Rates

4. The system will generate trip rate information and presents the Trip Rate Table in a new window.

\section{View Trip Rate Table}

The system will load the HTML version of the Trip Rate Table in a separate pop-up window. Based on your Microsoft Internet Explorer's Pop-up blocker's setting, the Trip Rate Table window may be blocked by your Microsoft Internet Explorer. You must allow pop-up windows in your Microsoft Explorer to load and view the Trip Rate Table. 
The next example shows the top page of the Trip Rate Table. The trip table also contains active content which may be blocked by your Internet Explorer. Please allow the blocked content in order for this page to be properly displayed on Internet Explorer.

There are ten tables for each Census Tract by household size and by household vehicle ownership. They are:

- Number of Households

- Person Trip Rates (Person Trips per Household)

- Person Miles of Travel Rates (Person Miles per Household)

- Vehicle Trip Rates (Vehicle Trips per Household)

- Vehicle Miles of Travel Rates (Vehicle Miles per Household)

- Percent of Home-Based Work Person Trips

- Percent of Home-Based Shopping Person Trips

- Percent of Home-Based Social-Recreational Person Trips

- Percent of Other Home-Based Person Trips, and

- Percent of Non-Home-Based Person Trips

Instead of ten, there is only one trip rate information table for TAZ level file. There are no detailed breakdowns by household size and vehicle ownership.

Please use the tabs labeled with the table name at the bottom of the page to navigate to any desired table. 


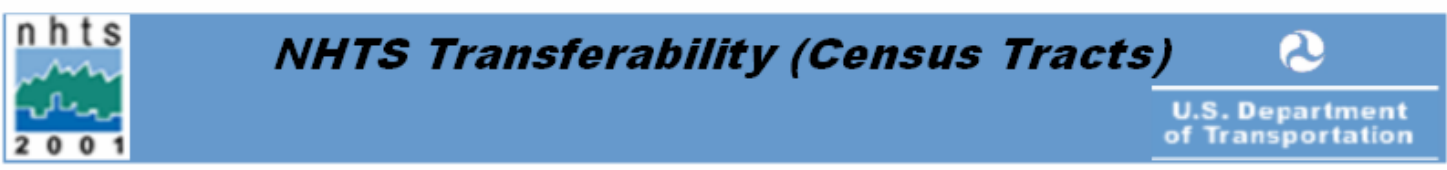

This page contains "active content" which may be blocked by your Internet Explorer. Please allow the blocked content in order for this page to be properly displayed on Internet Explorer.

There are ten tables for all Census tracts. Please use the tabs labeled with the table name on the bottom of the page to navigate to any desired table.

\section{Download Zipped Trip Rate Excel File} Download Zipped Trip Rate ArcView Shape Files

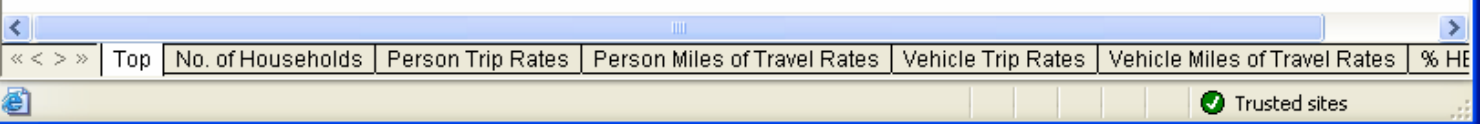

The next example shows a partial "Number of Households" table by household size and by household vehicle ownership for all tracts in Knox County, Tennessee. 
Transferring 2001 National Household Travel Survey

Thttp://chinhp002.ornl.gov/TripRates/Tract154846.htm - Microsoft Internet Explorer

$0 \square$

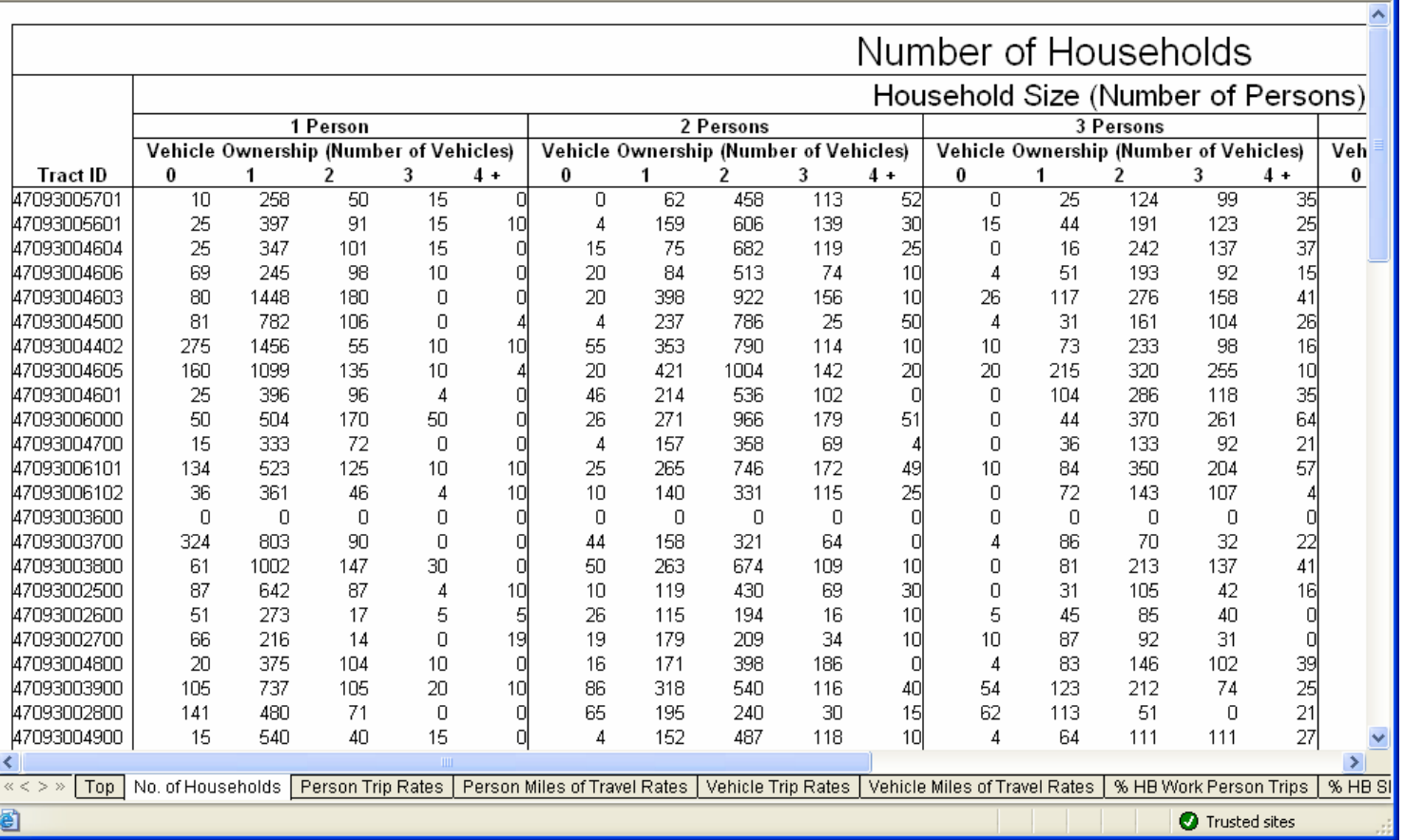

\section{Download Trip Rate Table}

Navigate back to the "top" page of the Trip Rate Table and click on Download Zipped Trip Rate Excel File and/or Download Zipped Trip Rate ArcView Shape Files . The system will "open", "save", or "cancel" the file download as shown in the next example. Please select the "Save" option. 


\section{File Download}

Do you want to open or save this file?

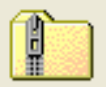

Name: Tract154846.zip

Type: Compressed (zipped) Folder, 51.0 KB

From: chinhp002.ornl.gov

\section{Qppen}

\section{Save}

Cancel

Always ask before opening this type of file

While files from the Internet can be useful, some files can potentially harm your computer. If you do not trust the source, do not open or save this file. What's the risk?

After you have selected the "Save" option, the system will save the file(s) after the user selects where to save them, and the file name it should be saved under, as shown in the following figure.

\section{Save As}

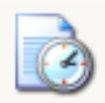

My Recent

Documents

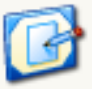

Desktop

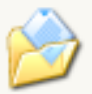

My Documents

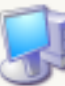

My Computer

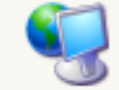

My Network
File name:

Save as type:

Tract154846.zip V

Compressed (zipped) Folder
Save

Cancel 
Transferring 2001 National Household Travel Survey

\section{Pop-up Blocker}

Three options within the system display information in a separate new window. These are, display Data Source, display Tutorial, and display Trip Rate Table. The Microsoft Internet Explorer treats such windows as pop-up windows and they will be blocked by the Pop-up Blocker. These windows will not be visible if the user doesn't turn off their pop-up blocker.

\section{Active Content Blocker}

The Trip Table Display also contains active content which may be blocked by the user's Internet Explorer. Please allow the blocked content in order for this page to be properly displayed on Internet Explorer.

\section{Tract Selection and Trip Rate Table Download}

Processing tract selection, and subsequent generation of the trip rate table and download files are processing-extensive tasks. It is highly recommended that the user select a relatively small number of tracts (less then 50 ), generate the trip rate table, and download the trip rate information of the selected tracts to the user's own computer. Repeat the process to download trip rate information for additional tracts.

\section{Map Layers}

Some of the map layers contain detailed geographic information. Setting the visibility to "on" while the Map Display covers a large area will make the system extremely slow, the Map Display will look overwhelming, and the user will comprehend little information.

In order to save processing time, two tract boundary map layers are included. One at the national level and one at the state level. The state level Tract Boundary file is used in processing all user requests. The national level Tract Boundary map layer is provided for the user wishing to see the tract boundaries for multiple states.

The next figure shows the Tract Boundary map layer visibility at the national level. 


\section{Transferring 2001 National Household Travel Survey}

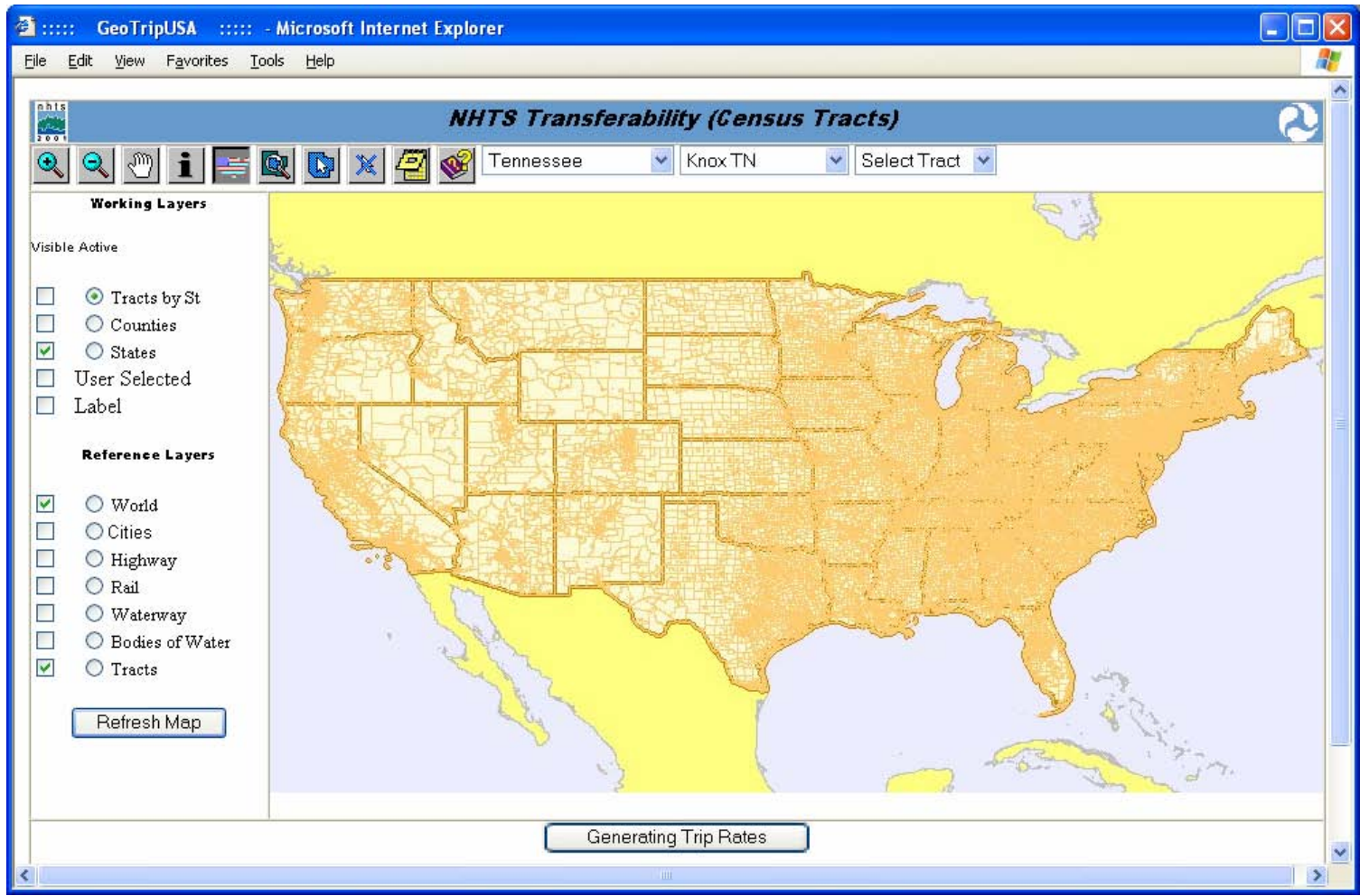

